NBER WORKING PAPER SERIES

\title{
THE HIDDEN COSTS OF SECURING INNOVATION: THE MANIFOLD IMPACTS OF COMPULSORY INVENTION SECRECY
}

\author{
Daniel P. Gross \\ Working Paper 25545 \\ http://www.nber.org/papers/w25545 \\ NATIONAL BUREAU OF ECONOMIC RESEARCH \\ 1050 Massachusetts Avenue \\ Cambridge, MA 02138 \\ February 2019, Revised April 2022
}

I thank Ashish Arora, Pierre Azoulay, Wes Cohen, Alberto Galasso, Shane Greenstein, Deepak Hegde, Je Kuhn, Hong Luo, Fabian Waldinger, Martin Watzinger, numerous seminar and conference audiences, three very thoughtful referees, the Associate Editor, and Editor Toby Stuart for helpful comments. I am grateful to Alessandro Iaria, Carlo Schwarz, and Fabian Waldinger for sharing code and to Je Kuhn for discussing the mechanics of semantic analysis. I also thank Hayley Pallan, Greg Saldutte, and Senan Hogan-Hennessy for outstanding research assistance, and Harvard Business School and the NBER Innovation Policy grant (2016) for nancial support. The views expressed herein are those of the author and do not necessarily reflect the views of the National Bureau of Economic Research.

NBER working papers are circulated for discussion and comment purposes. They have not been peer-reviewed or been subject to the review by the NBER Board of Directors that accompanies official NBER publications.

(C) 2019 by Daniel P. Gross. All rights reserved. Short sections of text, not to exceed two paragraphs, may be quoted without explicit permission provided that full credit, including () notice, is given to the source. 
The Hidden Costs of Securing Innovation: The Manifold Impacts of Compulsory Invention Secrecy

Daniel P. Gross

NBER Working Paper No. 25545

February 2019, Revised April 2022

JEL No. N42,N72,O31,O32,O34,O38

\begin{abstract}
One of the U.S. Patent and Trademark Office's (USPTO) most commanding powers is to compel inventions into secrecy, withholding patent rights and prohibiting disclosure, to prevent technology from leaking to foreign competitors. This paper studies the impacts of compulsory secrecy on firm invention and the wider innovation system. In World War II, USPTO issued secrecy orders to $>11,000$ patent applications, which it rescinded en masse at the end of the war. Compulsory secrecy caused implicated firms to shift their patenting away from treated classes, with effects persisting through at least 1960. It also restricted commercialization and impeded follow-on innovation. Yet it appears it was effective at keeping sensitive technology out of public view. The results provide insight into the effectiveness of compulsory secrecy as a regulatory strategy and into the roles, and impacts, of formal intellectual property in the innovation system.
\end{abstract}

Daniel P. Gross

Fuqua School of Business

Duke University

100 Fuqua Drive

Durham, NC 27708

and NBER

daniel.gross@duke.edu 
Compulsory secrecy is one of the most imposing discretionary powers the U.S. Patent and Trademark Office (USPTO) and other patent offices have today. Since World War II, USPTO has had the legal authority to order firms and inventors to keep secret inventions in, and suspend examination of, patent applications whose disclosure it deems may pose risks to national security—not only withholding intellectual property (IP) rights, but effectively impounding new invention. The purpose of the policy is to protect domestic invention from (mis)appropriation by foreign competitors. Compulsory secrecy is ordinarily invoked with careful discretion, but in a crisis the prospects for its use grow, and increasing pressures of foreign technological competition have prompted recent considerations of expanding its use to protect economic security.

Little is known about how compulsory secrecy affects innovation. Broad invocation is not unprecedented: in World War II, USPTO ordered over 11,000 patent applications into secrecy, covering inventions as diverse as radar, cryptography, and synthetic materials. The vast majority of these secrecy orders were rescinded when the war ended. The scope and scale of the policy, and its abrupt conclusion, present a rare opportunity to study the effects of compulsory secrecy on innovation and diffusion. Doing so can also offer insight on the value of patents and the ways in which holding up formal IP can interfere with ordinary inventive and commercial activity.

In this paper, I study how this program affected individual firms and the wider innovation system. I show that firms which received secrecy orders at high rates during the war shifted their patenting away from technology areas in which they were affected, and some temporarily stopped patenting altogether. This was particularly true for firms which were not involved in the wartime research effort. The patents of these firms which were secret for long periods were also less likely to be cited by future patents, and a deeper dive suggests this is the result of a missing generation of follow-on invention. Evidence from a case study of one firm (Du Pont) suggests that secret inventions were temporarily precluded from being commercialized. Collectively, these results point to a number of potential costs of compulsory secrecy, distorting the direction of invention and undermining firm investments in innovation. Yet the policy appears to have worked as intended: new terms in titles of secret patents saw limited mention in patent text and the wider literature until after the war ended, such that these repercussions should be evaluated against the seeming effectiveness of the policy in keeping sensitive technological content out of public view.

To understand these results, it is useful to take a step back and consider the roles patents play in the innovation ecosystem, and how compulsory secrecy might interfere with its regular functioning. The patent system is designed to provide incentives for innovation by granting a temporary monopoly 
on invention, which is predicated on patents granting, in exchange for disclosure. Exclusivity with commercial opportunity allow firms to earn returns on their research investment. Information about new invention, conveyed in patent publications or otherwise, can clarify competitive positions and delineate property rights, helps inventors build on prior art, and enables others to produce and sell the invention when IP rights expire. Compulsory secrecy in the United States directly defies these goals by holding up patent rights and forbidding disclosure.

The results of this paper illustrate what can happen when these functions are suppressed. Firms caught in the crossfire might lose access to inventive inputs and opportunities to profit from their investment, and reduce or reallocate research and development (R\&D) investments accordingly. Restrictions on disclosure affect follow-on innovation, which can in turn limit competition (a second, indirect channel through which incentives for innovation might be suppressed). Though World War II was an extraordinary time, unlike in Europe the domestic U.S. economy was still functioning. The evidence is thus suggestive of the impacts a similar intervention may have in other crises or even in regular times. It is not hard to imagine, for example, secrecy orders being used to protect COVID-19 vaccine development, as they once were in wartime.

The evidence points to the private value of the rights to, and commercial opportunities for, inventions which secrecy orders essentially impounded. Without exclusivity, let alone commercialization, the returns to R\&D are often eradicated. In comparison to compulsory licensing, compulsory secrecy can be even more costly to firms, as it can foreclose the possibility of market entry for as long as restrictions are in place-leaving firms in the interim with only internal applications as opportunities to profit from their invention. Firms might even choose to avoid applying for patent protection to preclude the risk of being compelled into secrecy. That said, the incidence is unlikely to be uniform. Incumbent firms and firms that already rely on secrecy may stand to benefit from compulsory secrecy if it protects them from competing innovation or harms rivals. Consistent with this possibility, I show that large firms were relatively less affected.

This paper also speaks to the role of information in the functioning of the wider innovation system. A growing literature explores the role of patents in this domain, including through increasing access to patent documents (Furman et al. 2021) and policy changes which accelerated patent publication (Hegde et al. 2019), and even uses modern invention secrecy to argue for patent disclosure (de Rassenfosse et al. 2020). Although these papers detect positive effects on local patenting, patent citations, and licensing, these results are in tension with skepticism from legal scholars (e.g., Roin 2005, Fromer 2009, Devlin 2010), who point out that much of the information in patents is available 
through other sources, and that inventors and patent attorneys are incentivized to avoid reading prior art and draft broad patents that disclose as little as possible. ${ }^{1}$ Relative to these examples, however, compulsory secrecy imposes significantly broader restrictions on disclosure than preventing patent publication alone. Their effects on subsequent invention are thus suggestive of the value of unrestricted information flows in supporting cumulative innovation.

More broadly, this paper fits into a wider literature on crisis innovation, especially in wartime. The two World Wars have served as laboratories for many other questions about innovation, including around compulsory licensing and scientific communication (e.g. Moser and Voena 2012, Biasi and Moser 2021, Iaria et al. 2018). Recent work by Gross and Sampat (2020) suggests World War II was fertile breeding ground for innovation, giving rise to new firms and industries, especially among those involved in the wartime research effort. Firms squelched by compulsory secrecy and lacking a government customer, however, may not have been so lucky.

The paper is organized as follows. Section 1 describes compulsory secrecy as implemented during World War II, traces its history, and discusses its relevance today. Section 2 introduces the data and provides an empirical characterization of the World War II secrecy program. Section 3 studies the effects of compulsory secrecy on firms, and Section 4 on innovation more broadly. In each case, I attack the question from multiple angles. Section 5 then presents countervailing evidence that the program was effective in its goal of protecting sensitive technology from public disclosure. Section 6 concludes with competing perspectives on the importance of these results and their implications for managers, policymakers, and innovation.

\section{Historical Background}

World War II began in 1939 when Germany invaded Poland; France, the United Kingdom, and other countries declared war on Germany; and Russia counter-invaded Poland from the east. By the summer of 1940, Germany occupied France, Belgium, Luxembourg, the Netherlands, Denmark, and Norway and had begun bombing England. Although the U.S. did not enter the war until after the attack on Pearl Harbor at the end of 1941, it recognized the brewing crisis and began preparing for its eventual entry after the fall of France in May 1940.

\footnotetext{
${ }^{1}$ Even the legal literature is mixed, as Ouellette (2012) shows that inventors in some fields, like nanotechnology, use patents as a source of background knowledge, even as other legal scholars find otherwise (see Ouellette (2012) for a review). Graham and Hegde (2015) nevertheless argue that patent publication can serve to publicize an invention's "existence, quality, and scope" to competitors, investors, and potential licensees.
} 
Among these preparations was the re-introduction of compulsory secrecy. On July 1, 1940, the U.S. Congress passed a law (Public Law 700, henceforth P.L. 700) to renew an invention secrecy program first introduced near the end of World War I which had empowered the USPTO to issue secrecy orders on patent applications. The law specifically authorized USPTO to order that inventions in patent applications be kept secret, and withhold the granting of a patent, for as long as needed if its disclosure might be "detrimental to the public safety or defense." Recipients of secrecy orders were, however, permitted to tender their inventions to the federal government and seek compensation for government use if a patent was eventually granted. Violations were initially punishable by loss of patent rights, but supplementary legislation a year later increased penalties to up to two years in prison and a $\$ 10,000$ fine, while adding a prohibition on all foreign filing. ${ }^{2}$ In 1942 , the policy was further amended to remain in force for as long as the U.S. was at war.

To implement P.L. 700, the USPTO created a new internal office named the Patent Office Defense Committee (later the Patent Office War Division, or POWD) to handle secrecy evaluations (Donnelly 1942). ${ }^{3}$ When patent applications arrived at the USPTO, they were first assigned to one of 65 patent examining divisions, each led by a primary examiner and specializing in a particular subject matter. The secrecy evaluation process began with these primary examiners, who forwarded to the POWD applications for inventions which in their opinion "discloses a matter related to the national defense" (OSRD Administrative Circular 10: Patents, April 27, 1944).

At the POWD, technical staff from four agencies - the War Department (represented by the Army and Navy Patent Advisory Board, or ANPAB), War Production Board (WPB), Office of Scientific Research and Development (OSRD), and Petroleum Administration for War (PAW) - evaluated these applications and made recommendations on secrecy. Appendix A shows examples of secrecy determination forms which accompanied each application and circulated among the evaluators. As soon as one recommended secrecy, a secrecy order was issued and patent examination suspended. The applicant was sent a standardized notification letter explaining that a secrecy order had been issued, instructing not to disclose the invention without USPTO permission at risk of a fine, jail time, and forfeiture of the patent, suggesting that the applicant tender the invention to the gov-

\footnotetext{
${ }^{2}$ The initial legislation prohibited the disclosure of inventions ordered secret, including via foreign filing, except with approval from the USPTO. This statute left a loophole for inventions filed in foreign countries prior to being filed at the USPTO, which were as such previously-disclosed. The 1941 amendment closed this loophole by prohibiting individuals from filing any patent on U.S. inventions in foreign countries without prior consent of the USPTO, irrespective of the issuance of a secrecy order, punishable by dispossession of existing patents and permanent disbarment from filing or assisting in the filing of patents thereafter. When permits for foreign filing were granted, they were typically to file in the U.K., which had an invention secrecy program of its own.

${ }^{3}$ Information on the administration of secrecy orders described here compiled from Fenning (1940), Donnelly (1942), OSRD (1944), JAG (1945), OWI (1945).
} 
ernment, and offering no means for appeal (example notification letters are shown in Appendix B). Upon enactment of P.L. 700, the USPTO began by reviewing recently-allowed patents which were ready to issue, followed by pending applications and new applications.

Although the issuance of secrecy orders may have been noisier in the earliest stages of the program (as review procedures were being developed), contemporary evidence suggests administrators were generally careful to avoid issuing secrecy orders without compelling reasons (Moore 1945). Once issued, secrecy orders could be reviewed and rescinded if it was determined that the enemy had access to comparable technology or an invention was no longer of strategic value. When one of the reviewing agencies sought to have a secrecy order rescinded, a copy of the application in question would be re-circulated to reviewers from the other three agencies, who then had to concur in the rescission for the secrecy order to be lifted - a process which could take two to six months - but the "natural tendency [was] to 'play it safe' and leave the secrecy order in effect" (Stoutenburgh 1945). Records of OSRD correspondence suggest that these case-by-case rescissions were relatively rare, and that most were issued in 1945 , near the end of the war. ${ }^{4}$

The war in Europe ended on May 7, 1945; in the Pacific, on September 2. On August 30, a newlyappointed Patent Commissioner (Casper Ooms) organized an inter-agency meeting to discuss the "expedited removal" of outstanding secrecy orders (Moore 1945). When representatives from the War Department raised concerns about inventions they believed should stay secret, the participants agreed to a 90-day grace period in which these advisory agencies could compile a list of those patents which they wished to be excepted from a mass rescindment. The meeting ended in the issuance of a "General Rescinding Order" (henceforth GRO) under which all outstanding secrecy orders were rescinded effective November 30, 1945, except those which the recommending agencies requested be exempt - and OSRD made sure that patents from the atomic fission project would remain under seal (Bush 1945). By the end of the year, there were less than 800 secrecy orders outstanding, with most on nuclear energy patents (JAG 1945, U.S. Congress 1980).

Contemporary records from the U.S. Army's Judge Advocate General's office (JAG 1945) indicate that 11,182 secrecy orders were issued through June 14, 1945. Given that the program wound down that summer, the true total is likely on the order of 11,200. Its records show that secrecy orders

\footnotetext{
${ }^{4}$ For example, of the 4,837 secrecy orders identified in OSRD records, only 311 were noted in these records as having been rescinded. Contemporary documents do indicate, however, that the WPB conducted a review in 1944 of the 1,700 applications which it had recommended for secrecy, and that by September 1945, nearly all had been rescinded (Moore 1945). Of the 6,353 patents with secrecy orders observed in the data, 1,134 (17.9\%) were granted before the General Rescinding Order took effect on November 30, 1945, implying that their secrecy orders were rescinded early - though it appears that the vast majority of these were rescinded that year.
} 
accelerated in the early years of the war, peaking in 1943-1944. Figure 1 confirms these patterns in the data, which will be introduced and discussed in Section 2 .

\section{Post-war invention secrecy policy}

Although the war ended in 1945, the need to protect recent and ongoing developments in sensitive technology like atomic energy persisted into the 1950s and beyond. The USPTO's wartime authority to issue secrecy orders remained in place through 1952, when the World War II national emergency was officially terminated. Prior to doing so, Congress enacted a peace-time invention secrecy policy to continue these wartime sequestrations under the Invention Secrecy Act of 1951. Although the restrictions and penalties remained the same, the new law made a few key departures from P.L. 700, the most important being (i) fixed, one-year terms, subject to renewal by the requesting agency, which nominally subjected outstanding secrecy orders to annual review (whereas secrecy orders during the war had no expiration); and (ii) a means of appeal.

Secrecy orders have issued under the Invention Secrecy Act ever since, although the available data suggest at lower frequency than during World War II: between 2005 and 2015, the USPTO issued 1,171 secrecy orders among 5.8 million applications (FAS 2018), whereas during World War II it did so on roughly 1 out of every 25 patents filed. Thus, although compulsory secrecy is ordinarily invoked with discretion, in a crisis the prospects for its use grow.

Increasing global technological competition has prompted a re-examination and proposed expansion of compulsory secrecy to protect U.S. "economic security", defined as ensuring that U.S. firms realize the full benefit of their R\&D investment. When the U.S. House of Representatives raised the possibility and USPTO solicited public comments (77 F.R. 23662), the request for comments posed several of the questions asked in this paper, including:

1. What would be the effect of establishing a new regulatory scheme based on economic security on United States businesses, industries, and the economy?

2. How would it affect the public notice function that underlies the policy of publication, including the ability of U.S. inventors and innovators to timely access the newest technical information upon which to build and stay ahead?

3. How would it affect firms with operations or sales in foreign countries?

Various firms and lobbying groups responded with concerns that such a policy would deprive inventors of technical information (e.g., IPOA 2012); preclude commercialization of innovations 
which are easily observed or reverse-engineered (AIPLA 2012); and discourage R\&D or drive it away from the U.S. patent system (IPOA 2012, ABA 2012).

These objections are consistent with views in the 1940s. OSRD's Director (Vannevar Bush) noted that its contractors were uneasy about the possibility that "foreign companies would be able to enter the world commercial market [ahead] of the U.S. manufacturers," due to compulsory secrecy (Stoutenburgh 1945). Even those in charge of administering the compulsory secrecy program had hesitations: in discussing the possibility of a peace-time policy at the August 30, 1945 meeting, representatives from various agencies were concerned that it would drive invention underground, delay diffusion, and slow technological progress (Moore 1945). ${ }^{5}$

\section{Data}

To study the effects of compulsory secrecy, I combine several sources of data, beginning with the complete record of the nearly 2.5 million patents granted between 1920 and 1979 from the USPTO historical master file (Marco et al. 2015), which includes, grant dates, patent class (USPC), and 2-digit NBER technology category (Hall et al. 2001). I supplement these data with patent serial numbers (i.e., application numbers) and filing dates collected from FreePatentsOnline.com, from which I also collect the complete network of forward and backward front-page citations, and with standardized assignee names from Clarivate's Derwent Innovation.

Using the assignee names, I classify assignees into four categories: firms, universities and hospitals, government agencies, and individuals. At certain points in the paper I will also distinguish between patents assigned to OSRD contractors (performing R\&D for the war effort) and non-contractors, which were identified from OSRD archival records (see Gross and Sampat 2020). Concurrent with these efforts, I also identify all patents associated with the Manhattan Project research program from Streifer (2017) and exclude them from the analysis below, as both the narrative history and the data indicate that these patents were not only (very) secret, but also exempted from the 1945 rescinding order. Appendix A describes in detail how these data were prepared, as well as steps taken to improve the quality of the data on serials, filing dates, and assignee names. Together with Appendix $\mathrm{C}$ it also shows that Manhattan Project patents were fundamentally different than other

\footnotetext{
${ }^{5}$ This was more than a theoretical possibility: Stoutenburgh (1945), for example, describes one firm (National Cash Register) which was threatened with the loss of patent rights in the United Kingdom if it did not prosecute a patent application which USPTO had ordered secret - and which the U.S. secrecy order prohibited.
} 
secret patents, with later filing dates and much longer grant delays, and clearly not subject to the rescinding order-motivating my dropping them from the sample.

I use the records of three agencies - OSRD, the Office of Production Research and Development (OPRD), and the U.S. Army Judge Advocate General (JAG) - to identify patent applications with secrecy orders. Collectively, these records identified 8,475 patent applications which were ordered secret during the war (roughly $75 \%$ of the likely true total of $\approx 11,200$, which rises to 9,518 , or $85 \%$, if the non-intersecting Manhattan Project serials from Streifer (2017) are added). Of these, 6,353 (75\%) were granted by 1979 , with the remainder either abandoned or still secret (for example, two such applications on cryptographic inventions remained secret until they were granted in 2000). ${ }^{6}$ The OSRD and OPRD records also identify roughly 19,000 patent applications which were formally evaluated for secrecy but "disapproved", and the 13,131 of these which were granted will be used later as a comparison group for patents which were ordered secret.

In addition to numeric data on patents and citations, this paper also uses information from patents' textual content. I obtain from Google the title and full text of each patent in the 1920-1979 sample, and I identify words (more precisely, word stems) first used in the title of a patent filed between 1940 and 1945. New words are used in this paper as a measure of new ideas which entered the patent record during World War II (Iaria et al. 2018), whose diffusion can be traced both within the patent record and beyond it, using other data sources like books and product catalogs. Measuring words in patent titles presents two advantages over the full text: not only are titular words the most meaningful in describing the invention, but they are also available with minimal transcription error. Full text OCR errors are pervasive in historical patents, leading to severe bias when measuring words' earliest usage, though not their overall frequency. ${ }^{7}$

\section{Completeness of secrecy order records}

There are two ways in which these data might be mismeasured. The first is truncation: there may be patent applications from the 1940s that we know were ordered secret (because they appear in the archival lists of secret serials) but which remain secret, and have thus not yet granted. The second

\footnotetext{
${ }^{6}$ Although I observe only a subset (albeit a considerable majority) of secrecy orders, this undercounting only presents a risk of bias in a conservative direction due to attenuation: if the control group includes unobserved secret patents, then treatment-control differences will simply be understated.

${ }^{7}$ To confirm this intuition, I experimented with measuring new words in patents' full text. OCR errors cause many words which were in fact new in the 1940s to be dropped as an existing word because it appears in the full text of earlier patents due to OCR error. For example, "radar" first appears in the title of patent 3015096, "Radar counter-measure radio repeater", filed on March 30 1942, and in the OCR full text of several patents from the 1800s, including patents on washing machines, cigar bundlers, and burglar alarms.
} 
is measurement error: there may be granted patents which were secret but we do not measure as secret, because these records are incomplete. In other words, there may be inventions which we know were secret but we cannot measure in the grant data, and vice versa.

Given how much time has elapsed, it is unlikely that many World War II era patents remain secret today, though inevitably it is difficult to know for sure. Of the known-secret serials that have since granted, $93 \%$ granted by $1950,99 \%$ by 1960 , and $99.9 \%$ by 1970 . Unmeasured secrecy orders might be a more binding concern, but here we may be assured by three considerations: (i) if Manhattan Project patent applications are included, we have identified around $85 \%$ of all applications with secrecy orders; (ii) insofar as secrecy orders are undermeasured, this is likely to bias comparisons in a conservative direction, as the control group will have some (unmeasured) secret patents in it; and (iii) this bias will tend to be small in magnitude, because secret applications were only a fraction of total applications (albeit higher in some technology areas).

\section{Patent citations as a measure of follow-on invention}

The analysis will open in Section 3 by studying the effects of compulsory secrecy on directly-treated firms, before widening our aperture to study its effects on innovation broadly in Section 4. Forward patent citations will be used throughout this section to measure follow-on invention, supplemented later by content-based measures. To interpret these results, it is useful to first understand how citations were historically generated, and what they represent.

At its most literal, the patent citations measured in this paper are references to relevant prior art. As Appendix A shows, prior art references have been a part of patent examination since before USPTO began requiring that published patents list these references on the last (now, front) page. In the course of patent examination, examiners make reference to prior art which they have used to evaluate the novelty of the applicant's claims, and in 1947, USPTO began requiring that these

references be printed on the published patent itself. Until the USPTO established applicants' "duty to disclose" related prior art in 1992, it appears these references were made primarily by patent examiners. As such, patent citations identify closely-related invention, not information flows per se, but this is enough to measure de facto follow-on invention.

Given the historical data-generating process, many of the concerns about what citations measure in the modern period (e.g., Alcácer et al. 2009, Sampat 2010, Cotropia et al. 2013, Roach and Cohen 2013) are less relevant than they would otherwise be. That most (if not nearly all) of the citations 
in these data will be examiner-added is also potentially important, and discussed at more length in Appendix A. However, as Moser et al. (2017) have shown with more recent data, examiners tend to use the characteristics of an invention (rather than performance) to identify prior art. Presuming this generalizes to the historical period, the citations in this paper are best described as a measure of intellectual proximity and content-driven connections.

\subsection{Characteristics of secrecy orders}

It is useful to begin with a descriptive account of patenting and secrecy orders in the World War II period. Figure 1 shows monthly patent filings at USPTO from 1935 to 1952 (in blue, measured by left axis), and monthly applications ordered into secrecy (in red, measured by right axis). Aggregate patenting declined by nearly $50 \%$ by the height of the war in 1943, as resources were diverted away from invention and into war and military production. Naturally, however, this is also when secrecy orders were issued most intensively, trailing off by mid-1945.

[Figure 1 about here]

Figure 2 shows the distribution of patenting and secrecy orders across one-digit NBER patent categories. Although aggregate patenting declined during the war, its distribution across technology areas was relatively stable (Panel A). The fraction of patents ordered secret, on the other hand, varied significantly over the course of the war and across technologies, with the most affected of these broad classes (Computers \& Communications, which included radar) having nearly one of every three to four patents sequestered between 1942 and 1944.

[Figure 2 about here]

The technological priorities of the war effort can be seen more precisely in the set of patent classes in which secrecy orders were issued at particularly high frequency. Table 1 lists the top ten classes by the fraction of applications between 1939 and 1945 ordered secret, where for the purposes of this table I include Manhattan Project patents and measure them as secret. On this list are nuclear reactions, cryptography, radar, synthetic rubber, and catalytic cracking (fuel production) - most of which are technologies with both military and commercial value. At the height of the war, more than half of filings in these classes were ushered into secrecy. 
[Table 1 about here]

Secrecy orders were inevitably not randomly issued: the narrative evidence suggests that patent applications were evaluated carefully and in good faith, with more-sensitive and important inventions being the primary focus. As a test for selection, Table 2 estimates mean differences in patents' forward citations as a function of whether a given patent was issued a secrecy order and/or evaluated for a secrecy order. The regressions in this table condition on fixed effects for each patent's (i) primary class and filing year (for within-cohort comparisons) and (ii) grant year (because patents only become "citeable" after grant). The estimated equation is:

$$
Y_{i}=\beta_{1} \cdot \mathbb{1}(\text { Secret })_{i}+\beta_{2} \cdot \mathbb{1}(\text { Evaluated })_{i}+\alpha_{c t}+\gamma_{g}+\varepsilon_{i}
$$

where $i$ indexes patents (the unit of observation), $c, t$, and $g$ represent the patent's class, filing year, and grant year (fixed for each patent $i), \mathbb{1}\left(\right.$ Secret) ${ }_{i}$ indicates that patent $i$ was ordered secret, $\mathbb{1}(\text { Evaluated })_{i}$ indicates that patent $i$ was formally evaluated for secrecy (irrespective of whether it was then ordered secret), $\alpha_{c t}$ and $\gamma_{g}$ are fixed effects, and standard errors are clustered by patent class. Table 2 shows that patents evaluated for secrecy were cited more, by more parties, and by patents in more classes than those which were not. Patents with a secrecy order were cited even more, on average receiving more than $1.5 \mathrm{x}$ as many citations as the typical patent from the same class and year (up 2.6 citations on an average of 4.6).

[Table 2 about here]

Among the many narrative records describing the secrecy program and internal agency memoranda, including by the two OSRD employees who were assigned to review patent applications for secrecy and whose names are on most of the secrecy determination forms in the OSRD records (e.g., Beckler 1944), there is no indication that the standard for secrecy varied over time. Although this standard was not explicit, one reviewer from the War Production Board noted that he "used... two criteria in deciding whether secrecy should be imposed" (Moore 1945):

1. Does the invention in question have direct bearing on the war effort?

2. Could the information in the application be useful to our enemies?

Additional evidence in Appendix D shores up this interpretation. Empirically, characteristics of patents that correlate strongly with future citations, like patent length, were stable for secret 
and non-secret patents throughout the war (e.g., Appendix Figure D.1). Among patents formally evaluated for secrecy, the fraction ordered secret increased slightly over the period, from around $25 \%$ in 1941 to $40 \%$ in 1945 , which could be a result of either (i) patent examiners applying higher standards in deciding which patents to submit to secrecy evaluation, such that fewer were evaluated and a larger fraction of this set was ordered secret; or (ii) the evaluated pool remaining fixed, and secrecy evaluators lowering the threshold for a secrecy order.

\section{Immediate effect: Delayed grant and publication}

Although secrecy orders were sometimes rescinded early, the majority were in place until the GRO took effect in late 1945. Table 3 illustrates the effect that this had on total pendency, estimating the incremental grant lag of patents filed each year from 1939 to 1945 with a secrecy order, relative to others in the same class and filing year. ${ }^{8}$ The effect of secrecy on grant lags is on average about 2.5 extra years for 1940 and 1941 applications, doubling the mean-and not significantly different from zero by 1945. Note that the table includes 1939 filings for completeness, as many were ordered secret, but patents filed in 1939 which received a secrecy order were necessarily still pending as of the enactment of P.L. 700 in July 1940, and their grant lags are thus in part mechanical. For this reason, later tables will focus on the July 1940 to June 1945 period.

[Table 3 about here]

Figure 3 shows the full distribution of grant lags for secret patents shifting down monotonically over time to match that of their non-secret counterparts in the same class and filing year by 1945 . No comparable differences emerge when comparing patents evaluated for secrecy but not ordered secret against those not evaluated for secrecy at all (Appendix Figure C.1), suggesting that it was secrecy, not evaluation, which generated these delays.

[Figure 3 about here]

\footnotetext{
${ }^{8}$ Appendix Table C.1 shows unconditional average grant lags by filing year for (i) patents not evaluated for secrecy; (ii) those evaluated for secrecy but not secret; and (iii) those ordered secret. It further divides these lags into years from filing to secrecy evaluation and from secrecy evaluation to grant, where known. The increase in total pendency for secret patents is shown here to be driven by the secrecy, specifically.
} 


\section{Effects of Compulsory Secrecy on Firms}

We begin by examining how compulsory secrecy affected firm invention. A useful thought experiment to have in mind as we build to the analysis is to imagine the strategic challenge facing patent filers after they receive their first secrecy order, or after receiving many secrecy orders. Some filers may not even know that USPTO has the authority to order inventions into secrecy, with all the repercussions that brings, until they receive the notice that informs them that examination is indefinitely on hold, the invention cannot be disclosed, and there is no process for appeal, though they can tender their inventions for government use with a soft promise of eventual remuneration. Should filers continue inventing, or patenting, in the technology area that they have now discovered is at risk? Should they continue inventing or filing at all?

A natural instinct might be to exploit an assignee's first secrecy order as a "shock" and compare its patenting before and after. This approach, however, is intrinsically problematic because patenting is serially correlated, and a secrecy order by definition implies that a patent application was filed, increasing the likelihood of others arriving before and after — which leads to spurious pre-trends and positive effects. The approach I take instead is to compare assignees' pre- and post-war patenting, as function of their wartime exposure to compulsory secrecy.

Concretely, I estimate assignees' propensity to patent in a given 2-digit technology category, as well as in any category, before and after the war, as a function of the rate at which they received secrecy orders during the war itself. The analysis will initially be performed at the assignee-category level before aggregating up to the assignee level. The focal outcome variables will measure whether the assignee filed at least one patent in a given category, or at all, in five-year intervals around World War II: 1930-1934 and 1935-1939 (pre-war), and 1946-1950, 1951-1955, and 1956-1960 (post-war), and the treatment variable, denoted SecrecyRate ${ }_{i}$, measures the fraction of an assignee's filings between 1940 and 1945 (in a given category, or overall, as the case may be) which were ordered into secrecy. I thus estimate the following specification:

$$
Y_{i t}=\sum_{t} \beta_{t} \cdot \text { SecrecyRate }_{i} \cdot \text { Period }_{t}+\alpha_{i}+\delta_{t}+\varepsilon_{i t}
$$

where $i$ indexes assignees/assignee-categories (the units), $t$ indexes periods, $\alpha_{i}$ and $\delta_{t}$ are unit and time fixed effects, and standard errors are clustered by unit.

In implementing this analysis below, I further condition the sample in two ways. The first is to restrict to incumbent filers: I require that assignees in the sample have at least one patent pre-1940. 
Because firms inventing in areas at risk of secrecy orders may be different than those that are not, I also require that assignees have at least one secrecy order in the war, ensuring that the estimated effects are estimated off of the intensive margin of secrecy.

The results for assignee-category patenting are shown in Table 4. This table examines whether a given assignee patents in a given technology area in each of the periods shown, as a function of the intensity with which it received secrecy orders in that area during the war. All estimates are relative to 1930-1934 (the omitted category). The first column provides results for all assignees in this sample, and the latter columns for different assignee subsamples. The last two columns examine entrants, rather than incumbents, defined locally (no pre-1940 patents in the given technology area, Column 6) and globally (no patents at all pre-1940, Column 7). The results indicate that assignees more heavily affected by compulsory secrecy were more likely to stop patenting in technology areas where they were affected, with these effects persistent through 1960. A closer look at the results by subsample provides further clues: these effects are primarily driven by non-OSRD contractors (Column 2) - that is, firms without a government customer - and by "small" assignees (Column 4), defined here as those with fewer than 20 patents pre-1940.

[Table 4 about here]

Table 5 performs similar analysis at the assignee level, asking whether a given assignee patents at all, as a function of the intensity with which it received secrecy orders during the war. The table bears a similar format to Table 4, adding two columns subsampling assignees which I label as technologically "focused" or "diversified", measured with an indicator for whether all of their pre1940 patents were concentrated in one technology area. Here I find similar but somewhat attenuated results, with stronger effects for non-OSRD, small, and technologically-focused assignees. In other words, those who had their patents sequestered at high rates, without a government customer or much technological flexibility, were less likely to patent thereafter.

[Table 5 about here]

Appendix Tables D.2.1 and D.2.2 re-estimate Equation 2 with a binned (rather than continuous) treatment measure. For the assignee-category regressions, these bins are secrecy rates in $(0,0.25]$, $(0.25,0.75]$, and $(0.75,1]$; for assignees, they are $(0,0.1],(0.1,0.25]$, and $(0.25,1]$. The precise intervals are chosen to be easy to interpret yet each have enough mass to support estimation. The results 
in these tables indicate that the patterns above are driven by those assignees whose World War II era patents were ordered into secrecy at the highest rates.

Given the reliance on patent data, it is hard to be certain whether the results reflect reduced invention or simply reduced patenting, with a concomitant shift to informal IP such as trade secrets. Either result may be concerning to both managers and regulators. The latter would reflect a weakening of formal IP, and by driving invention underground - away from the patent system - it might undermine other functions it is designed to achieve, such as disclosure. That the effects are more pronounced for smaller firms, however, suggests firm responses are on the $R \& D$ margin, because if they were on the IP strategy margin, large firms would be more sensitive (Png 2017). The persistence of these effects might be due to fixed costs of changing R\&D direction (e.g., of reverting to pre- or mid-war projects) after compulsory secrecy ended in 1945, or the extension of compulsory secrecy policy to peacetime in the early 1950s.

Of these two interpretations, the former could have broad implications, especially had compulsory secrecy been sustained at the levels applied in the war-or should it be expanded again. Rigidities and switching costs in R\&D portfolios can spring from many sources, including specific R\&D assets that are slow or costly to build-like human capital and know-how, commercialization infrastructure, or established routines and organizational structures - or managerial inertia due to incentives or ambiguity aversion. For some firms, compulsory secrecy might have eliminated opportunity costs to shifting direction, and once these changes were made, reverting was costly. Others may have pulled out of R\&D entirely, especially without a government customer. That the effects in Table 5 are larger for smaller and more technologically-focused assignees, with fewer existing alternatives to reallocate to, hints that some rigidities may be at play.

\section{Restricted commercialization}

In the case of inventions which might be disclosed through licensing or sales to customers, compulsory secrecy could have conceivably impeded firms from commercialization. Finding inventions that fit these criteria and whose commercial sale can be measured is difficult, but a natural place to start is with inventions which are themselves final goods.

The most accessible setting which I could find for testing this question is the specialty chemicals industry. Much as they do now, large chemical manufacturers in the 1940s circulated product catalogs listing their commercial products, where we can search for chemical terms from contemporary 
patents. I specifically focus on the Du Pont chemical company, whose catalogs are available from the Du Pont collection at the Hagley Museum. Du Pont was the largest U.S. chemical manufacturer at this time, with the most patents and the most secrecy orders. For this exercise, I extracted the text of five editions: 1938, 1944, 1946, 1949, and 1955-56.

To build a sample of words to search for in these catalogs, I began with the set of words whose stems first appeared in the title of a patent which was filed between 1940 and 1945 and classified in a chemical patent class. I then reviewed these stems to identify 572 stems which relate to chemical compounds or processes, and programmatically searched for words with these stems in each edition of the catalog. The test is then whether the stems from secret versus non-secret patent titles were differentially likely to appear in each edition of the catalog.

Appendix Table E.1 shows the results: stems which first appeared in a secret patent are less likely to be included in the catalog in 1944 and 1946, with no significant differences in the other years, nor for stems from patents evaluated for secrecy but not ordered secret. When compared against the baseline rate of $\approx 10 \%$ of non-evaluated stems appearing in the catalog, the effect size indicates that almost none of the stems from secret patents show up in 1944 and 1946 - which, as the table shows, is in fact true by the raw counts in each volume. These differences could be due to Du Pont inventions being withheld from the product market, or a reduction in licensing and sale of external inventions - either would be consistent with the restrictions of secrecy orders. If the former, it is worth noting that the welfare implications are ambiguous, since we cannot rule out that products serving similar functions were developed and commercialized by others, but this can be true at the same time as private costs were incurred by treated firms.

\section{Effects on Follow-on Invention}

Compulsory secrecy may also interfere with the broader functioning of the patent system, beyond the directly-treated firms alone. Patents are potentially important not only to incentives for innovation, but also to expanding access to frontier technical information (e.g., Furman et al. 2021). Suppressing disclosure more broadly could undermine innovation and innovation strategy, since one firm's inventive output is another's input. ${ }^{9}$ The World War II episode provides an opportunity to explore whether compulsory secrecy may thwart this function.

\footnotetext{
${ }^{9}$ Reflecting the importance of information to firm innovation, many firms historically kept on-site technical libraries with books, journals, conference proceedings, and patents for their research staff to reference (NSF 1958) - resources which have since been supplanted by electronic indexing and digital libraries.
} 
In this section, I the effects of secrecy on follow-on invention. Simple comparisons between secret and non-secret patents' citations can be problematic because secrecy orders (and evaluations) were selected (Table 2). I instead focus on the intensive margin: variation in filing dates, combined with en masse rescindment, generates variation in secrecy duration. ${ }^{10}$ Exploiting the mass rescindment event, I am able to compare patents which were secret for more versus less time, differencing against contemporaries in the same patent class and filing year. The sample for this analysis will be all patents filed between July 1, 1940, when P.L. 700 was enacted, and June 30, 1945. Restricting the sample to patents filed after July 1, 1940 drops some earlier filings which were still pending as of that date and were subsequently ordered secret, but because these are already selected on longer examination, I focus on patents filed after P.L. 700 was active.

Throughout this section, I estimate variants of the following specification via OLS:

$$
\begin{aligned}
Y_{i}= & \sum_{t=1941}^{1945} \beta_{1 t} \cdot \mathbb{1}(\text { Secret })_{i}+\sum_{t=1941}^{1945} \beta_{2 t} \cdot \mathbb{1}(\text { Evaluated })_{i} \\
& +\gamma_{1} \cdot \mathbb{1}(\text { Secret })_{i}+\gamma_{2} \cdot \mathbb{1}(\text { Evaluated })_{i}+\alpha_{c t}+\gamma_{g}+\varepsilon_{i}
\end{aligned}
$$

where $\beta_{1 t}$ and $\beta_{2 t}$ are estimated by filing year and other variables are defined as before. $Y_{i}$ will alternately be (i) whether the patent was ever cited, (ii) whether it reached particular citation thresholds, or (iii) citation counts, estimated with a count model-each measured through 1979, by which point these patents will have realized most of their eventual citations (Hall et al. 2001). I estimate separate effects by filing year to enable comparisons between secret and non-secret patents filed earlier or later in the war, with 1940 being the omitted category. With this specification, we will be able to make statements about the difference between secret patents and their non-secret contemporaries in the same class filed in 1945, and compare it to same such difference for those filed in 1940, for which a secrecy order was far more imposing.

Although secrecy orders were restrictive, contemporary sources suggest secret inventions could in select cases be shared. Moreland (1943) and Stewart (1943) both indicate that OSRD contractors could request permission to disclose inventions, especially to military suppliers. Griffiths (1942) states as much explicitly: "If for the purpose of development or manufacture it appears necessary to communicate to one or more reliable and responsible persons ... an application held in secrecy, a

\footnotetext{
${ }^{10}$ Variation in filing dates combined with mass rescindment generates intent-to-treat variation in secrecy duration. Noncompliance (in the econometric sense) exists in the form of early rescindments, but as Section 1 explains, these were relatively uncommon, and most were issued in 1945, shortly before the mass rescindment, such that the effects of noncompliance are limited — as confirmed by Figure 3 and Table 3.
} 
petition for modification of the order [can be] made, stating the purpose of the proposed disclosure, vouching for the reliability and integrity of these persons." I will thus distinguish between patents of OSRD contractors and other assignees in my analysis below.

Contemporaneous trends in U.S. invention (e.g., the growth of immigrant inventors in Moser et al. 2014) will be accounted for by class-year fixed effects. But a remaining threat to this approach is the possibility of time-varying selection into secrecy: if evaluators applied more stringent standards later in the war, then what appears to be an effect of a shorter secrecy term may just be positive selection. The evidence from Section 2 suggests this is unlikely to be the case, with little evidence that evaluation standards, or characteristics of patents that predict future citations, varied systematically over time - and if anything, it raises the possibility of loosening evaluation standards, which would bias the estimates towards zero. To further explore this possibility, I run robustness checks controlling for a series of patent- and assignee-level characteristics. I also discuss the degree of selection on unobservables that would be required to explain the results (Oster 2019). As a placebo test, I also separately estimate Equation 3 for non-self citations and self citations, as secrecy should only affect the former, whereas selection will be reflected in both.

The main limitation of historical citation-based analysis is the fact that the citation record only begins in February 1947, which is when the USPTO first required granted patents to include formal references to prior art. As a result, any citations observed in these data are necessarily from patents granted after 1947, which will undercount follow-on invention granted prior to this date (although modern evidence suggests that the bulk of forward citations are accumulated over longer horizons, e.g. Hall et al. 2001). This truncation of the citation record will affect earlier applications more than later ones, which have fewer years of "missing" citations - but it should affect secret and non-secret patents of the same class and vintage in a similar way. The class-year fixed effects will account for any truncation in citation counts flexibly by technology area.

\section{Forward citations}

In Table 6, I estimate the probability that a patent is ever cited. Column (1) does so for the full sample, and finds no statistical differences in the likelihood that earlier or later secret patents are subsequently cited. When we split the sample into non-OSRD contractors and OSRD contractors (Columns 2 and 3), we see heterogeneity. Non-contractor patents filed early in the war are significantly less likely to be cited than contemporaries, but this effect reverses for later filings, with the effect approximately monotonic in the filing year, consistent with longer secrecy terms reducing 
the likelihood of future citation. The point estimates suggest that secret patents filed in 1945 are nearly $15 \%$ more likely to later be cited than those filed in 1940. There are no such patterns for patents evaluated for secrecy but not ordered secret - with these estimates being relatively precise zeros - suggesting that the effects are driven by secrecy specifically. ${ }^{11}$ In contrast, there is no detectable effect of compulsory secrecy on citations of inventions by OSRD contractors. The final two columns of the table show results from a triple-differences specification, where the focal variables are included alone and interacted with an indicator for OSRD contractors, but where fixed effects can be estimated off of the pooled sample. The results are consistent.

[Table 6 about here]

Table 7 explores the robustness of these results to a variety of controls. Column (1) reproduces the result from Table 6 for non-OSRD contractors. Column (2) then controls for other observable patent characteristics, with fixed effects for the number of inventors and patent length (measured as number of pages and drawings), which correlate with citations (Appendix C). Column (3) controls for other assignee characteristics, with fixed effects for firms and individuals, and fixed effects for the assignee's pre-war patenting in the 1930s, as a measure of assignees' prior experience in and intensity of invention. Column (4) includes both the patent and assignee controls, and Column (5) replaces the latter with assignee fixed effects. Across all five specifications, the empirical patterns are unchanged - although standard errors increase in Column (5), due to the more limited within variation available for estimating the effects of secrecy.

[Table 7 about here]

In both tables I calculate and present the Oster $\delta$-statistic for each of the focal parameters, which informs us how large selection on unobservables has to be, relative to the selection on observables, for the true parameters to be zero, given estimated values (Oster 2019). When $\delta$ is low, it takes little selection on unobservables to reverse the controlled effect; that is, the estimated effect is accurate only if there is approximately zero selection on unobservables. When $\delta$ is high (e.g., $>1$ ), the effect is relatively robust to selection on unobservables. ${ }^{12}$ I find that this statistic is consistently above

\footnotetext{
${ }^{11}$ This evidence mirrors that in Figure 3 and Appendix Figure C.1, which show that secrecy delayed grant significantly for patents filed in the early 1940s, but secrecy evaluation had no such effects.

${ }^{12}$ The intuition behind the Oster method is to see how much the focal parameter changes between a short regression and a regression with the other right-hand side variables, and how much this increases the regression $R^{2}$, and use this information to bound any potential remaining bias that could result from selection on unobservables. This exercise requires specifying a (hypothetical) maximum $R^{2}$ that could be achieved if the specification included all observed and unobserved controls. I follow Oster's suggestion and set this to be $\min \{1.3 \tilde{R}, 1\}$, where $\tilde{R}$ is the $R^{2}$ from the estimated regression (see Oster 2019, p. 189 for details).
} 
one for the statistically-significant, later-year parameters.

Appendix D presents additional results. Tables D.3.2 and D.3.3 reproduce the regressions in Table 6, first excluding secret patents which granted prior to August 30, 1945 (indicating that they were rescinded early), and then excluding patents in weapons-related classes, which were of high military priority but had only limited commercial potential, such as firearms, ammunition, ordnance, and explosives. The results are not sensitive to either restriction. Table D.3.4 separately estimates the effects for non-self and self citations, and citations from firms versus individuals, where we see that the results are driven by non-self citations, with no such effects for self citations, and by citations from firms, rather than individuals. The latter result, in particular, suggests that secrecy impeded the flow of information feeding an ecosystem of firm invention.

Appendix Table D.3.5 studies effects on forward citation in levels, first using indicators for different citation thresholds (Columns 1 to 6), which can be estimated via OLS with multi-level fixed effects without an incidental parameters problem and is thus the preferred approach, and then for citation counts (Column 7), estimated as a conditional fixed-effects Poisson with filing and grant year fixed effects, reported as incidence rate ratios. The table shows that the effects of secrecy are strongest at lower citation thresholds, particularly for the probability of receiving at least one or two citations, but not detectable for higher thresholds. The Poisson estimates suggest that secret patents filed in 1945 receive roughly $1.65 x$ the citations of those filed in 1940 .

\section{Alternative measure: Diffusion of new words}

Although researchers from Jaffe et al. (1993) to Galasso and Schankerman (2015) have used patent citations to measure of follow-on invention, and many of the idiosyncracies of modern citation data do not apply in the period studied in this paper, the analysis above still faces two limitations. The first is that patents only become "citeable" when published-which motivated the inclusion of grant year fixed effects. An additional limitation which is particularly germane to this paper is that the patent citation record only begins in 1947, as the USPTO did not require inventors to list references to prior art on published patents until February 4, 1947. ${ }^{13}$

I thus develop a workaround content-based measure of follow-on invention which can be constructed for patents throughout this period. I identify new word stems in patent titles as ideas which entered

\footnotetext{
${ }^{13} \mathrm{~A}$ third, more subtle limitation is that secret patents might not have been accessible or salient to patent examiners in prior art searches, through which citations are generated. However, a subset of examiners necessarily had knowledge of the prior art, since secrecy review began with the examining divisions. That secret applications were considered in interferences also suggests that this was not limiting. See Appendix A.
} 
the patent record during the war (see Section 2), and measure later patents' use of stems which first appeared in secret versus non-secret patents. The approach is similar to that of Iaria et al. (2018), who study the introduction of new words in the title of scientific publications as a proxy for new scientific concepts, and the use of those words in patents. ${ }^{14}$

In preparing the data, I take the 1,143 stems first appearing in the title of a patent filed between July 1, 1940 and June 30, 1945, and for each stem I identify all subsequent patents with that stem in its title. This approach yields a panel of usage for every stem, and it allows us to compare the nearly 100 stems which originated in secret patents against the remainder which did not. Comparisons in levels remain difficult, due to positive selection: new stems from secret patents are subsequently used more than their non-secret counterparts, much like the patterns in Table 2. However, we can estimate variants of Equation 3 for word usage in place of patent citations.

The results are shown Table 8 for the 561 word stems which originated in patents of non-OSRD contractors filed between July 1940 and December 1944 (because there were no stems originating in secret patents from 1945, the 1945 year is omitted). Due to the small sample, these regressions reduce the class-year fixed effects to filing year fixed effects only, as class-year fixed effects would leave too little residual variation to identify the focal parameters.

[Table 8 about here]

The results are similar to those in Tables 6 and 7. Column (1) estimates the effects on log stem usage (through 1979) and finds that new stems from secret patents filed in 1940 on average have lower subsequent usage, but these effects more than reverse for new stems from later filings in 1943 and 1944. We see similar patterns for the probability of achieving 10, 20, 30, and 50 uses (Columns 2 to 5), though the effects are statistically weaker at higher thresholds. As before, there are no statistically significant effects for stems first appearing in patents evaluated for secrecy but not ordered secret, though in this case the estimates are somewhat noisy.

\section{Mechanisms: Temporarily veiled or permanently forgotten?}

The results invite the question of why a temporary secrecy policy would affect long-run citations. One possibility is a "missing generation" of follow-on invention. An alternative with perhaps more

\footnotetext{
${ }^{14}$ Williams (2013) and Sampat and Williams (2019) have also made successful inroads in studying follow-on innovation in the form of scientific research and commercial products which build on and can be directly linked back to the IP-protected innovation, especially human gene sequences.
} 
serious implications is that sequestered inventions were permanently forgotten, with entire threads of innovation left behind. To explore which of these two mechanisms is driving the results, Appendix Table D.3.6 estimates analogous regressions for the probability of being cited in subsequent cohorts of inventions, focusing on patents filed between 2 and 25 years later, to see whether the differences between patents with shorter and longer secrecy terms arise in the short run or long run. The results suggest a "lost generation" interpretation: patents with shorter secrecy are more likely to be cited by patents filed 3-4 years later than are those with longer secrecy, but these differences fade when comparing the likelihood of citation by later patents.

\section{$5 \quad$ Were Secrecy Orders Effective at Preventing Disclosure?}

Whether or not the consequences of compulsory secrecy were understood at the time, the intent of the policy was to safeguard invention whose disclosure might be "detrimental to the public safety or defense." Other security measures were also in place during the war, including traditional security classification of government activities. As part of these broader measures, was compulsory secrecy effective at keeping sensitive new technology out of public view?

I take two approaches to answering this question. Both examine the wider use of new terms from secret patents, not limiting ourselves to patent titles alone. I first turn to patent full text. For each stem which first appeared in the title of a patent filed in 1940 to 1945, I measure the fraction of nonsecret patents using that stem in their full text, by year. I then compare the annual frequency of stems first appearing in secret patents versus non-secret patents, by year, truncating to stems below the 90th percentile of pre-titular usage so as to eliminate already-common language - although the results below are similar for 75 th, 90th, or 95th percentile truncation. ${ }^{15}$ Specifically, I run the following regression on a sample of 1,143 unique stems from 1935 to 1955, where $i$ indexes stems and $t$ indexes years, and standard errors are clustered by stem:

$$
\text { Pct. of } \operatorname{corpus}_{i t}=\sum_{t=1936}^{1955} \beta_{1 t} \cdot \mathbb{1}(\text { Secret })_{i}+\sum_{t=1936}^{1955} \beta_{2 t} \cdot \mathbb{1}(\text { Evaluated })_{i}+\alpha_{i}+\delta_{t}+\varepsilon_{i t}
$$

Figure 4 plots the annual differences (the $\beta_{1 t}$ parameters), along with the associated $95 \%$ confidence intervals. The results indicate that prior to 1945, there was not differential usage of words whose

\footnotetext{
${ }^{15}$ That is to say, I eliminate stems whose total number of in-text uses before its first use in a title was above the 90 th percentile of all stems on this measure, treating these cases as stems already in common use.
} 
stem first entered the patent record in secret or non-secret patents, but that beginning in 1945, the use of words from secret patents' titles in the full text discretely jumps, with the difference persistent through at least 1955. Incremental effects are found for stems originating in the title of patents evaluated but not made secret (Appendix Figure D.4.1).

[Figure 4 about here]

I next turn to the Google Books corpus, as a data source which can measure broader use beyond patents alone, and perform a similar exercise. Google makes publicly available data on the annual usage of individual words and phrases (N-grams) in the books it had scanned into its Google Books service as of 2012, which provides insight into a wide corpus. Prior work has argued that this corpus can be treated as a library and used to characterize lexica (Pechenick et al. 2015). Because this corpus is increasingly populated by scientific texts across the twentieth century, it is also well-suited to measuring the diffusion of technical or scientific concepts.

For this exercise, I retrieved the annual usage of words with stems which entered the patent record in the title of a patent filed from 1940 to 1945 (as before), as well as the total number of words in the corpus by year, to calculate focal stems' frequency as a fraction of the corpus in a given year. 1,089 (95\% of the original 1,143) stems from patent titles match to the Google Books data in this way. I then compare the annual frequency of stems first appearing in secret patents versus non-secret patents, by year, again truncating to stems below the 90th percentile of pre-patent usage in the Google Books corpus, though the results below are likewise similar for 75th, 90th, or 95th percentile truncation. I re-estimate Equation 4 on this sample.

Figure 5 presents the results. There is again no differential usage prior to 1945 of words whose stem first entered the patent record in secret or non-secret patents, but beginning in 1945, the use of words from secret patents in this corpus discretely jumps, with a persistent difference thereafter. Moreover, no such effects are present for stems originating in patents evaluated for secrecy but not made secret (Appendix Figure D.4.2). That the sharp jump in the use of technical words from secret patents occurs only after secrecy orders were rescinded in 1945 suggests the policy was indeed relatively effective at achieving its intended security objective.

[Figure 5 about here]

In Appendix Tables D.4.1 and D.4.2, I estimate a difference-in-differences version of Equation 4, comparing stem usage in the pre- and post-1945 eras. In both tables, the dependent variable in the 
first three columns is annual stem frequency, and in the last three columns is the annual fraction of works in the corpus which include the stem; each individual column denotes sample truncations at assorted percentiles of pre-war usage. These tables confirm the difference-in-difference estimates are statistically significant at traditional levels, and there is no such difference for stems from patents evaluated for secrecy but not ordered secret.

\section{Discussion and Concluding Remarks}

Bringing the collective evidence into full view, this paper shows that compulsory secrecy has myriad effects on firms and the wider innovation system, discouraging firms from inventing or filing patents in affected technology technology areas, impeding commercialization, and obstructing follow-on innovation - in the interest of protecting domestic technology from leaking to foreign competitors. Perhaps reassuringly, it appears that the intervention worked as intended with respect to security goals, though readers might also wish to consider at what cost.

Although the setting is historical, the intervention has direct modern relevance at a time when firms and governments in the U.S. and other Western countries are battling foreign misappropriation of intellectual property, and especially in a crisis like a global war or pandemic. This paper highlights the tradeoffs that managers and regulators might wish to consider when compulsory secrecy is a policy option. With respect to foreign competitive threats, domestic firms and regulators may have (relatively) aligned interests and be able to work collaboratively in evaluating these tradeoffs. More broadly, managers may wish to consider mitigating measures and prepare contingencies for compulsory secrecy, including strengthening informal IP protection.

That said, not all firms are likely to be equally affected by compulsory secrecy. Some may even stand to benefit. Restricting information flows creates a dynamic tradeoff for an R\&D-investing firm: it loses access to information about rivals that might advance its investments in innovation today, but its rivals do as well, averting competing innovation tomorrow. These restrictions might be advantageous for incumbents, who can keep earning rents from past R\&D investments when innovation and entry are stymied. Similarly, the abrogation of formal IP rights may be advantageous for firms that do not rely heavily on them, and have built systems and structures to protect IP by other means - because they may not be affected by compulsory secrecy, but their rivals may be. The tensions that policies like this one present, and the incidence they have on different types of firms, are undoubtedly interesting and deserving of more attention. 
The broader lesson from this historical episode pertains to the roles, and impacts, of intellectual property in the innovation system. Basic principles of both intellectual property rights and scientific openness have been enshrined in U.S. law and policy since the Patent Act of 1790 required inventors to disclose their inventions in exchange for property rights. The results of this paper illustrate what can happen when these rights and requirements are forbidden, even temporarily: patenting may decline or shift towards protected subjects, and commercial impacts and follow-on invention may be stymied. They also provides a rare window into the effects of secrecy-one of the main tools that firms use to protect innovation (Levin et al. 1987, Cohen et al. 2000). Though the example in this paper is compulsory rather than voluntary, it provides a reference point for understanding how secrecy can affect the functioning of the innovation system.

The evidence nevertheless leaves us with unresolved questions. For example, the effects of compulsory secrecy could potentially have been very different had it been in place for a longer time, or had the policy been applied throughout the war as intensively as it was at its height in 1943 (Figure 1). Understanding how the effects of patent policies vary with their duration or provisional status is an important question for future work, if beyond the scope of this paper. The aggregate effects are also not fully known. In this case, patent classes in which secrecy orders were issued at the highest rates during the war were growing quickly both before and after the war, relative to others (see Appendix F), suggesting the impact on aggregate invention may have been limited - but pre-trends and the absence of a clean control group make conclusive inference on this front impossible, and in future applications, the aggregate impacts could be more severe.

These and other questions around compulsory and voluntary secrecy are left to future research. As it is, perhaps the biggest open question is what firms or regulators can do to combat foreign threats to intellectual property and preserve competitive positions with less collateral damage than the World War II intervention. It is not an easy question, but it is one where more research and experimentation is acutely needed, as this article brings into focus the heretofore hidden costs of existing policies and programs for securing innovation. 


\section{References}

Alcácer, Juan, Michelle Gittelman, and Bhaven N. Sampat. 2009. "Applicant and Examiner Citations in US Patents: An overview and analysis," Research Policy, Vol. 38, No. 2, pp. 415-427.

American Bar Association (ABA). 2012. Response to Request for Comments on the Feasibility of Placing Economically Significant Patents Under a Secrecy Order and the Need To Review Criteria Used in Determining Secrecy Orders Related to National Security, 77 Fed. Reg. 23662 (April 20, 2012).

American Intellectual Property Law Association (AIPLA). 2012. Response to Request for Comments on the Feasibility of Placing Economically Significant Patents Under a Secrecy Order and the Need To Review Criteria Used in Determining Secrecy Orders Related to National Security, 77 Fed. Reg. 23662 (April 20, 2012).

Beckler, David Z. 1944. Question as to Desirability of Continuing Examination of Patent Applications by a Member of the OSRD Liaison Office. Memorandum from David Z. Beckler to Francis S. Cooper, February 10, 1944. Available from the National Archives and Records Administration: Records of the Office of Scientific Research and Development.

Biasi, Barbara and Petra Moser. 2021. "Effects of Copyrights on Science: Evidence from the WWII Book Republication Program," American Economic Journal: Microeconomics, Vol. 13, pp. 218-260.

Bush, Vannevar. 1945. Letter to Casper W. Ooms. Letter from Vannevar Bush to Casper W. Ooms, August 21, 1945. Available from the National Archives and Records Administration: Records of the Office of Scientific Research and Development.

Cohen, Wesley M., Richard R. Nelson, and John P. Walsh. 2000. Protecting Their Intellectual Assets: Appropriability Conditions and Why U.S. Manufacturing Firms Patent (or Not). NBER Working Paper 7552.

Cotropia, Christopher A., Mark A. Lemley, and Bhaven N. Sampat. 2013. "Do Applicant Patent Citations Matter?" Research Policy, Vol. 42, No. 4, pp. 844-854.

de Rassenfosse, Gaétan, Gabriele Pellegrino, and Emilio Raiteri. 2020. Do Patents Enable Disclosure? Evidence from the Invention Secrecy Act. Working paper.

Devlin, Alan. 2010. "The Misunderstood Function of Disclosure in Patent Law," Harvard Journal of Law 83 Technology, Vol. 23, No. 2, pp. 401-446.

Donnelly, A. E. 1942. "June Issue," Journal of the Patent Office Society, Vol. 24, p. 511.

Federation of American Scientists (FAS). 2018. Invention Secrecy Activity. Available at https://fas.org/sgp/ othergov/invention/stats.html.

Fenning, Karl. 1940. "Patents and National Defense," Journal of the Patent Office Society, Vol. 22, pp. 869-884.

Fromer, Jeanne C. 2009. "Patent Disclosure," Iowa Law Review, Vol. 94, pp. 539-606.

Furman, Jeffrey, Markus Nagler, and Martin Watzinger. 2021. "Disclosure and Subsequent Innovation: Evidence from the Patent Depository Library Program," American Economic Journal: Economy Policy, forthcoming, Vol. 13, pp. 239-270.

Galasso, Alberto and Mark Schankerman. 2015. "Patents and Cumulative Innovation: Causal Evidence from the Courts," Quarterly Journal of Economics, Vol. 130, pp. 317-369.

Graham, Stuart and Deepak Hegde. 2015. "Disclosing Patents' Secrets," Science, Vol. 347, pp. 236-237.

Griffiths, A. W. 1942. Memorandum to the London Office. Memorandum from A. W. Griffiths to the OSRD London Office concerning the preservation of invention secrecy, December 9, 1942. Available from the National Archives and Records Administration: Records of the Office of Scientific Research and Development.

Gross, Daniel P. and Bhaven N. Sampat. 2020. Inventing the Endless Frontier: The Effects of the World War II Research Effort on Post-war Innovation. NBER Working Paper No. 27375. 
Hall, Bronwyn H., Adam B. Jaffe, and Manuel Trajtenberg. 2001. NBER Patent Citations Data File: Lessons, Insights and Methodological. NBER Working Paper No. 8498.

Hegde, Deepak, Kyle Herkenhoff, and Chenqi Zhu. 2019. Patent Publication and Innovation. Working paper.

Iaria, Alessandro, Carlo Schwarz, and Fabian Waldinger. 2018. "Frontier Knowledge and Scientific Production: Evidence from the Collapse of International Science," Quarterly Journal of Economics, Vol. 133, No. 2, pp. 927-991.

Intellectual Property Owners Association (IPO). 2012. Response to Request for Comments on the Feasibility of Placing Economically Significant Patents Under a Secrecy Order and the Need To Review Criteria Used in Determining Secrecy Orders Related to National Security, 77 Fed. Reg. 23662 (April 20, 2012).

Jaffe, Adam B., Manuel Trajtenberg, and Rebecca Henderson. 1993. "Geographic Localization of Knowledge Spillovers as Evidenced by Patent Citations," Quarterly journal of Economics, Vol. 108, No. 3, pp. 577-598.

Levin, Richard C., Alvin K. Klevorick, Richard R. Nelson, and Sidney G. Winter. 1987. "Appropriating the Returns from Industrial Research and Development," Brookings Papers on Economic Activity, Vol. 3, pp. 783-831.

Marco, Alan C., Michael Carley, Steven Jackson, and Amanda Myers. 2015. The USPTO Historical Patent Data Files: Two Centuries of Innovation. SSRN working paper, available at https://ssrn.com/abstract=2616724.

Moore, William Cabler. 1945. Meeting of the Patent Office Advisory Committee. Letter from William Cabler Moore to D. B. Keyes, September 5, 1945. Available from the National Archives and Records Administration: Records of the War Production Board.

Moreland, E. L. 1943. Letter to J. R. Killian. Letter from E. L. Moreland to James R. Killian, Jr., President of MIT, July 3, 1943. Available from the National Archives and Records Administration: Records of the Office of Scientific Research and Development.

Moser, Petra, Joerg Ohmstedt, and Paul W. Rhode. 2017. "Patent Citations-An Analysis of Quality Differences and Citing Practices in Hybrid Corn," Management Science, Vol. 64, No. 4, pp. 1926-1940.

Moser, Petra and Alessandra Voena. 2012. "Compulsory Licensing: Evidence from the Trading with the Enemy Act," American Economic Review, Vol. 102, pp. 396-427.

Moser, Petra, Alessandra Voena, and Fabian Waldinger. 2014. "German Jewish Émigrés and U.S. Invention," American Economic Review, Vol. 104, pp. 3222-3255.

Office of War Information (OWI). 1945. U.S. Government Manual. 1st edition (Revisions through March 10).

Oster, Emily. 2019. "Unobservable Selection and Coefficient Stability: Theory and Evidence," Journal of Business $\&$ Economic Statistics, Vol. 37, No. 2, pp. 187-204.

Ouellette, Lisa Larrimore. 2012. "Do Patents Disclose Useful Information?" Harvard Journal of Law E Technology, Vol. 25, pp. 545-607.

Pechenick, Eitan Adam, Christopher M. Danforth, and Peter Sheridan Dodds. 2015. "Characterizing the Google Books Corpus: Strong Limits to Inferences of Socio-cultural and Linguistic Evolution," PLoS One, Vol. 10, No. 10, pp. 1-24.

Png, Ivan P. L. 2017. "Secrecy and Patents: Theory and Evidence from the Uniform Trade Secrets Act," Strategy Science, Vol. 2, No. 3, pp. 176-193.

Roach, Michael and Wesley M. Cohen. 2013. "Lens or Prism? Patent citations as a measure of knowledge flows from public research," Management Science, Vol. 59, No. 2, pp. 504-525.

Roin, Benjamin N. 2005. "The Disclosure Function of the Patent System (Or Lack Thereof)," Harvard Law Review, Vol. 118, pp. 2007-2028.

Sampat, Bhaven N. 2010. "When Do Applicants Search for Prior Art?" Journal of Law and Economics, Vol. 53, No. 2, pp. 399-416. 
Sampat, Bhaven and Heidi L. Williams. 2019. "How Do Patents Affect Follow-on Innovation? Evidence from the Human Genome," American Economic Review, Vol. 109, pp. 203-236.

Stewart, Irvin. 1943. Form letter. Letter from Irvin Stewart to unspecified recipient(s), October 9, 1943. Available from the National Archives and Records Administration: Records of the Office of Scientific Research and Development.

Stoutenburgh, Paul P. 1945. Coordination of Rescission of Secrecy Orders with British Release of Information. Letter from Paul P. Stoutenburgh to Vannevar Bush, April 27, 1945. Available from the National Archives and Records Administration: Records of the OSRD.

Streifer, Bill. 2017. U.S. Department of Energy List of U.S. Patents Related to the Manhattan Project. Obtained via FOIA request by Bill Streifer and available at the Wilson Center History and Public Policy Program Digital Archive, https://digitalarchive.wilsoncenter.org/document/165247.

United States Army Office of the Judge Advocate General (JAG). 1945. Legal Work of the War Department, 1 July 1940 - 31 March 1945: A History of the Judge Advocate General's Department. Available at http: //www.loc.gov/rr/frd/Military_Law/pdf/Legal-Work_War-Department.pdf.

United States Patent and Trademark Office (USPTO). 2012. Notice of Request for Comments on the Feasibility of Placing Economically Significant Patents Under a Secrecy Order and the Need To Review Criteria Used in Determining Secrecy Orders Related to National Security. 77 F.R. 23662 (April 20, 2012).

U.S. House Committee on Government Operations. 1980. The Government's Classification of Private Ideas. Hearings before a Subcommittee of the Committee on Government Operations, United States House of Representatives, 96th Congress, Second Session.

U.S. National Science Foundation (NSF). 1958. Nonconventional Scientific and Technical Information Systems in Current Use. Washington: Government Printing Office.

U.S. Office of Scientific Research and Development (OSRD). 1944. Administrative Circular 10 (Patents). Enclosure to letter from Irvin Stewart of the OSRD to Colonel F. H. Vanderwerker of the Army and Navy Patent Advisory Board, April 27, 1944. Available from the National Archives and Records Administration: Records of the OSRD.

Williams, Heidi L. 2013. "Intellectual Property Rights and Innovation: Evidence from the Human Genome," Journal of Political Economy, Vol. 121, pp. 1-27. 
Figure 1: Monthly patent applications, 1935-1952

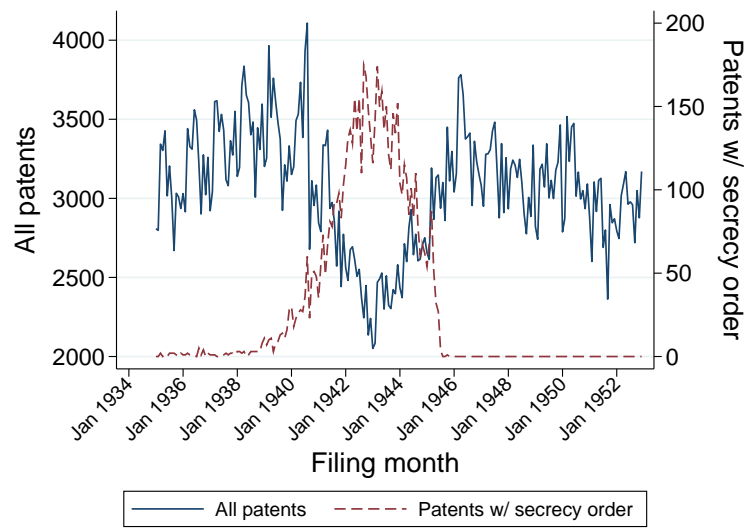

Notes: Figure shows monthly counts of (i) patent filings from 1935 to 1952 (in blue/left axis), and (ii) filings observed in the data as having been issued secrecy orders under P.L. 700 (in red/right axis).

Figure 2: Patterns in distribution of patent applications across NBER patent categories

Panel (A): Fraction of applications in each top-level NBER category, 1939-1945

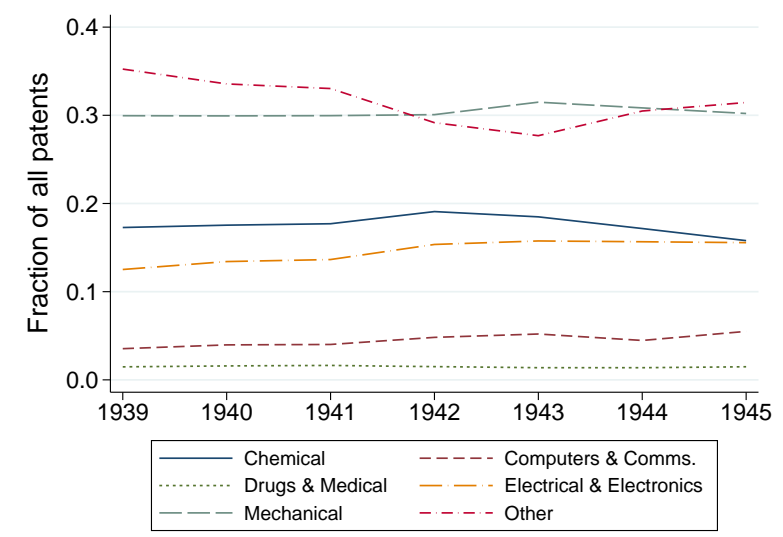

Panel (B): Fraction of applications in each top-level NBER category issued secrecy order

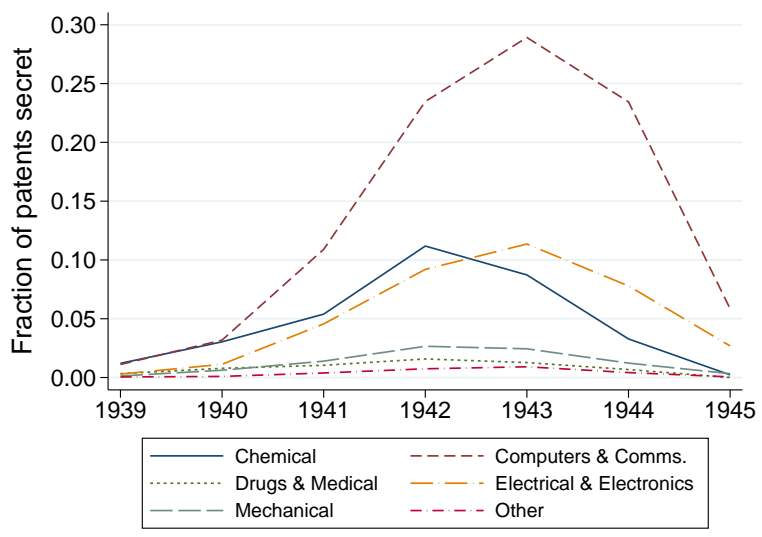

Notes: Panel (A) shows the distribution of patent filings across 1-digit technology categories in each year from 1939-1945. Panel (B) shows the rate at which filings in each category were issued secrecy orders over time. 
Figure 3: Application-grant lags of patents placed under secrecy vs. others, 1939-1945

Applications in 1939

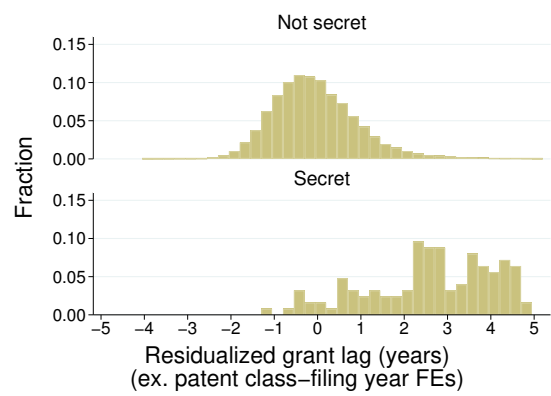

Applications in 1943

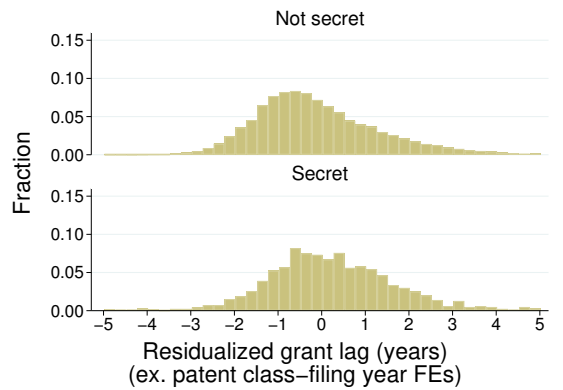

Applications in 1941

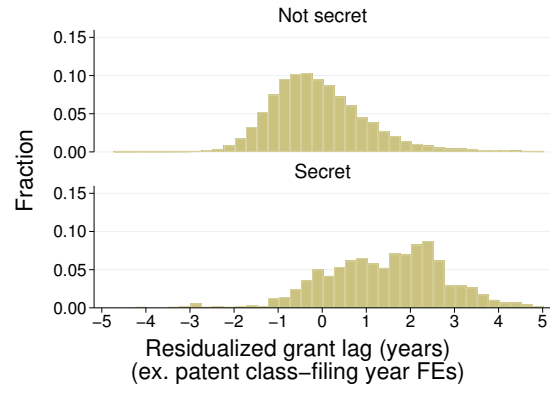

Applications in 1945

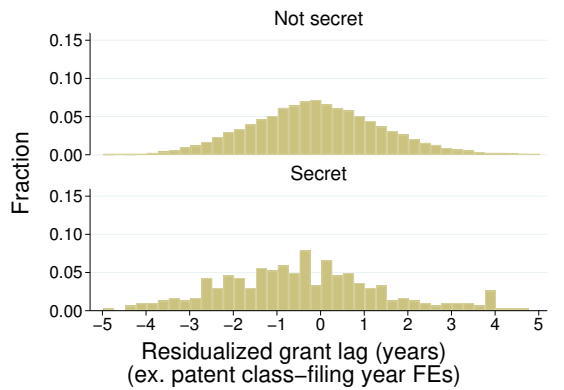

Notes: Figure shows the distribution of residual grant lags of patent applications with vs. without secrecy orders, after controlling for patent class-year FEs. Note that patent applications filed prior to July 1940 were only evaluated for secrecy if still under examination (such that pre-1940 differences in total pendency are in part selected). 
Figure 4: Annual use of new word stems from secret vs. non-secret patent titles, measuring use in patents' full text

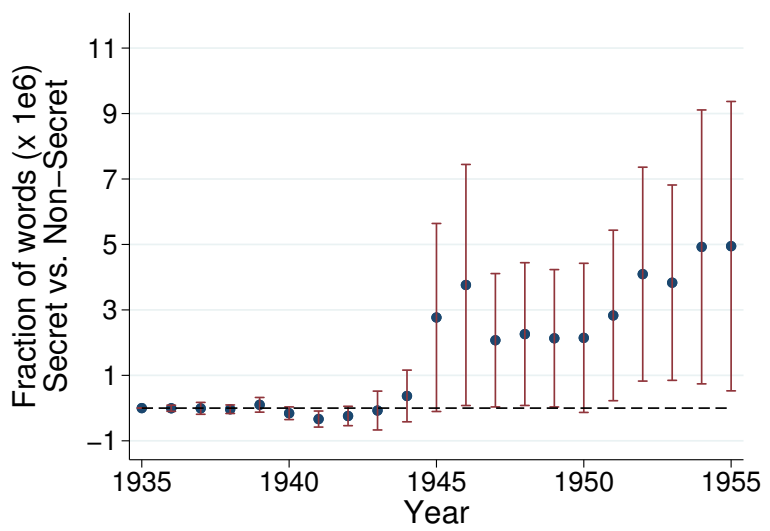

Notes: Figure shows estimated differences over time in the patent full text frequency of word stems which first appeared in the title of a secret versus non-secret patent filed in the 1940-1945 period. In the underlying regression, observations are new stems in patent titles from this period, crossed by year, and the outcome variable is the fraction of non-secret patents with the stem in their full text in the given year. This outcome is regressed on indicators for the year, interacted with indicators for whether the stem was first used in the title of a patent which was (i) evaluated for secrecy and (ii) ordered secret. The figure plots effects for the latter. Specification includes stem fixed effects, such that comparisons are within stems, over time. Omitted category is 1935 for stems from both secret and non-secret patents. Sample censors stems at the 90th percentile of pre-patent usage in patents' full text, to eliminate already-common language. Error bars represent $95 \%$ confidence intervals, computed from SEs clustered at the stem level.

Figure 5: Annual use of new word stems from secret vs. non-secret patent titles, measuring use in the Google Books corpus

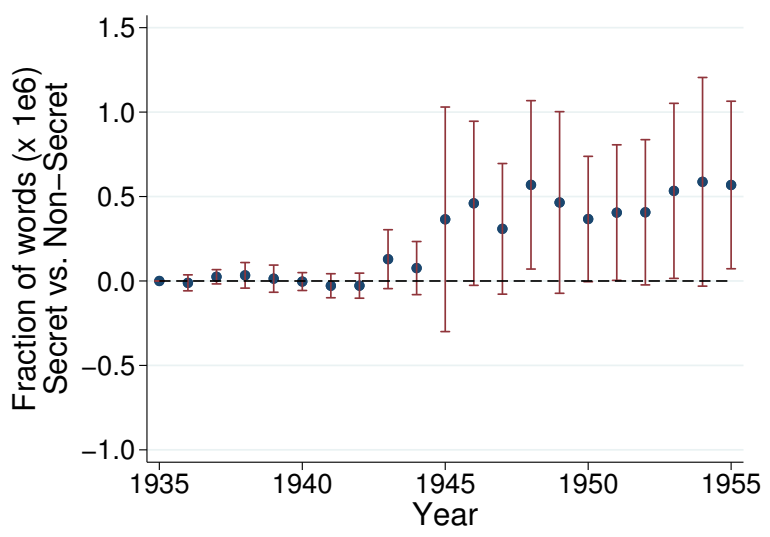

Notes: Figure shows estimated differences over time in the Google Books frequency of word stems which first appeared in the title of a secret versus non-secret patent filed in the 19401945 period. In the underlying regression, observations are new stems in patent titles from this period, crossed by year, and the outcome variable is each stem's fraction of all words in the Google Books corpus in the given year. This outcome is regressed on indicators for the year, interacted with indicators for whether the stem was first used in the title of a patent which was (i) evaluated for secrecy and (ii) ordered secret. The figure plots effects for the latter. Specification includes stem fixed effects, such that comparisons are within stems, over time. Omitted category is 1935 for stems from both secret and non-secret patents. Sample censors stems at the 90th percentile of pre-patent usage in the Google Books corpus, to eliminate already-common language. Error bars represent $95 \%$ confidence intervals, computed from SEs clustered at the stem level. 
Table 1: Top 10 patent classes with applications placed in secrecy, 1939-1945

\begin{tabular}{llcc}
\hline \hline & & $\begin{array}{c}\text { Pct. of applications w/ } \\
\text { USPC }\end{array}$ & $\begin{array}{c}\text { Max pct. secret in } \\
\text { any year, 1939-1945 }\end{array}$ \\
\hline 376 & Induced nuclear reactions & $74.8 \%$ & $90.9 \%$ \\
380 & Cryptography & $45.2 \%$ & $71.4 \%$ \\
342 & Directive radio wave systems/devices (radar) & $37.8 \%$ & $61.4 \%$ \\
367 & Acoustic wave systems/devices & $29.6 \%$ & $55.9 \%$ \\
526 & Synthetic resins or natural rubbers & $28.6 \%$ & $62.4 \%$ \\
333 & Wave transmission lines and networks & $28.1 \%$ & $51.8 \%$ \\
585 & Chemistry of hydrocarbon compounds & $25.9 \%$ & $51.9 \%$ \\
315 & Electric lamp and discharge device systems & $25.6 \%$ & $42.4 \%$ \\
327 & Electrical devices, circuits, and systems & $22.0 \%$ & $52.0 \%$ \\
343 & Radio wave antennas & $21.1 \%$ & $56.0 \%$ \\
\hline \hline
\end{tabular}

Notes: Table lists the 10 patent classes with the highest fractions of applications in 1939-1945 issued secrecy orders, in descending order, and the maximal fraction of applications in any one year ordered secret. The sample includes Manhattan Project patents, which I also measure as secret (see text and Appendix A). Data for eventually-granted patents only.

Table 2: Forward citations of secret vs. non-secret patents, 1939-1945

\begin{tabular}{lccccc}
\hline \hline & & & Outcomes: & \\
& Cites & Citers & Citing classes & Non-self & Self \\
\hline Secrecy ordered & $1.578^{* * *}$ & $1.232^{* * *}$ & $0.364^{* * *}$ & $1.422^{* * *}$ & $0.134^{* * *}$ \\
& $(0.349)$ & $(0.275)$ & $(0.080)$ & $(0.321)$ & $(0.039)$ \\
Secrecy evaluated & $0.926^{* * *}$ & $0.615^{* * *}$ & $0.293^{* * *}$ & $0.743^{* * *}$ & $0.170^{* * *}$ \\
& $(0.111)$ & $(0.077)$ & $(0.036)$ & $(0.100)$ & $(0.018)$ \\
\hline $\mathrm{N}$ & 242614 & 242614 & 242614 & 242614 & 242614 \\
$R^{2}$ & 0.09 & 0.09 & 0.12 & 0.09 & 0.06 \\
Grant year FEs & $\mathrm{Y}$ & $\mathrm{Y}$ & $\mathrm{Y}$ & $\mathrm{Y}$ & $\mathrm{Y}$ \\
Class-year FEs & $\mathrm{Y}$ & $\mathrm{Y}$ & $\mathrm{Y}$ & $\mathrm{Y}$ & $\mathrm{Y}$ \\
Mean of DV & 4.63 & 4.23 & 2.06 & 4.27 & 0.27 \\
s.d. of DV & 5.70 & 4.65 & 1.90 & 5.31 & 0.95 \\
\hline \hline
\end{tabular}

Notes: Table estimates differences in patents' forward citations, unique citing assignees, unique citing classes, non-self citations, and self citations for patents which were evaluated for secrecy and/or ordered secret. All columns control for (i) patent class by filing year and (ii) grant year fixed effects. *, **, $* * *$ represent significance at the $0.1,0.05$, and 0.01 levels, respectively. SEs clustered by patent class in parentheses.

Table 3: Effects of secrecy orders on application-grant lags, 1939-1945

\begin{tabular}{lccccccc}
\hline \hline & & \multicolumn{7}{c}{ Grant lag, for patents filed in: } \\
& 1939 & 1940 & 1941 & 1942 & 1943 & 1944 & 1945 \\
\hline Secrecy ordered & $3.272^{* * *}$ & $2.527^{* * *}$ & $2.303^{* * *}$ & $1.299^{* * *}$ & $0.826^{* * *}$ & 0.401 & 0.233 \\
& $(0.259)$ & $(0.154)$ & $(0.163)$ & $(0.118)$ & $(0.127)$ & $(0.268)$ & $(0.286)$ \\
\hline $\mathrm{N}$ & 40739 & 40361 & 35206 & 29524 & 28459 & 31962 & 36363 \\
$R^{2}$ & 0.17 & 0.20 & 0.23 & 0.22 & 0.20 & 0.20 & 0.19 \\
Class FEs & $\mathrm{Y}$ & $\mathrm{Y}$ & $\mathrm{Y}$ & $\mathrm{Y}$ & $\mathrm{Y}$ & $\mathrm{Y}$ & $\mathrm{Y}$ \\
Mean lag & 2.25 & 2.31 & 2.42 & 2.70 & 2.97 & 3.44 & 4.00 \\
\hline \hline
\end{tabular}

Notes: Table estimates differences in patents' grant lags for secret versus non-secret patents, by filing year. All columns include patent class FEs, such that comparisons are between patents in the same class in the given year. *, **, *** represent significance at the $0.1,0.05$, and 0.01 levels, respectively. SEs clustered by patent class in parentheses. 
Table 4: Effects of secrecy orders on $\operatorname{Pr}$ (Assignee patents in given class)

\begin{tabular}{lccccccc}
\hline \hline & $(1)$ & $(2)$ & $(3)$ & $(4)$ & $(5)$ & $(6)$ & $(7)$ \\
& All & Non-OSRD & OSRD & Small & Large & Entrant & Entrant \\
\hline Wartime Sec. Rate * $(1935-39)$ & 0.173 & 0.086 & 0.184 & -0.269 & 0.134 & & \\
& $(0.108)$ & $(0.133)$ & $(0.193)$ & $(0.182)$ & $(0.150)$ & & \\
& $-0.270^{* * *}$ & $-0.396^{* * *}$ & 0.119 & $-0.670^{* * *}$ & -0.217 & $-0.601^{* * *}$ & $-0.600^{* * *}$ \\
Wartime Sec. Rate * $(1946-50)$ & $(0.090)$ & $(0.109)$ & $(0.170)$ & $(0.151)$ & $(0.136)$ & $(0.055)$ & $(0.070)$ \\
& $-0.304^{* * *}$ & $-0.382^{* * *}$ & 0.088 & $-0.646^{* * *}$ & -0.181 & $-0.596^{* * *}$ & $-0.561^{* * *}$ \\
Wartime Sec. Rate * $(1951-55)$ & $(0.087)$ & $(0.104)$ & $(0.187)$ & $(0.145)$ & $(0.142)$ & $(0.058)$ & $(0.076)$ \\
& $-0.245^{* * *}$ & $-0.255^{* *}$ & 0.026 & $-0.401^{* *}$ & -0.179 & $-0.459^{* * *}$ & $-0.336^{* * *}$ \\
Wartime Sec. Rate * ${ }^{*}(1956-60)$ & $(0.085)$ & $(0.106)$ & $(0.180)$ & $(0.155)$ & $(0.134)$ & $(0.060)$ & $(0.076)$ \\
\hline $\mathrm{N}$ & 3635 & 1960 & 1675 & 905 & 2730 & 1809 & 1071 \\
$R^{2}$ & 0.51 & 0.51 & 0.39 & 0.46 & 0.45 & 0.20 & 0.20 \\
Assignee x NBER Cat FEs & $\mathrm{Y}$ & $\mathrm{Y}$ & $\mathrm{Y}$ & $\mathrm{Y}$ & $\mathrm{Y}$ & & $\mathrm{Y}$ \\
NBER Cat FEs & & & & & & $\mathrm{Y}$ & $\mathrm{Y}$ \\
\hline \hline
\end{tabular}

Notes: Table estimates the effect of the secrecy order program on affected assignees' post-war patenting, relative to pre-war patenting, in a given technology category where it received secrecy orders. Observations are assignees x NBER categories x years, in all cases organized into a balanced panel from 1930 to 1960, and aggregated to the periods 1930-1934, 1935-1939, 1940-1945, 1946-1950, 19511955, 1956-1960. The dependent variable measures whether the assignee filed any patent in the given NBER category and period. "Wartime secrecy rate" measures the fraction of the given assignee's filings from 1940 to 1945 in the given NBER category which received a secrecy order, which is then interacted with indicators for later periods to estimate effects over time. Samples are restricted to assignee-categories with $\geq 1$ pre-war patent and $\geq 1$ secrecy order, and omits the 1940-1945 period, such that the table shows a pre- vs. post-war comparison. All regressions include dummies for each of the interacted post-periods (not shown). ${ }^{*}, * *, * * *$ represent significance at the $0.1,0.05$, and 0.01 levels, respectively. SEs clustered by assignee in parentheses.

Table 5: Effects of secrecy orders on $\operatorname{Pr}$ (Assignee patents in any class)

\begin{tabular}{|c|c|c|c|c|c|c|c|c|}
\hline & $\begin{array}{l}(1) \\
\text { All }\end{array}$ & $\begin{array}{c}(2) \\
\text { Non-OSRD }\end{array}$ & $\begin{array}{c}(3) \\
\text { OSRD }\end{array}$ & $\begin{array}{c}(4) \\
\text { Small }\end{array}$ & $\begin{array}{c}(5) \\
\text { Large }\end{array}$ & $\begin{array}{c}(6) \\
\text { Focused }\end{array}$ & $\begin{array}{c}(7) \\
\text { Diversified }\end{array}$ & $\begin{array}{c}(8) \\
\text { Entrant }\end{array}$ \\
\hline Wartime Sec. Rate ${ }^{*}(1935-1939)$ & $\begin{array}{c}0.118 \\
(0.153)\end{array}$ & $\begin{array}{c}0.059 \\
(0.165)\end{array}$ & $\begin{array}{c}0.101 \\
(0.214)\end{array}$ & $\begin{array}{l}-0.226 \\
(0.186)\end{array}$ & $\begin{array}{c}0.157 \\
(0.177)\end{array}$ & $\begin{array}{l}-0.519 \\
(0.314)\end{array}$ & $\begin{array}{c}0.137 \\
(0.174)\end{array}$ & \\
\hline Wartime Sec. Rate * (1946-1950) & $\begin{array}{c}-0.272^{* *} \\
(0.134)\end{array}$ & $\begin{array}{c}-0.294^{* *} \\
(0.145)\end{array}$ & $\begin{array}{l}-0.043 \\
(0.288)\end{array}$ & $\begin{array}{c}-0.470^{* * *} \\
(0.167)\end{array}$ & $\begin{array}{l}-0.311 \\
(0.314)\end{array}$ & $\begin{array}{c}-0.614^{* *} \\
(0.282)\end{array}$ & $\begin{array}{c}-0.324^{* *} \\
(0.156)\end{array}$ & $\begin{array}{c}-0.600^{* * *} \\
(0.062)\end{array}$ \\
\hline Wartime Sec. Rate * (1951-1955) & $\begin{array}{c}-0.358^{* * *} \\
(0.108)\end{array}$ & $\begin{array}{c}-0.353^{* * *} \\
(0.116)\end{array}$ & $\begin{array}{l}-0.185 \\
(0.395)\end{array}$ & $\begin{array}{c}-0.509 * * * \\
(0.139)\end{array}$ & $\begin{array}{l}-0.451 \\
(0.296)\end{array}$ & $\begin{array}{c}-0.850^{* * *} \\
(0.227)\end{array}$ & $\begin{array}{c}-0.367^{* * *} \\
(0.135)\end{array}$ & $\begin{array}{c}-0.522^{\text {*** }} \\
(0.061)\end{array}$ \\
\hline Wartime Sec. Rate ${ }^{*}(1956-1960)$ & $\begin{array}{c}-0.211^{*} \\
(0.108)\end{array}$ & $\begin{array}{l}-0.186 \\
(0.118)\end{array}$ & $\begin{array}{c}0.085 \\
(0.368)\end{array}$ & $\begin{array}{c}-0.319^{* *} \\
(0.139)\end{array}$ & $\begin{array}{l}-0.200 \\
(0.309)\end{array}$ & $\begin{array}{c}-0.672^{* * *} \\
(0.228)\end{array}$ & $\begin{array}{l}-0.217 \\
(0.133)\end{array}$ & $\begin{array}{r}-0.352^{* * *} \\
(0.058)\end{array}$ \\
\hline $\mathrm{N}$ & 2380 & 1885 & 495 & 1290 & 1090 & 435 & 1945 & 969 \\
\hline$R^{2}$ & 0.52 & 0.51 & 0.34 & 0.47 & 0.46 & 0.43 & 0.51 & 0.22 \\
\hline Assignee FEs & $\mathrm{Y}$ & Y & Y & $\mathrm{Y}$ & $\mathrm{Y}$ & Y & Y & \\
\hline
\end{tabular}

Notes: Table estimates the effect of the secrecy order program on affected assignees' post-war patenting, relative to pre-war patenting, in any technology category. Observations are assignees $\mathrm{x}$ years, in all cases organized into a balanced panel from 1930 to 1960, and aggregated to the periods 1930-1934, 1935-1939, 1940-1945, 1946-1950, 1951-1955, 1956-1960. The dependent variable measures whether the assignee filed any patent in the period. "Wartime secrecy rate" measures the fraction of the given assignee's filings from 1940 to 1945 which received a secrecy order, which is then interacted with indicators for later periods to estimate effects over time. Samples are restricted to assignees with $\geq 1$ pre-war patent and $\geq 1$ secrecy order, and omits the 1940-1945 period, such that the table shows a pre- vs. post-war comparison. All regressions include dummies for each of the interacted post-periods (not shown). *, **, *** represent significance at the $0.1,0.05$, and 0.01 levels, respectively. SEs clustered by assignee in parentheses. 
Table 6: Effects of secrecy on probability of any forward citations

\begin{tabular}{|c|c|c|c|c|c|}
\hline & \multirow[b]{2}{*}{$\begin{array}{l}\text { All } \\
(1)\end{array}$} & \multirow[b]{2}{*}{$\begin{array}{c}\text { Non-OSRD } \\
(2)\end{array}$} & \multirow[b]{2}{*}{$\begin{array}{l}\text { OSRD } \\
(3)\end{array}$} & \multicolumn{2}{|c|}{ Triple difference } \\
\hline & & & & $\begin{array}{l}\text { All } \\
(4)\end{array}$ & $\begin{array}{c}\text { OSRD } \\
\text { (rel. to all) } \\
(5)\end{array}$ \\
\hline Secrecy ordered & $\begin{array}{c}-0.000 \\
(0.021)\end{array}$ & $\begin{array}{c}-0.065^{*} \\
(0.033)\end{array}$ & $\begin{array}{c}0.048 \\
(0.030)\end{array}$ & $\begin{array}{c}-0.065^{* *} \\
(0.031)\end{array}$ & $\begin{array}{c}0.115^{* * *} \\
(0.040)\end{array}$ \\
\hline * filed in 1941 & $\begin{array}{c}-0.024 \\
(0.024)\end{array}$ & $\begin{array}{c}0.026 \\
(0.041)\end{array}$ & $\begin{array}{c}-0.050 \\
(0.035)\end{array}$ & $\begin{array}{c}0.023 \\
(0.040)\end{array}$ & $\begin{array}{l}-0.083 \\
(0.051)\end{array}$ \\
\hline * filed in 1942 & $\begin{array}{c}0.011 \\
(0.022)\end{array}$ & $\begin{array}{c}0.048 \\
(0.038)\end{array}$ & $\begin{array}{c}-0.016 \\
(0.031)\end{array}$ & $\begin{array}{c}0.049 \\
(0.036)\end{array}$ & $\begin{array}{l}-0.075 \\
(0.046)\end{array}$ \\
\hline * filed in 1943 & $\begin{array}{c}0.018 \\
(0.023)\end{array}$ & $\begin{array}{c}0.086^{* *} \\
(0.042)\end{array}$ & $\begin{array}{l}-0.040 \\
(0.030)\end{array}$ & $\begin{array}{c}0.081^{* *} \\
(0.040)\end{array}$ & $\begin{array}{c}-0.115^{* *} \\
(0.047)\end{array}$ \\
\hline * filed in 1944 & $\begin{array}{c}0.020 \\
(0.026)\end{array}$ & $\begin{array}{c}0.069 \\
(0.044)\end{array}$ & $\begin{array}{c}-0.024 \\
(0.034)\end{array}$ & $\begin{array}{l}0.072^{*} \\
(0.042)\end{array}$ & $\begin{array}{c}-0.101^{* *} \\
(0.049)\end{array}$ \\
\hline * filed in 1945 & $\begin{array}{c}0.030 \\
(0.027)\end{array}$ & $\begin{array}{c}0.129^{* * *} \\
(0.044)\end{array}$ & $\begin{array}{l}-0.016 \\
(0.040)\end{array}$ & $\begin{array}{c}0.140^{* * *} \\
(0.041)\end{array}$ & $\begin{array}{c}-0.178^{* * *} \\
(0.051)\end{array}$ \\
\hline Secrecy evaluated & $\begin{array}{c}0.018 \\
(0.013)\end{array}$ & $\begin{array}{c}0.036^{* *} \\
(0.017)\end{array}$ & $\begin{array}{c}-0.011 \\
(0.022)\end{array}$ & $\begin{array}{c}0.039^{* *} \\
(0.016)\end{array}$ & $\begin{array}{c}-0.049^{* *} \\
(0.024)\end{array}$ \\
\hline * filed in 1941 & $\begin{array}{c}0.011 \\
(0.015)\end{array}$ & $\begin{array}{l}-0.001 \\
(0.019)\end{array}$ & $\begin{array}{c}0.027 \\
(0.024)\end{array}$ & $\begin{array}{l}-0.004 \\
(0.018)\end{array}$ & $\begin{array}{c}0.030 \\
(0.027)\end{array}$ \\
\hline * filed in 1942 & $\begin{array}{c}-0.004 \\
(0.014)\end{array}$ & $\begin{array}{l}-0.020 \\
(0.020)\end{array}$ & $\begin{array}{c}0.016 \\
(0.023)\end{array}$ & $\begin{array}{l}-0.022 \\
(0.018)\end{array}$ & $\begin{array}{c}0.037 \\
(0.024)\end{array}$ \\
\hline * filed in 1943 & $\begin{array}{c}0.010 \\
(0.015)\end{array}$ & $\begin{array}{l}-0.008 \\
(0.019)\end{array}$ & $\begin{array}{c}0.031 \\
(0.023)\end{array}$ & $\begin{array}{l}-0.013 \\
(0.018)\end{array}$ & $\begin{array}{l}0.044^{*} \\
(0.026)\end{array}$ \\
\hline * filed in 1944 & $\begin{array}{c}0.007 \\
(0.017)\end{array}$ & $\begin{array}{l}-0.014 \\
(0.022)\end{array}$ & $\begin{array}{c}0.028 \\
(0.025)\end{array}$ & $\begin{array}{l}-0.016 \\
(0.021)\end{array}$ & $\begin{array}{l}0.046^{*} \\
(0.028)\end{array}$ \\
\hline * filed in 1945 & $\begin{array}{c}0.011 \\
(0.019)\end{array}$ & $\begin{array}{l}-0.010 \\
(0.026)\end{array}$ & $\begin{array}{c}0.026 \\
(0.025)\end{array}$ & $\begin{array}{l}-0.021 \\
(0.025)\end{array}$ & $\begin{array}{l}0.059^{*} \\
(0.031)\end{array}$ \\
\hline Secret + Eval $=0$ & 0.39 & 0.45 & 0.05 & & \\
\hline Delta 1941 & -0.1997 & 0.5551 & -0.3460 & & \\
\hline Delta 1942 & 0.0552 & 0.9936 & -0.0577 & & \\
\hline Delta 1943 & 0.0951 & 1.4300 & -0.1762 & & \\
\hline Delta 1944 & 0.1309 & 1.9356 & -0.1215 & & \\
\hline Delta 1945 & 0.4041 & 3.4941 & -0.2052 & & \\
\hline
\end{tabular}

Notes: Table estimates the probability that a patent filed between July 1940 and June 1945 generates any forward citations, as a function of whether the patent was evaluated for secrecy and/or ordered secret, with estimates by filing year, and with 1940 being the omitted reference year. Column (1) includes all such patents. Columns (2) and (3) restricts the sample to patents by non-OSRD and OSRD contractors, respectively. Columns (4) and (5) repeat this comparison in a pooled, triple-differenced sample. All columns control for (i) patent class $\mathrm{x}$ filing year and (ii) grant year fixed effects. Specifications estimated via OLS. *, **, *** represent significance at the $0.1,0.05$, and 0.01 levels, respectively. SEs clustered by patent class in parentheses. 
Table 7: Effects of secrecy on probability of any forward citations: robustness to alternative specifications (non-OSRD only)

\begin{tabular}{|c|c|c|c|c|c|}
\hline & (1) & $(2)$ & (3) & (4) & $(5)$ \\
\hline Secrecy ordered & $\begin{array}{c}-0.065^{*} \\
(0.033)\end{array}$ & $\begin{array}{c}-0.065^{* *} \\
(0.033)\end{array}$ & $\begin{array}{c}-0.068^{* *} \\
(0.034)\end{array}$ & $\begin{array}{c}-0.067^{* *} \\
(0.033)\end{array}$ & $\begin{array}{c}-0.081 \\
(0.051)\end{array}$ \\
\hline * filed in 1941 & $\begin{array}{c}0.026 \\
(0.041)\end{array}$ & $\begin{array}{c}0.024 \\
(0.040)\end{array}$ & $\begin{array}{c}0.028 \\
(0.042)\end{array}$ & $\begin{array}{c}0.023 \\
(0.041)\end{array}$ & $\begin{array}{c}0.035 \\
(0.063)\end{array}$ \\
\hline * filed in 1942 & $\begin{array}{c}0.048 \\
(0.038)\end{array}$ & $\begin{array}{c}0.045 \\
(0.037)\end{array}$ & $\begin{array}{c}0.050 \\
(0.038)\end{array}$ & $\begin{array}{c}0.047 \\
(0.037)\end{array}$ & $\begin{array}{c}0.053 \\
(0.057)\end{array}$ \\
\hline * filed in 1943 & $\begin{array}{c}0.086^{* *} \\
(0.042)\end{array}$ & $\begin{array}{c}0.084^{* *} \\
(0.041)\end{array}$ & $\begin{array}{c}0.086^{* *} \\
(0.042)\end{array}$ & $\begin{array}{c}0.084^{* *} \\
(0.042)\end{array}$ & $\begin{array}{c}0.097 \\
(0.063)\end{array}$ \\
\hline * filed in 1944 & $\begin{array}{c}0.069 \\
(0.044)\end{array}$ & $\begin{array}{c}0.062 \\
(0.043)\end{array}$ & $\begin{array}{l}0.070^{*} \\
(0.042)\end{array}$ & $\begin{array}{c}0.065 \\
(0.042)\end{array}$ & $\begin{array}{c}0.064 \\
(0.060)\end{array}$ \\
\hline * filed in 1945 & $\begin{array}{c}0.129^{* * *} \\
(0.044)\end{array}$ & $\begin{array}{c}0.123^{* * *} \\
(0.044)\end{array}$ & $\begin{array}{c}0.129^{* * *} \\
(0.044)\end{array}$ & $\begin{array}{c}0.122^{* * *} \\
(0.044)\end{array}$ & $\begin{array}{c}0.150^{* *} \\
(0.059)\end{array}$ \\
\hline Secrecy evaluated & $\begin{array}{c}0.036^{* *} \\
(0.017)\end{array}$ & $\begin{array}{c}0.027 \\
(0.017)\end{array}$ & $\begin{array}{c}0.032^{*} \\
(0.017)\end{array}$ & $\begin{array}{c}0.024 \\
(0.017)\end{array}$ & $\begin{array}{c}0.026 \\
(0.027)\end{array}$ \\
\hline * filed in 1941 & $\begin{array}{l}-0.001 \\
(0.019)\end{array}$ & $\begin{array}{c}0.002 \\
(0.020)\end{array}$ & $\begin{array}{l}-0.002 \\
(0.019)\end{array}$ & $\begin{array}{c}0.001 \\
(0.019)\end{array}$ & $\begin{array}{c}0.005 \\
(0.029)\end{array}$ \\
\hline * filed in 1942 & $\begin{array}{l}-0.020 \\
(0.020)\end{array}$ & $\begin{array}{l}-0.015 \\
(0.020)\end{array}$ & $\begin{array}{c}-0.021 \\
(0.019)\end{array}$ & $\begin{array}{c}-0.017 \\
(0.019)\end{array}$ & $\begin{array}{l}-0.025 \\
(0.029)\end{array}$ \\
\hline * filed in 1943 & $\begin{array}{l}-0.008 \\
(0.019)\end{array}$ & $\begin{array}{c}-0.006 \\
(0.020)\end{array}$ & $\begin{array}{l}-0.010 \\
(0.019)\end{array}$ & $\begin{array}{c}-0.008 \\
(0.019)\end{array}$ & $\begin{array}{c}-0.022 \\
(0.030)\end{array}$ \\
\hline * filed in 1944 & $\begin{array}{l}-0.014 \\
(0.022)\end{array}$ & $\begin{array}{c}-0.009 \\
(0.022)\end{array}$ & $\begin{array}{l}-0.015 \\
(0.022)\end{array}$ & $\begin{array}{c}-0.011 \\
(0.022)\end{array}$ & $\begin{array}{c}-0.018 \\
(0.031)\end{array}$ \\
\hline * filed in 1945 & $\begin{array}{l}-0.010 \\
(0.026)\end{array}$ & $\begin{array}{l}-0.009 \\
(0.027)\end{array}$ & $\begin{array}{l}-0.015 \\
(0.026)\end{array}$ & $\begin{array}{c}-0.014 \\
(0.027)\end{array}$ & $\begin{array}{l}-0.036 \\
(0.039)\end{array}$ \\
\hline $\mathrm{N}$ & 125130 & 124962 & 125130 & 124962 & 124962 \\
\hline$R^{2}$ & 0.05 & 0.06 & 0.05 & 0.06 & 0.54 \\
\hline Secret + Eval $=0$ & 0.45 & 0.32 & 0.34 & 0.25 & 0.28 \\
\hline Delta 1941 & 0.5551 & 0.4844 & 0.5954 & 0.4719 & 0.5907 \\
\hline Delta 1942 & 0.9936 & 0.9496 & 1.0524 & 0.9751 & 0.8607 \\
\hline Delta 1943 & 1.4300 & 1.4304 & 1.4241 & 1.4119 & 1.2555 \\
\hline Delta 1944 & 1.9356 & 1.7289 & 1.9737 & 1.8158 & 1.2762 \\
\hline Delta 1945 & 3.4941 & 3.1574 & 3.4667 & 3.0952 & 2.8541 \\
\hline Grant year FEs & $\mathrm{Y}$ & $\mathrm{Y}$ & $\mathrm{Y}$ & $\mathrm{Y}$ & $\mathrm{Y}$ \\
\hline Class-year FEs & $\mathrm{Y}$ & $\mathrm{Y}$ & $\mathrm{Y}$ & $\mathrm{Y}$ & $\mathrm{Y}$ \\
\hline Patent ctrls & & $\mathrm{Y}$ & & $\mathrm{Y}$ & $\mathrm{Y}$ \\
\hline Assignee ctrls & & & $\mathrm{Y}$ & $\mathrm{Y}$ & \\
\hline Assignee FEs & & & & & $\mathrm{Y}$ \\
\hline Mean of DV & 0.86 & 0.86 & 0.86 & 0.86 & 0.86 \\
\hline s.d. of DV & 0.35 & 0.35 & 0.35 & 0.35 & 0.35 \\
\hline
\end{tabular}

Notes: Table estimates the probability that a patent filed between July 1940 and June 1945 generates any forward citations, as a function of whether the patent was evaluated for secrecy and/or ordered secret, with estimates by filing year, and with 1940 being the omitted reference year. Sample restricted to patents by non-OSRD contractors only. Column (1) presents the baseline result from Table 6. Columns (2), (4), and (5) control for various patent characteristics (fixed effects for the number of inventors, number of pages in the patent publication, number of drawings). Columns (3) and (4) control for characteristics of assignees (indicators for whether the assignee is a firm or individual, and fixed effects for the assignee's number of patents in the 1930s). Column (5) replaces these with assignee fixed effects. All columns control for (i) patent class x filing year and (ii) grant year fixed effects. Specifications estimated via OLS. *, **, *** represent significance at the 0.1, 0.05 , and 0.01 levels, respectively. SEs clustered by patent class in parentheses. 
Table 8: Effects of secrecy on diffusion of new word stems in patent titles

\begin{tabular}{|c|c|c|c|c|c|}
\hline & $\begin{array}{c}(1) \\
\operatorname{Ln}(\text { Uses })\end{array}$ & $\begin{array}{c}(2) \\
\text { Uses } \geq 10\end{array}$ & $\begin{array}{c}(3) \\
\text { Uses } \geq 20\end{array}$ & $\begin{array}{c}(4) \\
\text { Uses } \geq 30\end{array}$ & $\begin{array}{c}(5) \\
\text { Uses } \geq 50\end{array}$ \\
\hline Secrecy ordered & $\begin{array}{c}-0.987^{* * *} \\
(0.356)\end{array}$ & $\begin{array}{c}-0.667^{* * *} \\
(0.195)\end{array}$ & $\begin{array}{l}-0.333^{*} \\
(0.195)\end{array}$ & $\begin{array}{l}-0.333^{*} \\
(0.195)\end{array}$ & $\begin{array}{c}-0.167 \\
(0.154)\end{array}$ \\
\hline * filed in 1941 & $\begin{array}{c}0.699 \\
(0.829)\end{array}$ & $\begin{array}{l}0.708^{*} \\
(0.383)\end{array}$ & $\begin{array}{c}0.333 \\
(0.344)\end{array}$ & $\begin{array}{c}0.333 \\
(0.344)\end{array}$ & $\begin{array}{c}-0.000 \\
(0.280)\end{array}$ \\
\hline * filed in 1942 & $\begin{array}{c}0.784 \\
(1.094)\end{array}$ & $\begin{array}{l}0.702^{*} \\
(0.358)\end{array}$ & $\begin{array}{c}0.262 \\
(0.318)\end{array}$ & $\begin{array}{c}0.262 \\
(0.318)\end{array}$ & $\begin{array}{c}0.095 \\
(0.345)\end{array}$ \\
\hline * filed in 1943 & $\begin{array}{c}1.398^{* *} \\
(0.681)\end{array}$ & $\begin{array}{c}0.817^{* * *} \\
(0.248)\end{array}$ & $\begin{array}{c}0.308 \\
(0.298)\end{array}$ & $\begin{array}{c}0.375 \\
(0.285)\end{array}$ & $\begin{array}{c}0.408 \\
(0.251)\end{array}$ \\
\hline * filed in 1944 & $\begin{array}{c}1.876^{* * * *} \\
(0.709)\end{array}$ & $\begin{array}{c}0.967^{* * * *} \\
(0.258)\end{array}$ & $\begin{array}{c}0.533 \\
(0.333)\end{array}$ & $\begin{array}{l}0.633^{*} \\
(0.334)\end{array}$ & $\begin{array}{c}0.367 \\
(0.339)\end{array}$ \\
\hline Secrecy evaluated & $\begin{array}{c}0.208 \\
(0.405)\end{array}$ & $\begin{array}{c}0.207 \\
(0.201)\end{array}$ & $\begin{array}{c}0.050 \\
(0.208)\end{array}$ & $\begin{array}{c}0.158 \\
(0.206)\end{array}$ & $\begin{array}{c}0.018 \\
(0.164)\end{array}$ \\
\hline * filed in 1941 & $\begin{array}{c}0.616 \\
(0.566)\end{array}$ & $\begin{array}{l}-0.052 \\
(0.265)\end{array}$ & $\begin{array}{c}0.126 \\
(0.245)\end{array}$ & $\begin{array}{c}0.069 \\
(0.243)\end{array}$ & $\begin{array}{c}0.302 \\
(0.218)\end{array}$ \\
\hline * filed in 1942 & $\begin{array}{c}0.820 \\
(0.912)\end{array}$ & $\begin{array}{l}-0.066 \\
(0.287)\end{array}$ & $\begin{array}{c}0.105 \\
(0.299)\end{array}$ & $\begin{array}{c}0.091 \\
(0.296)\end{array}$ & $\begin{array}{c}0.335 \\
(0.262)\end{array}$ \\
\hline * filed in 1943 & $\begin{array}{c}-0.021 \\
(0.503)\end{array}$ & $\begin{array}{l}-0.182 \\
(0.237)\end{array}$ & $\begin{array}{c}0.031 \\
(0.259)\end{array}$ & $\begin{array}{c}-0.037 \\
(0.233)\end{array}$ & $\begin{array}{c}-0.044 \\
(0.188)\end{array}$ \\
\hline * filed in 1944 & $\begin{array}{l}-0.101 \\
(0.533)\end{array}$ & $\begin{array}{l}-0.044 \\
(0.259)\end{array}$ & $\begin{array}{c}-0.004 \\
(0.252)\end{array}$ & $\begin{array}{c}-0.130 \\
(0.248)\end{array}$ & $\begin{array}{c}0.009 \\
(0.206)\end{array}$ \\
\hline $\mathrm{N}$ & 561 & 561 & 561 & 561 & 561 \\
\hline$R^{2}$ & 0.03 & 0.03 & 0.02 & 0.03 & 0.04 \\
\hline Filing year FEs & $\mathrm{Y}$ & $\mathrm{Y}$ & $\mathrm{Y}$ & $\mathrm{Y}$ & $\mathrm{Y}$ \\
\hline Mean of DV & 2.82 & 0.54 & 0.35 & 0.28 & 0.19 \\
\hline s.d. of DV & 1.23 & 0.50 & 0.48 & 0.45 & 0.40 \\
\hline
\end{tabular}

Notes: Table estimates the subsequent usage of word stems which first appeared in the title of a patent filed in 1940 to 1944, as a function of whether the first patent with the stem was evaluated for secrecy and/or ordered secret, with estimates by filing year, and with 1940 being the omitted reference year. Sample restricted to new stems from non-OSRD contractors only; 1945 is omitted because there were no such stems originating in secret patents that year. Column (1) estimates effects on the number of subsequent patents with that stem in the invention title (through 1979). Columns (2) to (5) estimate effects on the probability of a stem generating 10, 20, 30, and 50 such uses. All columns control for filing year fixed effects. The latter four specifications are estimated via OLS. *, **, *** represent significance at the $0.1,0.05$, and 0.01 levels, respectively. SEs clustered by patent class in parentheses. 
Web Appendix 


\section{A Data Appendix}

\section{A.1 Construction of patent datasets}

\section{A.1.1 Base data}

The construction of the core patent-level dataset used in this paper begins with the USPTO historical master file (Marco et al. 2015), which provides a master list of granted patents with grant dates, patent class/subclass (USPC), and two-digit NBER category (Hall et al. 2001). In building this paper's dataset, I restrict the sample to patents granted between January 1, 1920 and December 31, 1979 - although most of the paper invokes only a subset of these. For all granted patents in this set, I obtain additional patent characteristics from the following sources:

- FreePatentsOnline.com (FPO): serial numbers, filing dates, and the network of forward and backward citations (front-page citations only)

- Derwent Innovation database (DI): (mostly) standardized assignee names ${ }^{1}$

A small subset of patents are missing filing dates and assignees. Table A.1 shows the number patents with missing data, by decade of grant. For the period sampled in this paper (1930-1960), approximately $2.4 \%$ of patents are missing a filing date and $2.5 \%$ missing an assignee (note: these percentages calculated for patents granted between 1930 and 1960, whereas the paper uses the sample of patents known to have been filed between 1930 and 1960).

Table A.1: Number of patents with missing data, by decade

\begin{tabular}{lccccc}
\hline \hline & & \multicolumn{2}{c}{ No filing date } & \multicolumn{2}{c}{ No assignee data } \\
Decade of grant & Patents & Number & Percent & Number & Percent \\
\hline $1920-1929$ & 414901 & 25738 & $6.2 \%$ & 25918 & $6.2 \%$ \\
$1930-1939$ & 442842 & 11102 & $2.5 \%$ & 11221 & $2.5 \%$ \\
$1940-1949$ & 307630 & 5470 & $1.8 \%$ & 5546 & $1.8 \%$ \\
$1950-1959$ & 425985 & 12461 & $2.9 \%$ & 12661 & $3.0 \%$ \\
$1960-1969$ & 567761 & 11203 & $2.0 \%$ & 11363 & $2.0 \%$ \\
$1970-1979$ & 689027 & 2 & $0.0 \%$ & 73 & $0.0 \%$ \\
\hline Total & 2848146 & 65976 & $2.3 \%$ & 66782 & $2.3 \%$ \\
\hline
\end{tabular}

Notes: Table shows counts of patents with missing data, and their fraction of all patents, by decade (of grant).

Because secrecy orders were issued to patent applications, they are identified by serial number. For the purposes of this paper, it is thus critical to have accurate data on serial numbers. The application-level data (serials and filing dates) from FPO were therefore manually reviewed and

\footnotetext{
${ }^{1}$ Note that serial numbers, filing dates, and the network of patent citations were also retrieved from the Derwent database for comparison against the FPO data, as a validation exercise. The two data sources overwhelmingly agreed, and where they disagreed, spot checks revealed that FPO was consistently the more accurate of the two, and when there was an error in the FPO data, it typically reflected the occasional typographical error on the printed patent publication itself, such as two flipped digits, or a digit one unit off the correct value. Given their reliability, the data for this paper thus use serial numbers, filing dates, and citations from FPO.
} 
validated for the period around the secrecy order program, by checking patents with serial numbers or filing dates which are out of sequence. The important feature of the USPTO's application numbering system for my purposes here is that applications are organized into application "series", which span several years, and identified by a serial number within that series, generally issued in the order in which patent applications arrive at the USPTO, with serial numbers never exceeding six digits. Application series increment, and serial numbers reset, at the beginning of a year in which the serial numbers from the previous series are expected to surpass 1,000,000. Series 2 begins January 1, 1935 and ends December, 1947 and is the focus of this data cleaning effort. I take all patents identified by FPO as belonging to Series 2 and sort these patents by serial. I then look for patents where the previous and next serial have the same filing date but the given patent has a different filing date, and then manually validate the serial and filing date for these patents. Out of over 370,000 patents in Series 2, corrections were made to 279 serials and 188 filing dates. Although these corrections are valuable for matching patents to secrecy orders, the low error rate for this sample also indicates that such errors are not widespread in the data.

\section{A.1.2 Harmonizing assignee names}

Although the assignee names from DI are largely already standardized, closer examination reveals that there are still variants on individual assignee names (e.g., BELL TELEPHONE LABOR INC with > 10,000 patents, and BELL TELPHONE LAB INC, BELL TEL PHONE LAB INC, and BELL TEIEPHONE LAB INC with 1 patent each). I undertake several procedures to further harmonize assignee names. I begin by sorting a unique list of assignees in alphabetical order, and for each assignee recording other nearby assignees up to 9 positions before and after in the sorted list. I then calculate the edit distance between the given assignee name and each of these nearby assignee names. When this edit distance is less than $25 \%$ of the length of the longer name in each pair, I flag that pair as a candidate for manual review. I then review all such matches for several categories of assignees, and standardize names when a match is found:

- Assignees with $\geq 15$ patents between 1930 and 1960

- Assignees with at least 1 secrecy order

- Assignees which were OSRD contractors

- Assignees identified as government agencies (see next section)

- Assignees identified as universities or hospitals (see next section)

- Assignees which were synthetic rubber manufacturers

- Assignees which were spinouts from Standard Oil

This process is repeated (because each round of harmonization may bring new assignees into the set with $\geq 15$ patents between 1930 and 1960) until no new matches are found.

This harmonization is neither perfect nor exhaustive, but it is believed to be effective for the purposes of this paper. It is also worth noting that for the vast majority of assignee names which 
were standardized by this procedure, there was clearly a primary spelling for that assignee in the original DI data, with hundreds or thousands of associated patents in the case of large assignees, and at worst a handful of secondary spellings with one or two associated patents - such that the actual effects of both (i) performing this harmonization for the priority assignees above, and of (ii) not performing it for non-priority assignees, are likely minimal.

\section{A.1.3 Determining assignee types}

Assignees are then classified into four categories - firms, universities and hospitals, government agencies, and individuals - through a combination of rule-based and manual classification. I begin by classifying assignees as firms when the assignee name includes any of roughly 120 words which indicate firms (e.g., CO, CORP, INC, LTD, SPA, GMBH, etc., as well as technical words such as AERO, AUTO, CHEM, ENG, MACHINE, OIL, PROD, TECH, WORKS; full list available on request). I then manually classify remaining assignees with $\geq 15$ patents between 1930 and 1960, as well as assignees whose name includes any of the following strings:

- COLLEGE, INST, UNIV, HOSP, RES FOUND

- US, CANADA, UK, FRANCE, GERMANY, SWITZERLAND, AUSTRALIA, JAPAN, ISRAEL, and assorted other countries

- $\operatorname{ATOM~(to~identify~international~atomic~energy~commissions)~}$

Assignees with $>200$ patents in the 1920-1979 period which are thus far unclassified are then classified as firms. Any remaining unclassified assignees are classified as individuals.

This classification procedure was developed over several years, and although - like the name harmonizationit is neither perfect nor exhaustive, random spot checks suggest it is overwhelmingly effective at categorizing assignees into the right bins. In total, $60.1 \%$ of patents with an assignee in the 19201979 sample are assigned to a firm, $0.2 \%$ to a university, $0.8 \%$ to a government agency, and $39.1 \%$ to an individual (numbers sum to $>100 \%$ because $5 \%$ of patents have multiple assignees, and $0.2 \%$ have assignees in multiple categories).

\section{A.1.4 Identifying patents of OSRD contractors}

As part of a broader data collection effort around U.S. science during World War II, I retrieved information on R\&D contracts let by Office of Scientific Research and Development (OSRD), the primary R\&D contracting agency during the war, from its archival collection at the U.S. National Archives and Records Administration (NARA). A complete list of contractors was compiled from contract lists and contractor directories. These contractors were then manually matched to the harmonized assignee names, making it possible to identify patents by government R\&D contractors versus non-contractors. Contractors spanned all sectors of the economy but were primarily firms 
and universities. Given that universities were not heavy filers of patents in this period, the vast majority of patents by OSRD contractors are by firms. ${ }^{2}$

\section{A.1.5 Identifying patents with secrecy orders}

Patent applications with secrecy orders were identified from the archival records of three U.S. government agencies: (i) the Office of Scientific Research and Development (OSRD), whose records yielded 4,837 serials with a secrecy order; (ii) the Office of Production Research and Development (OPRD), which yielded 2,047 serials; and (iii) the U.S. Army Office of the Judge Advocate General (JAG), which yielded 5,976 serials. These sets partly overlap, and collectively they identify a total of 8,475 patent applications which were at some point ordered secret. According to other contemporary records from the JAG office, a total of 11,182 secrecy orders were issued through June 14, 1945, when the war - and the secrecy program - were winding down and few new secrecy orders were being issued. The data thus identify roughly $75 \%$ of all secrecy orders. Undermeasurement is not a significant concern, particularly because it will only tend to attenuate comparisons between patents known to have been issued a secrecy order versus those not so observed. Of these 8,475 identified serials with secrecy orders, $6,353(75 \%)$ were eventually granted. ${ }^{3}$

${ }^{2}$ The OSRD contract and contractor data can be found at:

- "Index to Contracts, 1941-1947" in RG 227 (Records of the Office of Scientific Research and Development), located in Stack Area 130, Row 20, Compartment 11, Shelf 1, Boxes 1-5. Online catalog entry at https://catalog.archives.gov/id/6882818.

- "Contractor Lists, 1940-1946" in RG 227 (Records of the Office of Scientific Research and Development), located in Stack Area 130, Row 20, Compartment 11, Shelf 4, Boxes 1-2. Online catalog entry at https://catalog.archives.gov/id/16955595.

- "Contract Ledgers, 1941-1946" in RG 227 (Records of the Office of Scientific Research and Development), located in Stack Area 130, Row 22, Compartment 18, Shelf 2-3, Boxes 1-6. Online catalog entry at https://catalog.archives.gov/id/6920064.

${ }^{3}$ The OSRD records which yielded data on secrecy orders can be found at:

- "D-1 Forms Used by the War Division of the Patent Office, 1942-1946" in RG 227 (Records of the Office of Scientific Research and Development), located in Stack Area 130, Row 20, Compartment 34, Shelf 3, Boxes 1-3. Online catalog entry at https://catalog.archives.gov/id/6882835.

- "Correspondence Relating to Secrecy Orders, 1942-1945" in RG 227 (Records of the Office of Scientific Research and Development), located in Stack Area 130, Row 20, Compartment 42-43, Shelf 7 and 1-3, Boxes 1-27. Online catalog entry at https://catalog.archives.gov/id/16955603.

The OPRD records which yielded data on secrecy orders can be found at:

- "Index to Patent Applications, 1945-1945" in RG 179 (Records of the War Production Board), Office of Production Research and Development, located in Stack Area 570, Row 64, Compartment 12, Shelf 4 . Online catalog entry at https://catalog.archives.gov/id/567665.

The JAG records which yielded data on secrecy orders can be found at:

- "Records Pertaining to Patent Applications under Secrecy Orders Tendered to the Federal Government, 19411945" in RG 153 (Records of the Office of the Judge Advocate General), located in Stack Area 270, Row 2, Compartment 28, Shelf 6, Boxes 1-2. Online catalog entry at https://catalog.archives.gov/id/26335074.

- "Records Relating to Patents Tendered to the Federal Government Under Secrecy Orders, 1941-1949" in RG 153 (Records of the Office of the Judge Advocate General), located in Stack Area 270, Row 2, Compartment 28, Shelf 7, Box 1. Online catalog entry at https://catalog.archives.gov/id/17396215.

- "Patent cases, 1941-1952" in RG 153 (Records of the Office of the Judge Advocate General), located in Stack Area 270, Row 2, Compartment 28, Shelf 6, Box 1. Online catalog entry at https://catalog.archives.gov/id/17382698. 
The OSRD records contain two sources of data on secrecy orders: a 27-box collection of secrecy determination forms ("Form D-1"), which were used to evaluate patent applications for secrecy, and miscellaneous agency correspondence discussing the secrecy order program and patent applications affected by it. Together with wartime administrative histories of the agencies involved, the D-1 forms and internal correspondence from the OSRD records provide a rich picture of how P.L. 700 was implemented at the USPTO, and how the review process was executed.

Recall from the historical background section of the paper that when a patent application arrived at the patent office, it was assigned to an examining division, and the primary examiner for that division would forward applications he or she viewed as a candidate for a secrecy order to the Patent Office War Division (POWD), where representatives from various other agencies (namely: the Army and Navy Patent Advisory Board, the War Production Board, the OSRD, and/or the Petroleum Administration for War) would review these applications and make a recommendation for or against secrecy. For every application sent to the POWD, a D-1 form was drawn up with identifying information including the serial, filing date, title, inventor, assignee, patent attorney, patent office examining division and primary examiner, and date of receipt at the POWD (see Figures A.2 and A.3 for examples). The application was then read by the relevant reviewers, who would each sign or stamp the form with their recommendation. Often, reviewers would defer to other reviewers' judgments (typically, to the armed services). If all reviewers declined to recommend secrecy, the application would be "disapproved" (for secrecy) and sent back to Washington; if any reviewer requested secrecy, the application was issued a secrecy order.

There are approximately 24,000 D-1 forms in the OSRD records. I had these forms scanned and transcribed via double entry with verification (under which discrepancies in the transcription are manually reviewed). Given the importance of these data, and that the original print on some of these forms is hard to read, I had them transcribed via the same procedure a second time by a distinct contractor. I then personally reviewed all differences between the two transcriptions and performed numerous checks to validate the data, making corrections as needed, and sometimes even catching typographical errors on the original forms themselves (these checks include: (i) ensuring serials are consistent with filing dates, (ii) ensuring that date of receipt is after filing date, (iii) ensuring that date of review is after date of receipt (although there are a few cases where it appears the application arrived at the POWD already-recommended for secrecy), (iv) harmonizing primary examiner name spellings and ensuring that examiner names and examining divisions were paired in a consistent way). Although most of the contents of each form were transcribed, currently the only data being used in this paper are the serial and the recommendation.

Of these $\approx 24,000$ forms, 23,690 were for utility patent applications, covering 22,549 unique serials (some patent applications were evaluated multiple times), of which 3,557 were issued a secrecy order. Given that many more secrecy orders are known to have been issued during the war than are in this record set, it does not comprise an exhaustive list of applications formally reviewed for secrecy, let alone issued a secrecy order, but knowing patents which were evaluated for secrecy but disapproved allows us to specify a more refined control group than just the set of all patents which 
were not secret. Presumably, the applications covered by these forms are those which were reviewed by an OSRD representative, but the precise sampling conditions are not known. Unfortunately, no additional D-1 forms could be located in other NARA collections.

In addition to these forms, OSRD agency correspondence related to secrecy orders identifies 1,484 serials with a secrecy order. Most of this correspondence consists of letters between OSRD staff members notifying about the issuance of a secrecy order. The two sets of serials overlap, however, resulting in a total of 4,837 secrecy orders identified in OSRD records.

The next source of information on secrecy orders is an eight-box set of index cards in the archived records of the Office of Production Research and Development (OPRD), an agency whose mission was to promote the development of new materials and efficient methods for war production during World War II. According to documentation in the records, one set of index cards served as an index to patent applications "on which secrecy orders were imposed by the War Production Board and its predecessor agencies during the period 1941 to August 30, 1945." A second set indexed patent applications "on which no secrecy orders were issued... after examination by the War Production Board." A total of 2,047 unique serials appear in the set with secrecy orders, and 2,021 in the set without them. For unknown reasons, 135 serials appear in both sets. These serials are presumed to have been issued a secrecy order at some point in the war.

The final source of data on secrecy orders is a set of files from the records of the U.S. Army Judge Advocate General's office (JAG), which received patent applications with secrecy orders which were tendered to the government for its use, pursuant to the statutory terms of P.L. 700. These records contain lists of tendered inventions (see Figure A.4 for an example). The records also contain extensive agency correspondence that identifies additional serials with secrecy orders. In total, the lists of tendered inventions identify 5,957 unique serials with a secrecy order, and the correspondence identifies 928 serials. As with the other agencies, the two sets of serials overlap, resulting in a total of 5,976 secrecy orders found in JAG records.

I supplement these sources with a distinct list of patents associated with the Manhattan Project, obtained by an independent researcher via FOIA request to the U.S. Department of Energy and publicly hosted at the digital archives of the Woodrow Wilson Center (see Streifer 2017). This document lists 1,073 nuclear energy patent applications and 890 granted patents from World War II, including many designs for nuclear reactors. Only 20 of these patents were present in the NARA records described above. Although no formal indication of secrecy was included, it appears these patents were secret, given that the median grant lag for patents on this list is almost 12 years. The narrative record suggests that these patents were exempted from the 1945 General Rescinding Order (which otherwise generates key variation used in this paper) and remained secret long after the war ended. The evidence at our disposal reinforces this understanding: whereas the secrecy orders in our data ceased being issued in the summer of 1945, Manhattan Project patents were largely filed from 1945 to 1946 (Figure A.1, and not granted until the 1950s. For these reasons, I exclude these patents from the analysis throughout the paper. 
Figure A.1: Distribution of filing dates of secret patents

Panel (A): Filing dates of non-Manhattan Project secret patents

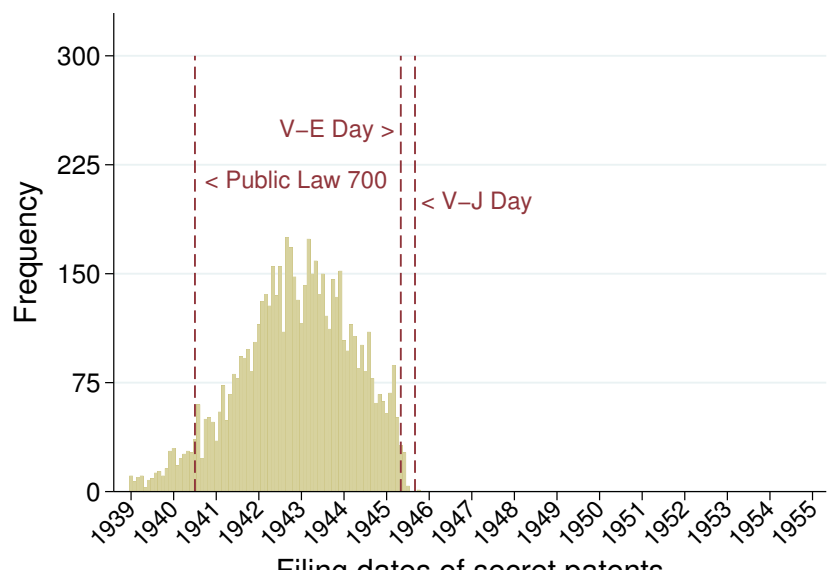

Filing dates of secret patents

Panel (B): Filing dates of Manhattan Project patents

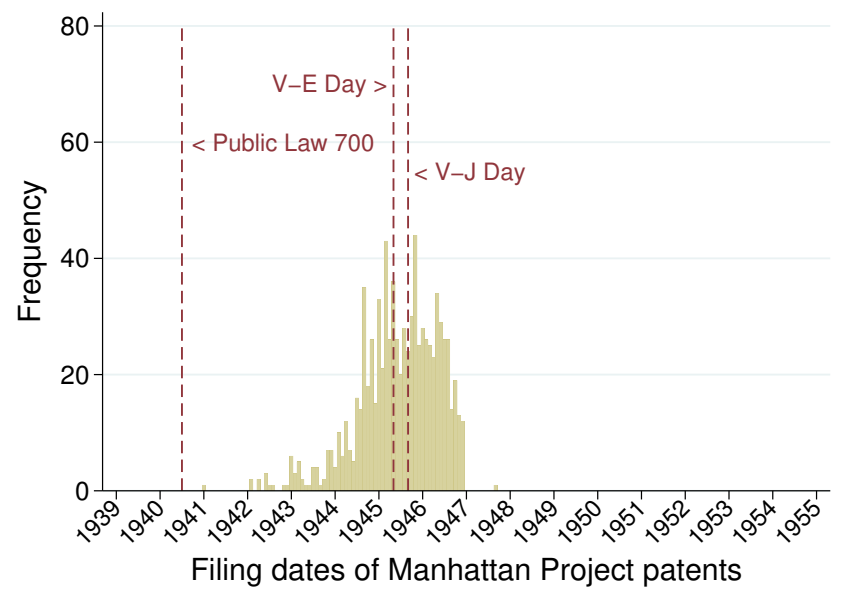

Notes: Figure shows the distribution of filing dates for (non-Manhattan Project) secret patents (Panel A) and Manhattan Project patents (Panel B). Whereas ordinary secrecy orders were largely halted in the summer of 1945, shortly before Victory in Japan Day (V-J Day) — which is also when the rescinding order was issued - most patents on nuclear energy inventions were filed at the end or after the end of the war, and these were presumably also ordered secret. 


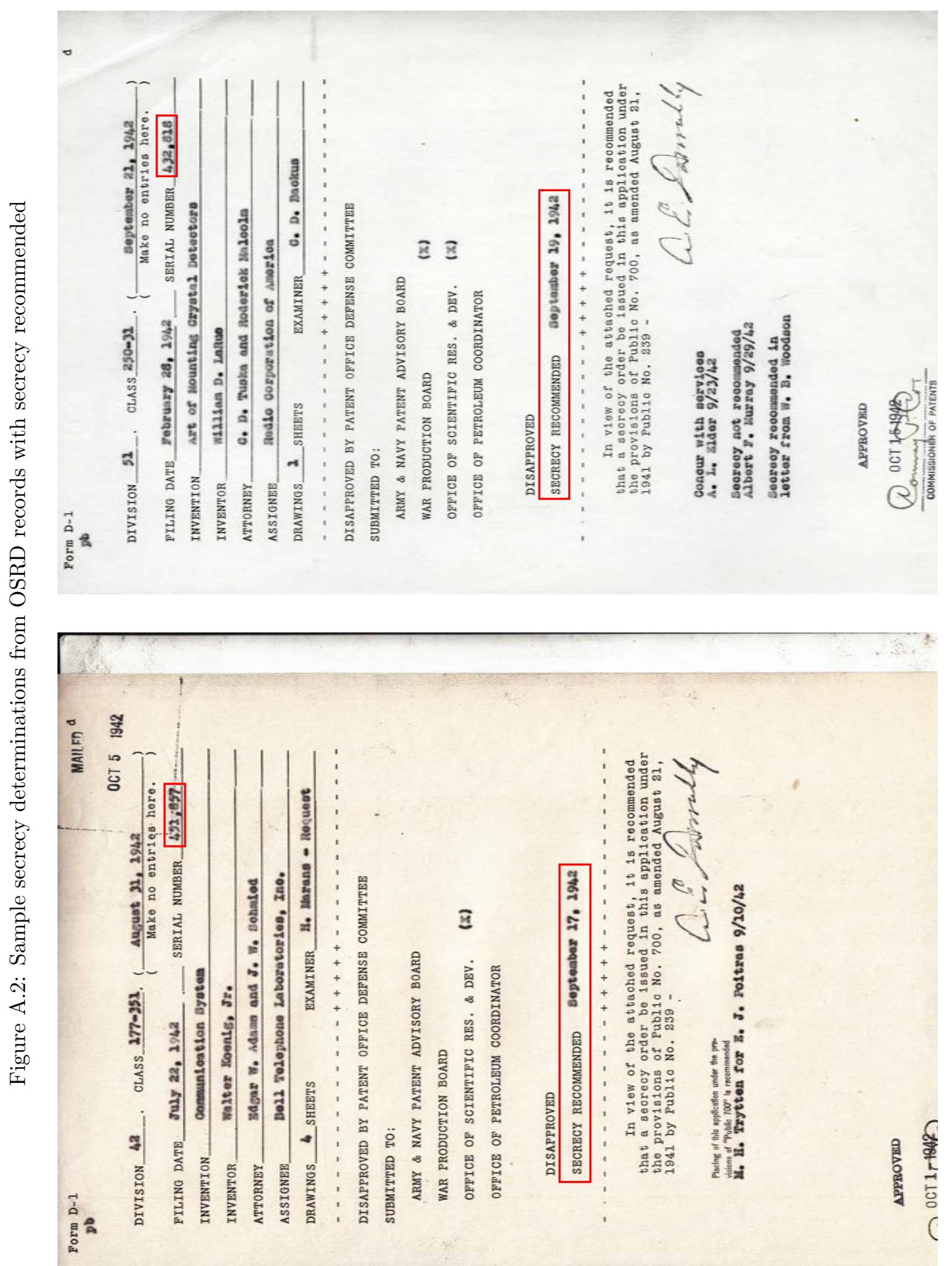



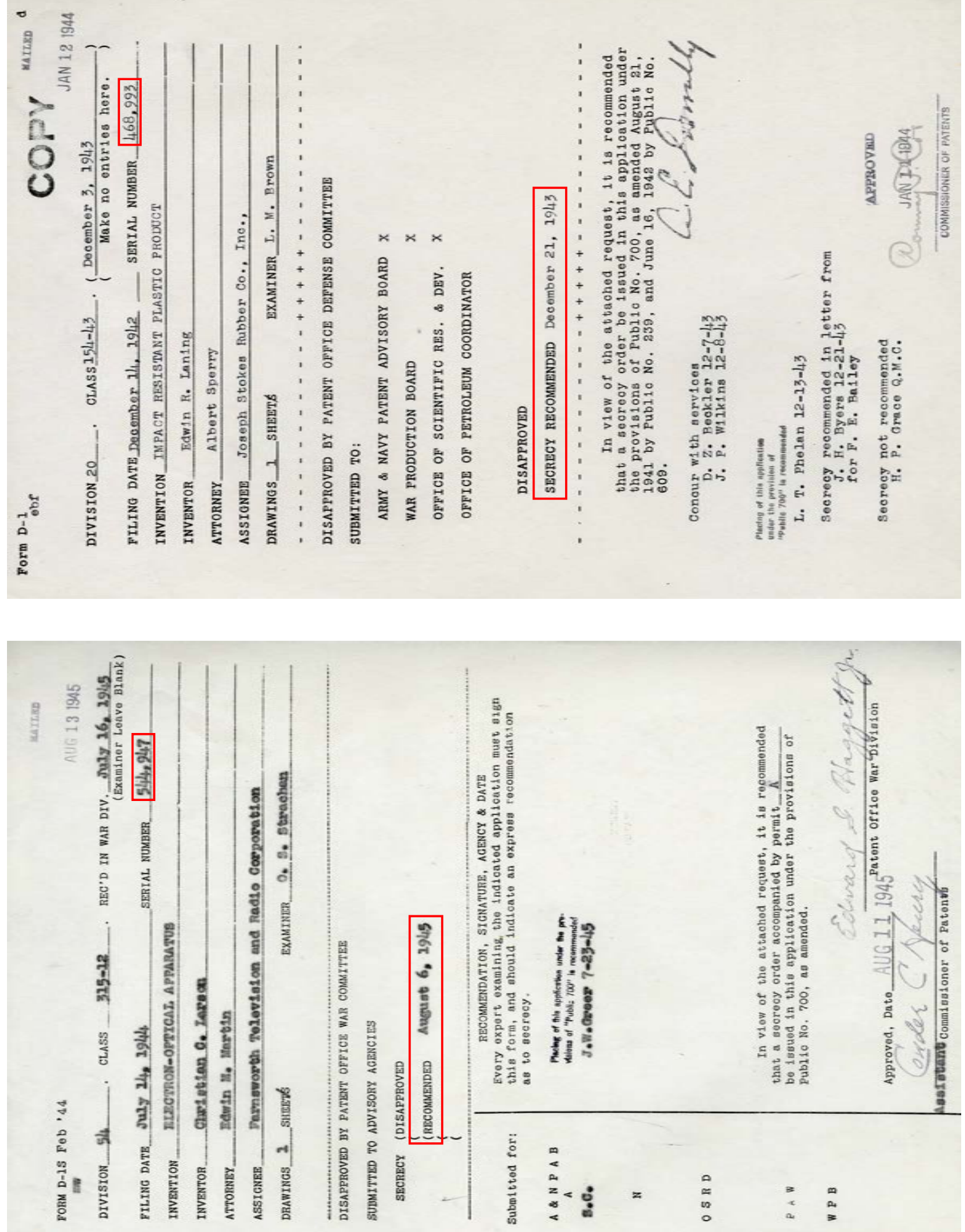


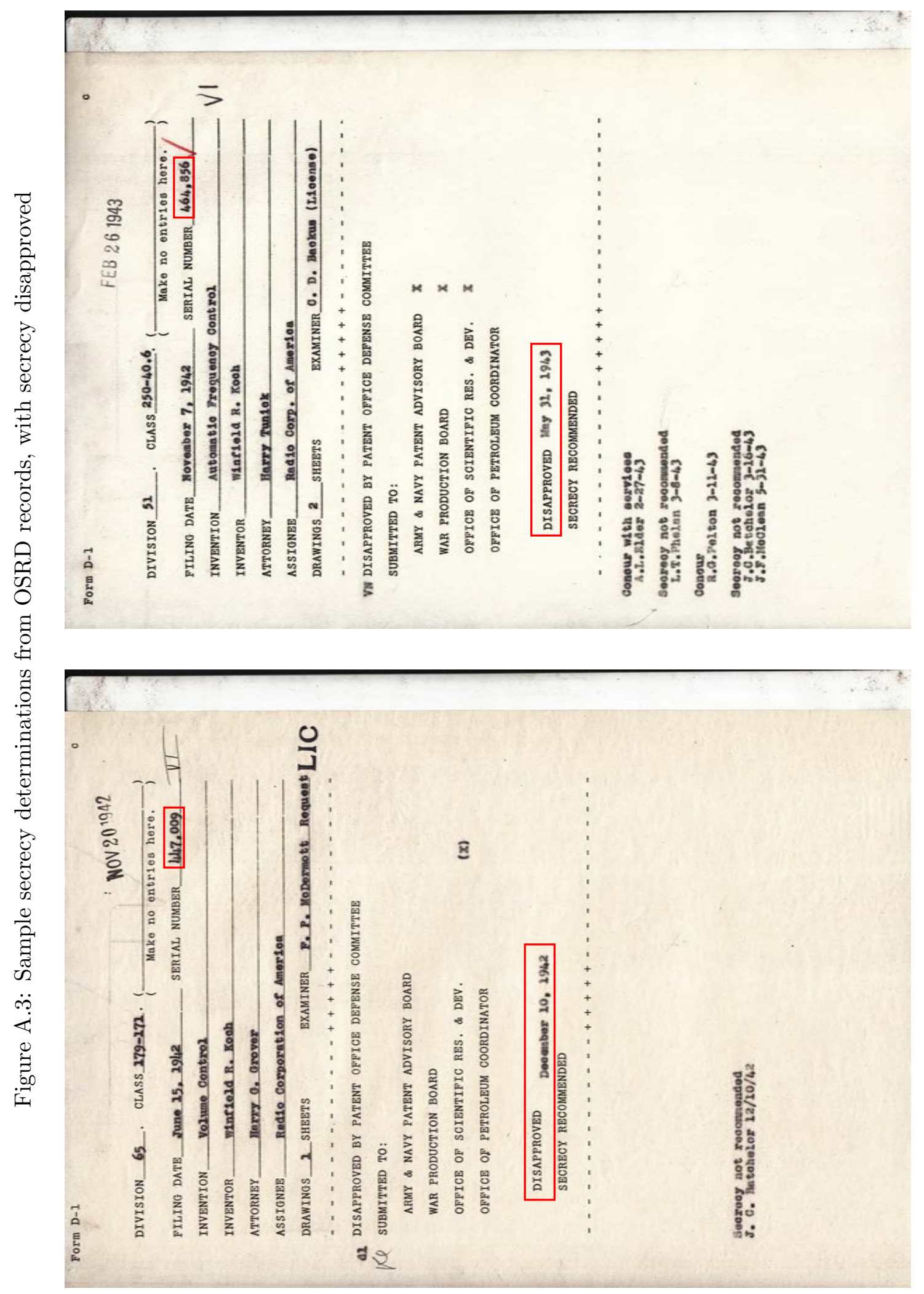


Figure A.4: Sample page from lists of tendered inventions in JAG records

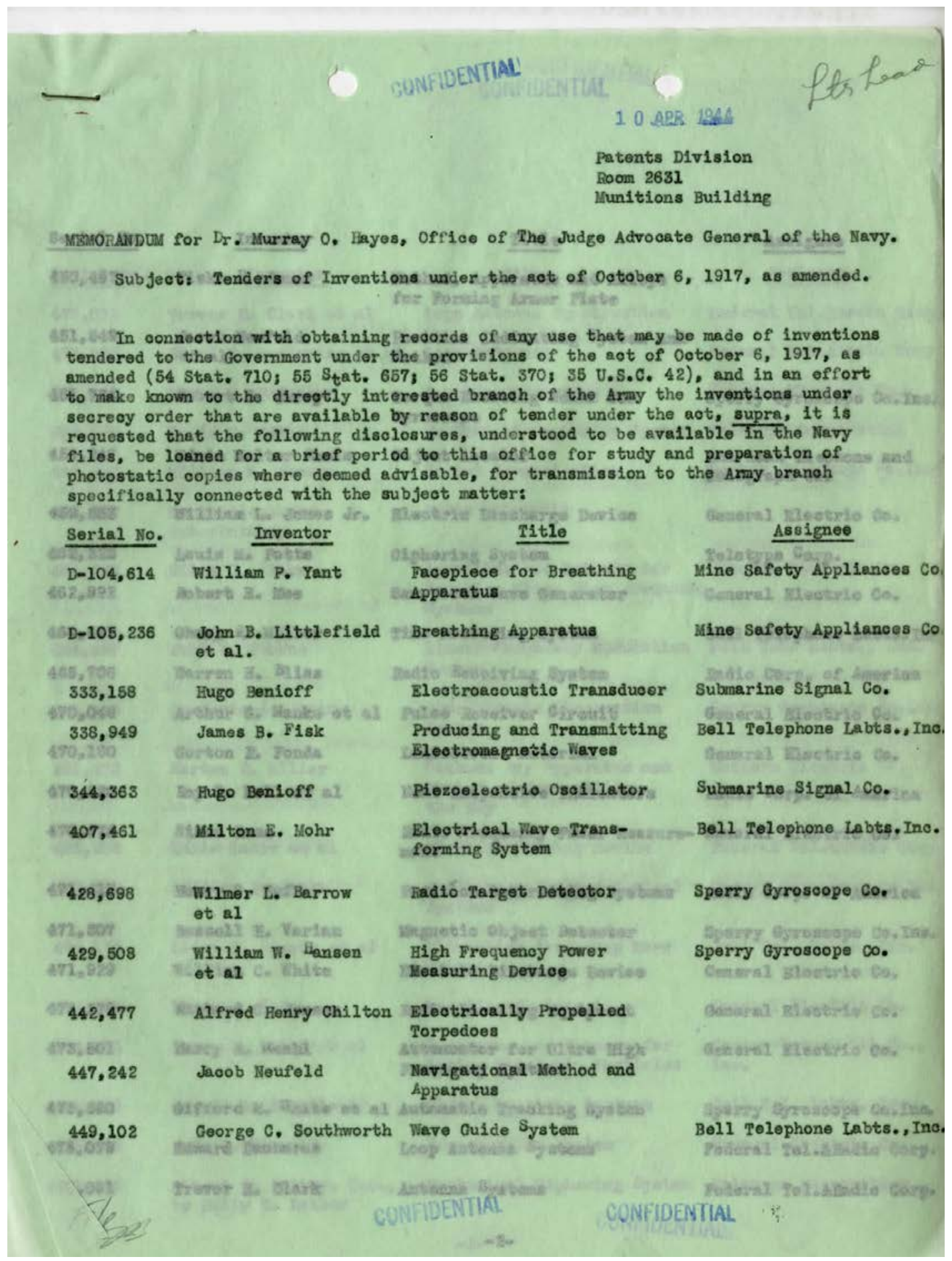




\section{A.2 Textual analysis: new words in patent titles}

The text-based analysis in this paper requires additional data on patents' content. For the pre-1976 period, patent text is not available in a clean, USPTO-issued machine-readable format. Google Patents makes available OCR full text for historical patents, but the quality of the character recognition is less than great and generally declines going further back in time, due to older documents and lower-quality typesetting, which increases the OCR error rate. Other data sources also provide the full text of pre-1976 patents but with the same limitations.

When the goal is to measure word frequency in the aggregate over time, misspellings can be tolerable as long as they are not systematic. When the goal is to identify "new" (first-time) uses of a word, misspellings are problematic: OCR errors often introduce words into the digital patent record far earlier than they were actually used. For example: the string "radar" first appears in the Google OCR patent text in an 1863 patent, but radar did not exist for another 70 years, and the acronym was only coined in 1940 by the U.S. Navy. To circumvent this problem, and more generally to mitigate concerns about how the OCR quality and spelling errors may influence the quality of "new word" measurement, I therefore seek out a cleaner source of data.

Google also makes available, via the Google Cloud Platform and its BigQuery web service, additional textual and text-based patent data. I used BigQuery to retrieve patent titles and "top terms" (according to Google, "the top 10 salient terms extracted from the patent's title, abstract, claims, and description"), which are both cleanly transcribed. ${ }^{4}$ Throughout the paper I prioritize titles, which have the added benefit of identifying words that are, according to the drafting attorney, important enough to describing the invention to be in the title.

New words (more specifically, new stems) are identified from patent titles as follows. After loading the patent titles, I remove numeric tokens, punctuation, and special characters. I then tokenize the remaining text in the title, splitting it into a list of constituent "words". I then loop over this list and drop (i) words which match a set of stop words, (ii) words with $<4$ or $>25$ characters, and (iii) words with a numeric character. ${ }^{5}$ The remaining words are then stemmed by the NLTK toolkit and reduced to a set of unique stems for each patent. To restrict our focus to stems which are neither exceedingly common nor vanishingly rare, and to minimize the computational burden of the remaining steps, I further reduce these stems to those (i) used by at least 5 patents but no more than $20 \%$ of patents in the complete 1920-1979 sample, and (ii) used by at least one patent filed between 1940 and 1945, as the focal stems will be in this set.

After reshaping the data to patent-stem pairs, the next step is to identify stems which were first

\footnotetext{
${ }^{4}$ Patent titles are from the BigQuery Patents dataset (patents-public-data $\rightarrow$ patents $\rightarrow$ publications $\rightarrow$ title_localized; see https://console.cloud.google.com/bigquery? $\mathrm{p}=$ patents-public-data\&d=patents\&t=publications), and top terms from the Google Patents Research dataset (patents-public-data $\rightarrow$ google_patents_research $\rightarrow$ publications $\rightarrow$ top_terms, embedding_v1; see https://console.cloud.google.com/bigquery?p=patents-publicdata\&d=google_patents_research\&t=publications)

${ }^{5}$ Stop words used in this step are a combination of off-the-shelf stop words from the NLTK toolkit for Python, stop words from Iaria et al. (2018), and stop words from Younge and Kuhn (2016).
} 
used in a patent filed between 1940 and 1945 - that is, stems which are ostensibly new to the patent record when they are used in the title of a patent filed in the early 1940s. The 1920 to 1939 period is used to define a stock of "existing" stems; this interval is considered sufficient for constructing a stock, since it includes nearly one million patents and covers the $20+$ most recent years of invention. The final step is to reduce the data to stems which were first used in the title of a patent filed in the 1940 to 1945 period. The empirical output from this procedure is a dataset of these stems and the patents using them in their title between 1940 and 1979. I also take these stems and identify patents which include them in their full text, notwithstanding any potential OCR errors, which can be used to measure their use over the 1920 to 1979 period.

Table A.2 lists the most-heavily used new stems from the 1940 to 1945 period, highlighting in red those which were first appeared in the title of a secret patent, and in light red those which ever did. The term semiconductor first appeared in a patent title during this period, as did radar, ultrasonic, monomer and elastomer, and antibiotics and penicillin. As this table demonstrates, the stemming procedure is also imperfect, as both "elastom" and "elastomer" enter this table, the former likely stemmed from "elastomer" itself, and the latter from words like "elastomerization". There is no perfect solution to this problem, as iterative stemming will often reduce words down to unrecognizable objects and cause unrelated words to get binned together into the same stem of stems. I thus limit the text cleaning procedure to one round of stemming, so that similar words (e.g., singular and plural variants of a noun) will be grouped into a common stem, at the same time recognizing the limitations or imperfections of the methods.

Table A.2: Most heavily used new stems in patent titles, 1940-1945

\begin{tabular}{|c|c|c|c|c|c|}
\hline & Stem & $\begin{array}{c}\text { Subseq. uses } \\
(1940-1979)\end{array}$ & & Stem & $\begin{array}{c}\text { Subseq. uses } \\
(1940-1979)\end{array}$ \\
\hline 1. & semiconductor & 6935 & 9. & antibiot & 940 \\
\hline 2. & disc & 3260 & 10. & phosphon & 894 \\
\hline 3. & radar & 2255 & 11. & elastomer & 848 \\
\hline 4. & ultrason & 2017 & 12. & curabl & 810 \\
\hline 5. & monom & 1366 & 13. & cryogen & 771 \\
\hline 6. & elastom & 1237 & 14. & readout & 672 \\
\hline 7. & waveguid & 1160 & 15 . & penicillin & 627 \\
\hline 8. & electrophotograph & 1158 & 16. & recognit & 601 \\
\hline
\end{tabular}

Notes: Red $=$ Stem first used in title of secret patent. Light red $=$ Stem ever used in title of secret patent.

This same procedure was repeated for patents' top terms, as well as for the union of titles and top terms. Although my focus in the paper is on titles only, the results in Sections 4 and Appendix E are similar when the analysis is based on top terms. (The analysis was not repeated for the union of titles and top terms; because they each measure distinct features of patents, their union is a strange object and was not considered suitable for analysis.) 


\section{Invoking the patent full text}

Having measured the introduction of new words in patent titles, I take these back to the OCRed patent full text, which Google also makes available through the Google Cloud Platform, to measure the frequency of these words in the aggregate over time. As noted above, the full text can be used towards this end, despite OCR errors: OCR error in this context should present as noise (rather than bias, as was the case above in measuring first uses).

\section{Other textual data sources}

In addition to looking for these words in the patent record, the paper also studies two other corpora: Du Pont product catalogs, and the Google Books N-gram database.

The Du Pont Products Index (DPPI) was a Du Pont product catalog published at regular intervals, and is used to look for focal chemical terms in Du Pont literature as a proxy for the product market. The 1938 edition of the DPPI is available online from Hathitrust, and working with the Hagley Museum in Wilmington, Delaware, which houses the Du Pont archival collection, I had four other editions of the DPPI digitized: 1944, 1946, 1949, and 1955-56, all of which are now available as well. These catalogs were then converted to text using ABBYY FineReader 14, which is subject to similar limitations as the OCR of historical patents previously discussed, although the OCR quality is higher because the scans are higher-resolution and the source documents have cleaner typesetting. The implications of using OCRed text for this part of the paper, and some robustness checks explored in light of these issues, are discussed in the paper. ${ }^{6}$

As explained in the paper, I make use of (publicly-available) Google Books N-gram data to measure the use of focal technical words in the broader public discourse. ${ }^{7}$ These data provide annual usage of unique N-grams in the Google Books corpus. This paper uses the data on 1-grams (i.e., words), matching words from patent titles to words in this set (specifically, I identify all words in patent titles whose stem entered the patent record in a patent filed between 1940 and 1945, link these to words in the N-grams data, and measure their use by year, in levels and as a fraction of all words in the Google Books corpus in the given year).

\section{A.3 What's being measured by patent citations}

Although researchers from Jaffe et al. (1993) to Galasso and Schankerman (2015) have used prior art references to measure linkages and follow-on invention, several papers have also highlighted the limitations of modern citation data, including the fact that citations can be strategic and that a large fraction are added by examiners rather than applicants (Alcácer et al. 2009, Sampat 2010,

\footnotetext{
${ }^{6}$ For the 1938 volume, see https://catalog.hathitrust.org/Record/001042925; for the 1944, 1946, 1949, and 1955-56 volumes, see https://digital.hagley.org/islandora/search/\%22Du\%20Pont\%20Products\%20Index\%22?type=edismax \&f\%5B0\%5D=-RELS_EXT_isMemberOfCollection_uri_ms\%3A\%28\%22info\%3Afedora/islandora\%3Aead\%22\%29.

${ }^{7}$ Data and documentation available at http://storage.googleapis.com/books/ngrams/books/datasetsv2.html.
} 
Cotropia et al. 2013, Roach and Cohen 2013), which is a concern because examiner-added citations may not measure intellectual inputs to invention. An additional wrinkle that more directly affects this paper is that the citation record only begins in 1947, as the USPTO did not require published patents to list references to prior art until February 4, 1947. Given the myriad issues, it is useful to include a more detailed discussion of what patent citations measure.

Prior art references have been an integral part of the patent examination process since well before the 1947 requirement that they be printed on the final page (now front page) of the patent document itself. The 1940 USPTO Rules of Practice, for example, instructs that:

Upon taking up an application for action on the merits the examiner shall make a thorough investigation of the prior art, with respect to the invention sought to be protected in the application. Upon the rejection of an application for want of novelty, the examiner must cite the best references at his command. When the reference shows or describes inventions other than that claimed by the applicant, the particular part relied on must be designated as nearly as practicable. The pertinence of the reference, if not obvious, must be clearly explained and the anticipated claim specified.

Thus, although the patent citation data used in modern research are drawn from published, frontpage/final-page references, and these begin only in 1947, it is not that prior art references were not previously made, but rather that they are not easily observed (a paper trail would have been kept in the examination file, not on the patent document itself). Moreover, prior to 1992, when the USPTO issued a new rule establishing applicants' "duty to disclose" information material to patentability (37 CFR §1.56), these references appear to have been made primarily (if not exclusively) by patent examiners, in the course of examination. Given the functional role they played, forward citations will identify closely-related subsequent invention, not information flows per se-but this is enough to measure de facto follow-on invention for the purposes of this paper.

\section{Examiner-added citations: curse or blessing?}

That patent citations in this period come from examiners is also important: as Moser et al. (2017) show with modern data, patent examiners use physical traits (rather than performance) to identify patents that should be cited as prior art, which provides reassurance that citations in this paper will be measuring intellectual proximity (even within patent classes, since most specifications include patent class fixed effects) rather than quality or importance.

Given that modern examiners rely on the results of prior art searches and may draw on a smaller pool of "favorite" examples of prior art during patent examination (e.g., Cockburn et al. 2002), a remaining concern is that differences in forward citations attributed to secrecy orders in Section 4

might actually just be driven by differences in what information the future examiners making these references knew or had access to with respect to earlier patents with secrecy orders. This concern is mostly obviated by the fact that secrecy orders were rescinded long before any of the citing patents in my data were granted (November 1945 versus February 1947), such that secrecy is not standing in the way of these inventions being found or cited as prior art. But a reasonable question 
is whether secrecy orders could have affected what enters the set of examiners' frequently-cited prior art, and could this then explain the patterns found in the paper.

However, this seems unlikely for two reasons. First, if secrecy orders kept certain patents out of the pool of prior art that examiners tended to cite, this would likely have applied equally to earlier and later applications - since it is a function of the secrecy order, not the timing. More importantly, it is my understanding that examiners had access to applications with secrecy orders, since these could still be used for interference (although formal notification and interference proceedings would be delayed until the priority application came off secrecy order). 


\section{B Historical Appendix}

This appendix provides supplementary material to accompany the discussion of the secrecy order program in Section 1 of the paper. Figure B.1 shows the text of Public Law 700, enacted July 1, 1940, which authorized the USPTO to issue secrecy orders. Figures B.2 to B.4 show examples of secrecy order notification letters mailed to inventors. Figure B.5 shows an announcement of the General Rescinding Order printed in the USPTO Official Gazette (the USPTO's weekly newsletter, accessible by subscription) on September 18, 1945.

Figure B.1: Public Law 700

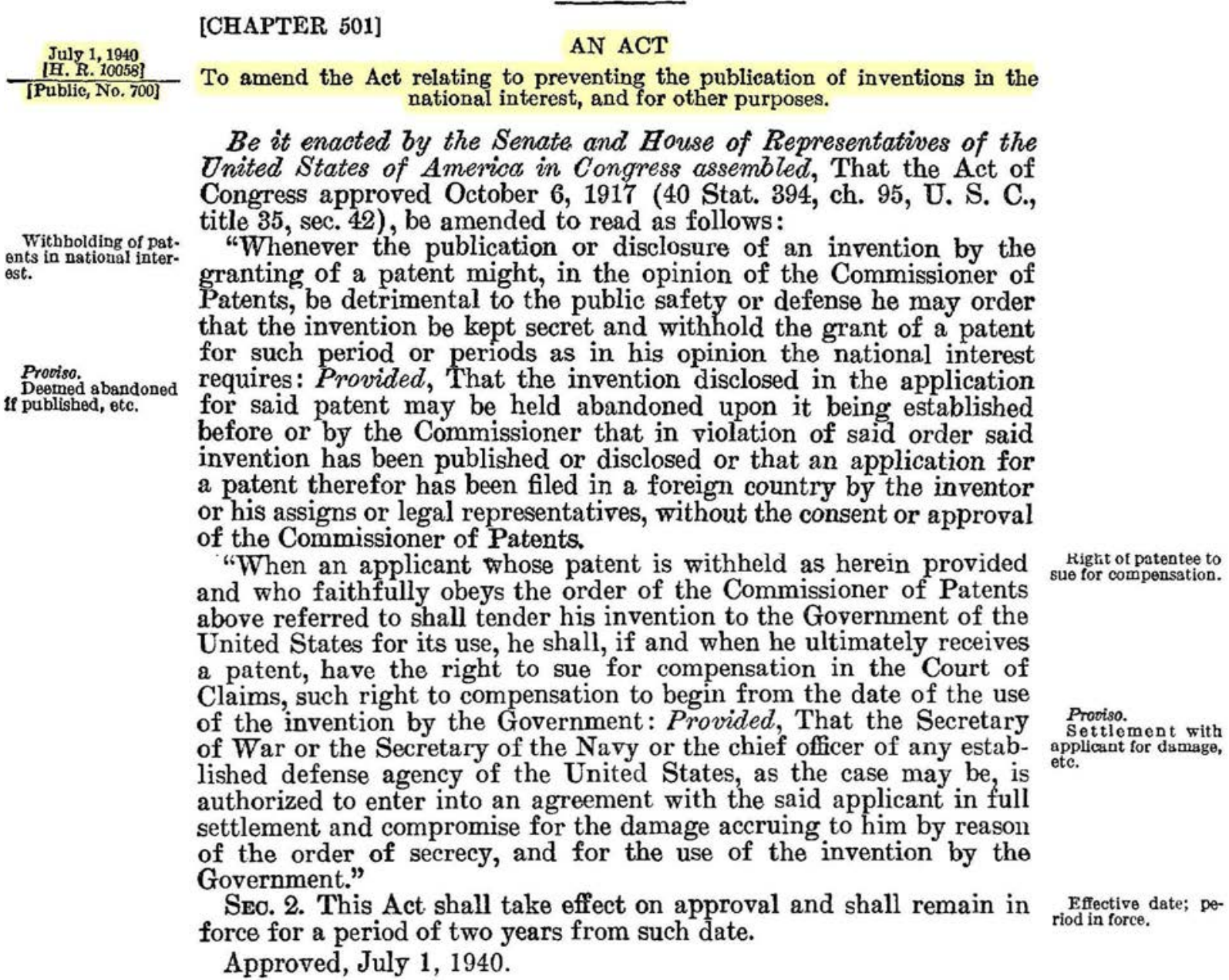


Figure B.2: Example Secrecy Order: Bell Labs

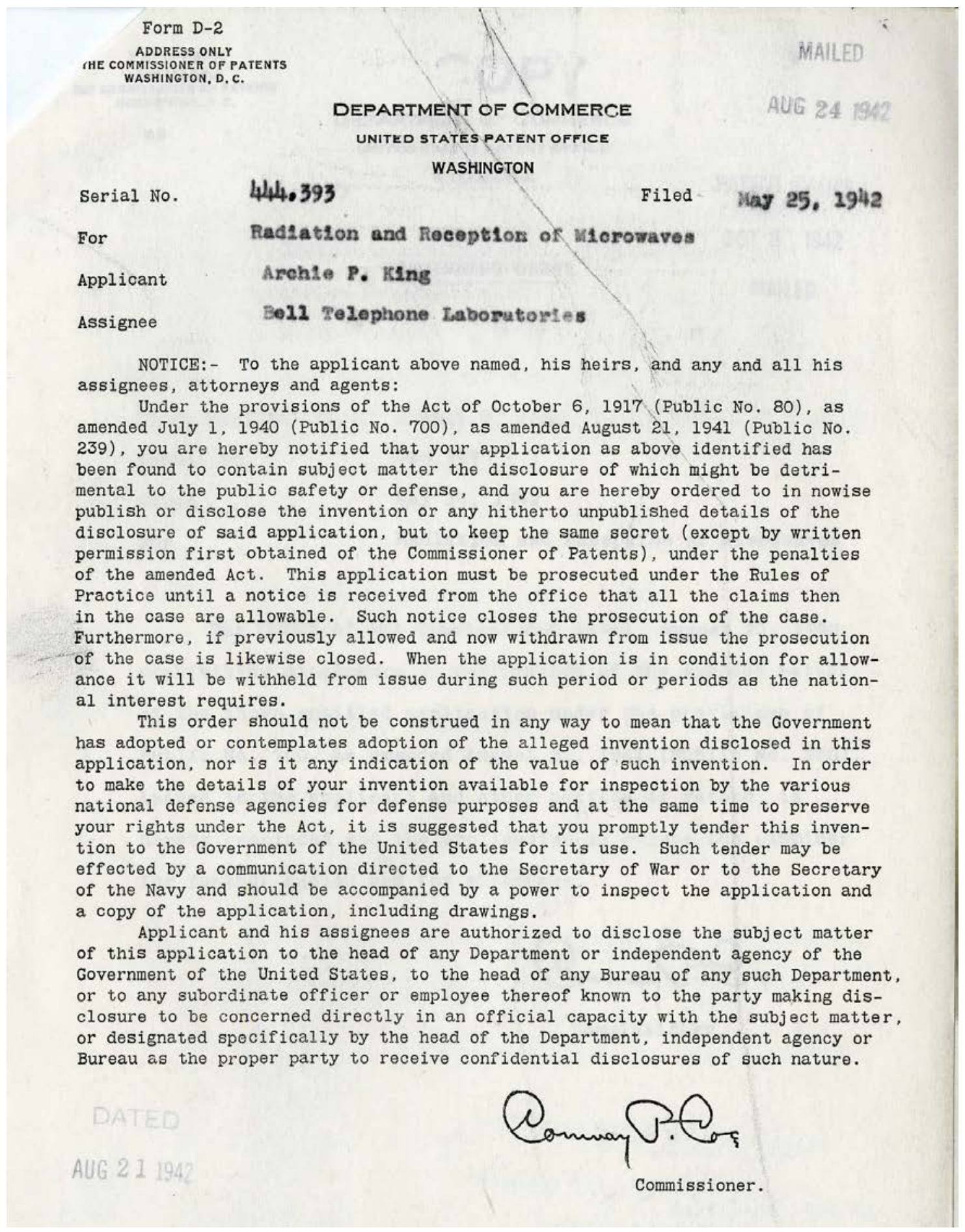


Figure B.3: Example Secrecy Order: Pittsburgh Plate Glass Co.

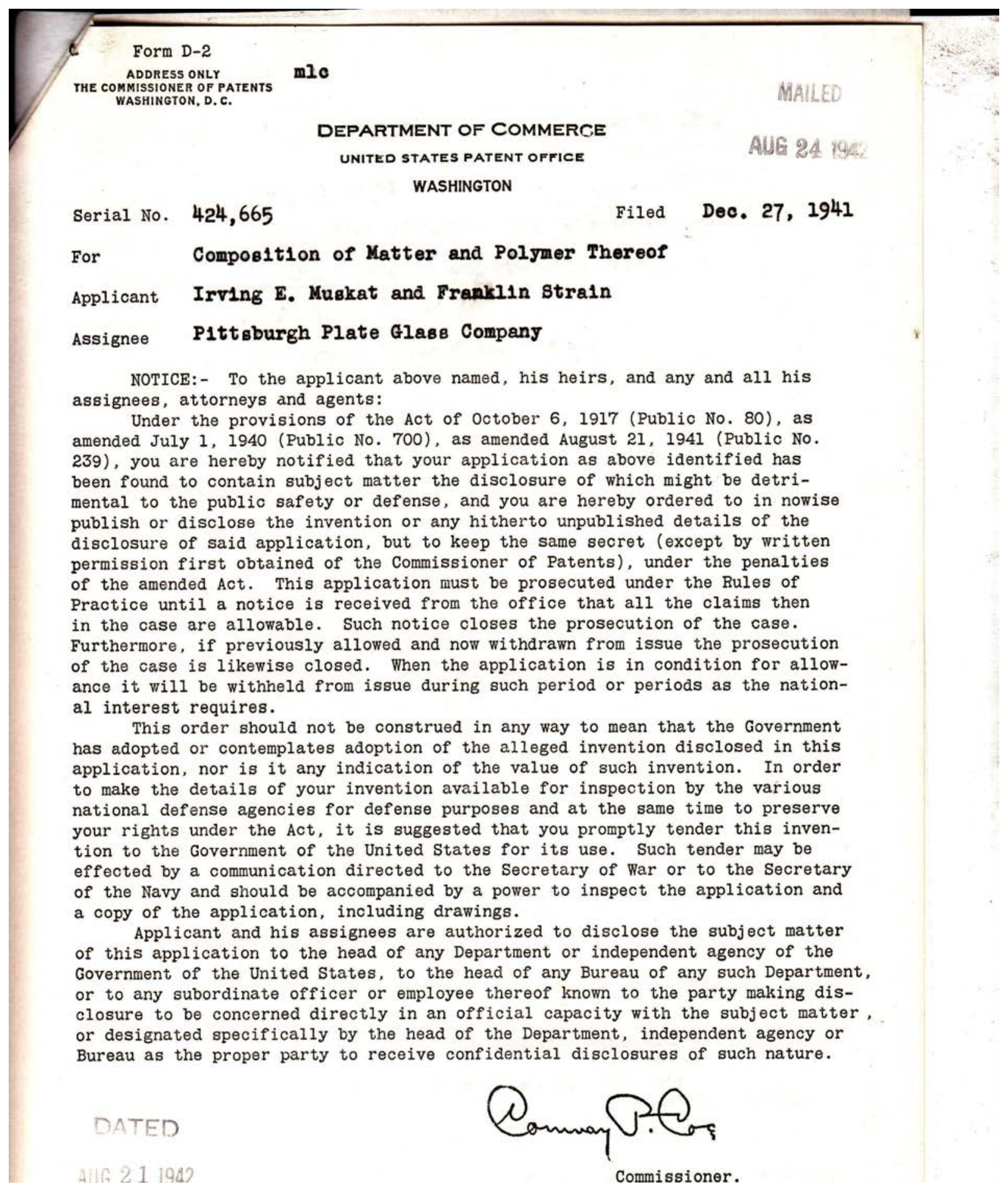


Figure B.4: Example Secrecy Order: Individual

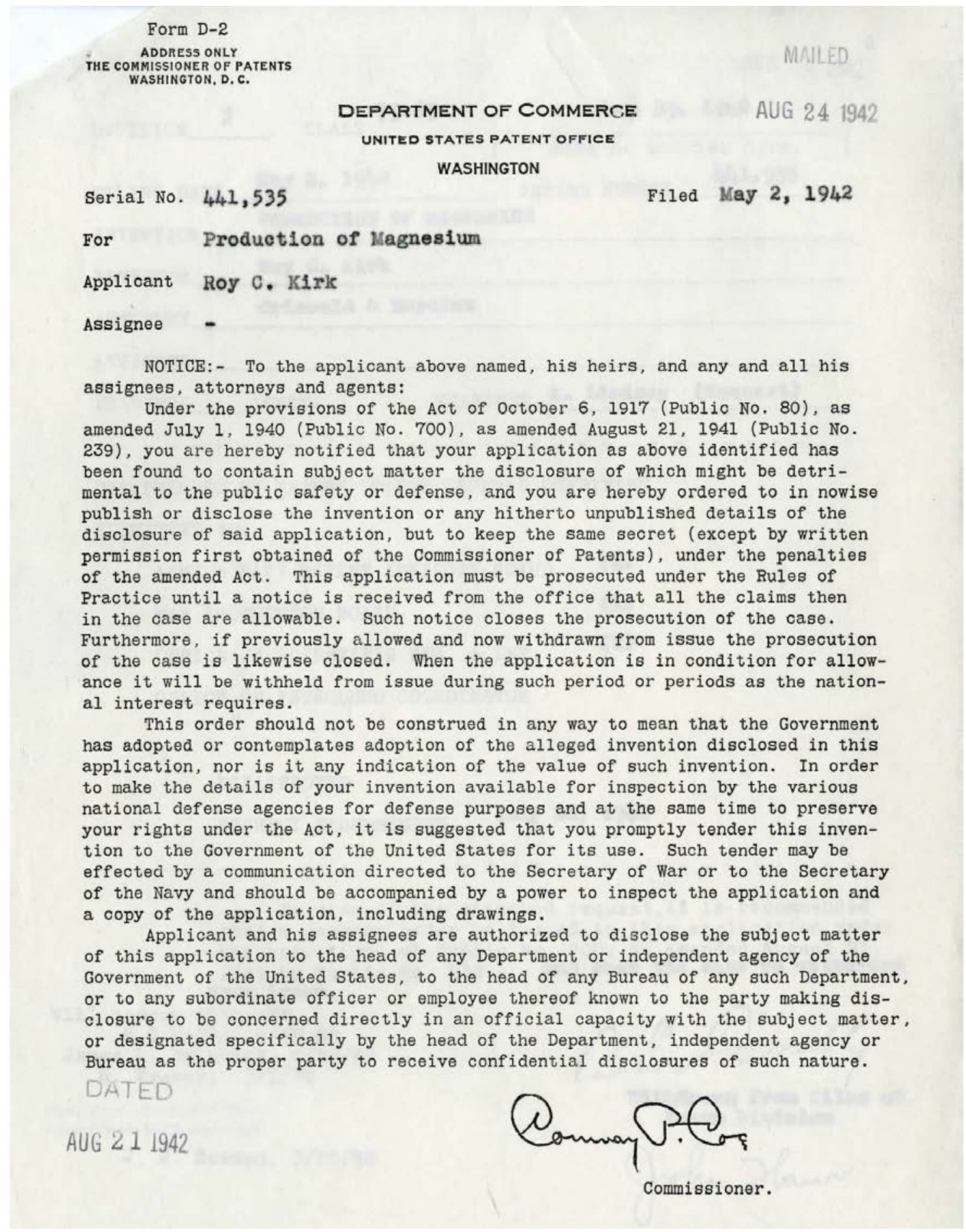


Figure B.5: Notice of General Rescinding Order in USPTO Official Gazette

\section{THE \\ OFFICIAL GAZETTE \\ OF THE \\ United States Patent Office}

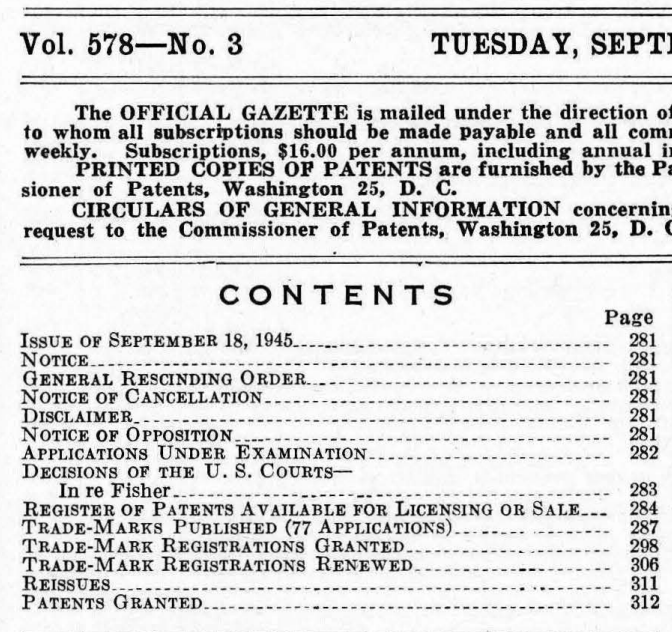

\begin{tabular}{|c|c|}
\hline \multicolumn{2}{|r|}{ September 18, 1945} \\
\hline $\begin{array}{l}\text { Trade-Marks. } \\
\text { T.M. Renewals.... } \\
\text { Reissues............ } \\
\text { Patents................. }\end{array}$ & $\begin{array}{l}134-\text { No. } 416,469 \text { to No. } 416,602 \text {, inclusive. } \\
87-\text { No. } 22,674 \\
139-\text { No. } 2,384,785 \text { to No. } 2,385,323 \text {, inclusive. }\end{array}$ \\
\hline Total & 761 \\
\hline
\end{tabular}

\section{Notice}

Under the provisions of Public Law 239, 77th Congress, Approved Aug. 21, 1941 (55 Stat. $657 ; 35 \mathrm{U}$. S. C. $42 a$ ),
the optional procedure authorized in regulation 16 will the optional procedure authorized in regulation 16 will
apply to all foreign countries excluding Japan, Germany, Bulgaria, Italy, Austria, Roumania, and Hungary. Assistant Commissioner of Patents.

\section{General Rescinding Order}

Subject to the exception hereinafter noted, all Orders of Secrecy heretofore issued by the Commissioner of Patents U. S. C., title 35 , sec. 42 ), as amended, are hereby rescinded.

The Commissioner of Patents may except any application from this order by written notice sent to the principal at their

This order shall take effect on November $30,1945$.

August $30,1945$.

$$
\text { CASPER W. OOMS, }
$$

August 30, $1945 . \quad$ Commissioner.
Price-\$16 per year

\section{Notice of Cancellation}

U. S. PAtent OfFice, Richmond, Va., Aug. $22,1945$. CeCo Manufacturing Company, Inc., its assigns or legal representatives, take notice:

A petition for cancellation having been filed in this Office by Argus, Incorporated, 405 Fourth St., Ann Arbor, of CeCo Manufacturing Company Inc 1200 Fad St Providence, R. I., No. 286,146, issued August 18, 1931, and the notice of such proceeding sent by registered mail to the said CeCo Manufacturing Company, Inc., at the said address having been returned by the post ofice undeliverable, notice is hereby given that unless said CeCo Manutives, shall enter an, from the first publication of this order the cancellation will be proceeded with as in the case of default. This notice will be published in the OFFICIAL GAZETTE for three consecutive weeks.

$$
\text { LESLIE FRAZER, }
$$
First Assistant Commissioner.

\section{Disclaimer}

2,259,527.-Keith R. Manville, Highland Park, N. J. SYNChronizing Mechanism. Patent dated Oct. 21, 1941. Disclaimer filed Aug. 24, 1945, by the inventor; the assignee, Mack Manufacturing Corporation, approving and consenting.

Hereby enters this disclaimer to claim 3 of said patent.

\section{Notice of Opposition}

U. S. Patent Office, Richmond, Va., Sept. 4, 1945. James A. S. Furlonge, his assigns or legal representatives, take notice:

An opposition proceeding has been instituted by this Office upon the petition of San-Nap-Pak Co., Inc., 1440 Broadway, New York, N. Y., against the application for S. Olive St o trade-mark to Jalifes A. S. Furlonge, 712 notified of the death of said Furlonge. An opportunity was afforded the legal representative of the deceased to intervene. No response having been made thereto, notice is hereby given that unless said Furlonge, his assigns or legal representatives, shall enter an appearance therein within thirty days from the first publication of this order, default. This notice will be published in the OFrIcIAr. GAzETTE for three consecutive weeks.

First Assistant Commissioner. 


\section{Additional Descriptives}

This appendix section provides descriptive results which supplement those in the paper.

Figure C.1 provides a counterpart to Figure 3 in the paper, comparing the grant lags of (i) patents formally evaluated for secrecy but not ordered secret, versus (ii) those not evaluated for secrecy. The figure shows little difference in grant lags as a result of simply being evaluated for secrecy (note that 1939 filings are included in this figure for completeness, because many were evaluated for secrecy, but a necessary condition was that they were still pending as of July 1940 - such that this set is selected on longer pendency). Recall, on the other hand, that Figure 3 compared the grant lags of secret versus non-secret patents, and showed that secret patents on average took longer to issue than their non-secret counterparts in the same class and filing year, with the difference diminishing over time. The results suggest that it was secrecy orders - rather than secrecy evaluations - which were the cause of the time-varying delays in patent grant and publication.

Figure C.1: Grant lags of non-secret applications evaluated for secrecy, vs. others, 1939-1945
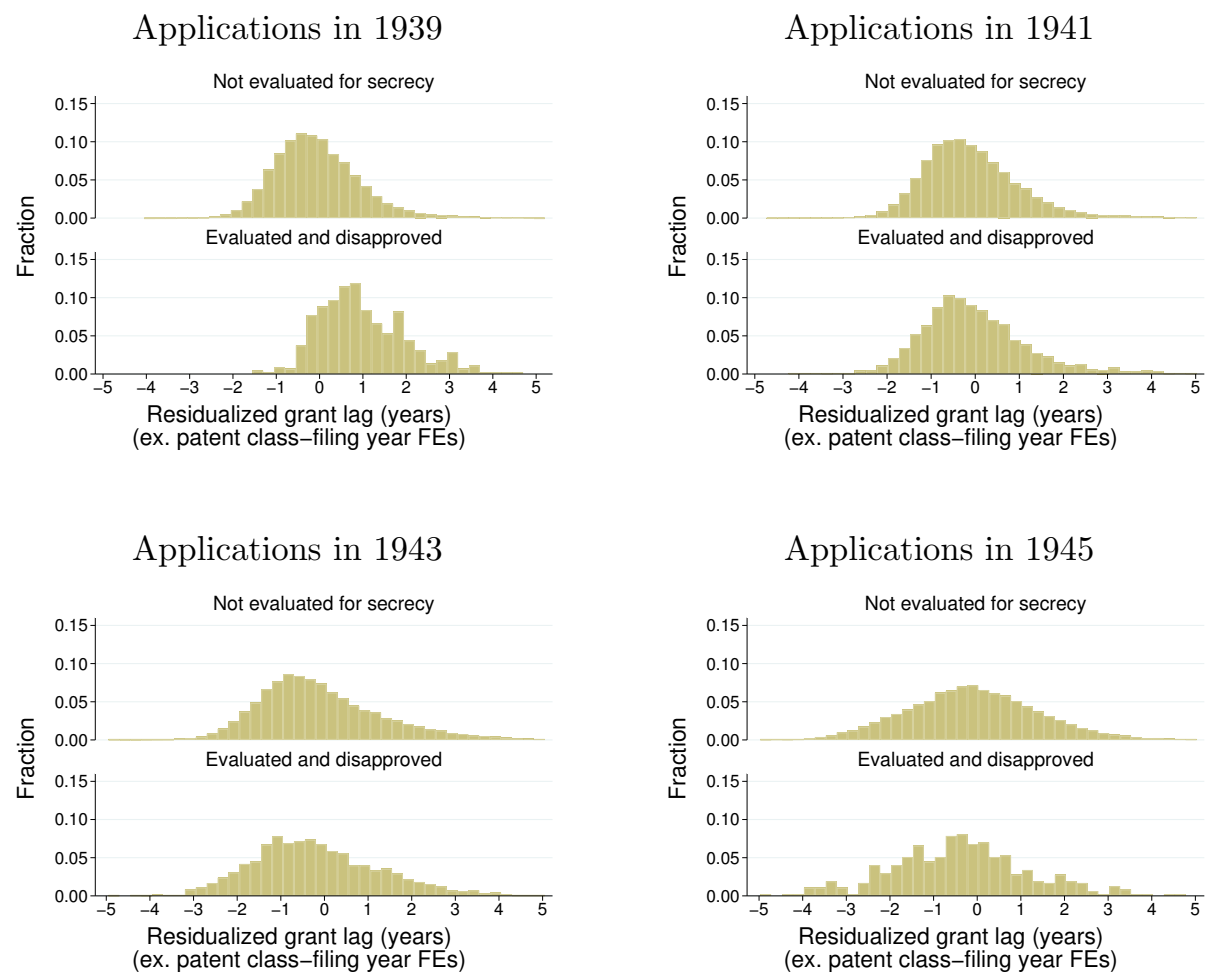

Notes: Figure shows the distribution of residual grant lags of patent applications evaluated for secrecy but not issued a secrecy order versus those not evaluated for secrecy, after controlling for patent class-year FEs. Note that patent applications prior to July 1940 were only evaluated for secrecy if still under examination (such that pre-1940 differences in total pendency are in part selected). 
Table C.1 shows the mean years from application to grant for patents filed between 1939 and 1945. Panel (A) shows this lag for (i) patents which were not evaluated for secrecy, (ii) those evaluated but not ordered secret, and (iii) those ordered secret, as well as (iv) Manhattan Project-related patents (Streifer 2017), which we will see are distinctive. Here we see that pendency was - in the aggregate -increasing throughout the war, with some incremental delay for secrecy evaluation that diminished to near-zero by 1945, and a lengthier delay for secrecy orders that diminished over the course of the war as well. Manhattan Project patents had far longer delays of 10-12 years to grant, and this lag did not vary by filing year. The latter evidence makes clear that these patents were in a class of their own and were not released from secrecy at the end of the war, motivating our dropping them from the sample throughout most of the paper - especially in analysis that exploits application year as an instrument for the duration of secrecy.

For the subset of patents which were evaluated for secrecy and for which we have the evaluation records, Panels (B) and (C) of Table C.1 subdivide this lag into the years from (i) application to secrecy evaluation, and (ii) secrecy evaluation to grant. Note that because we only know evaluation dates for a subset of secret patents, the data for the "Evaluated \& secret" category of patents in these panels do not add exactly to the total in the top panel.

Table C.1: Average years-to-evaluation and years-to-grant, by filing year, 1939-1945

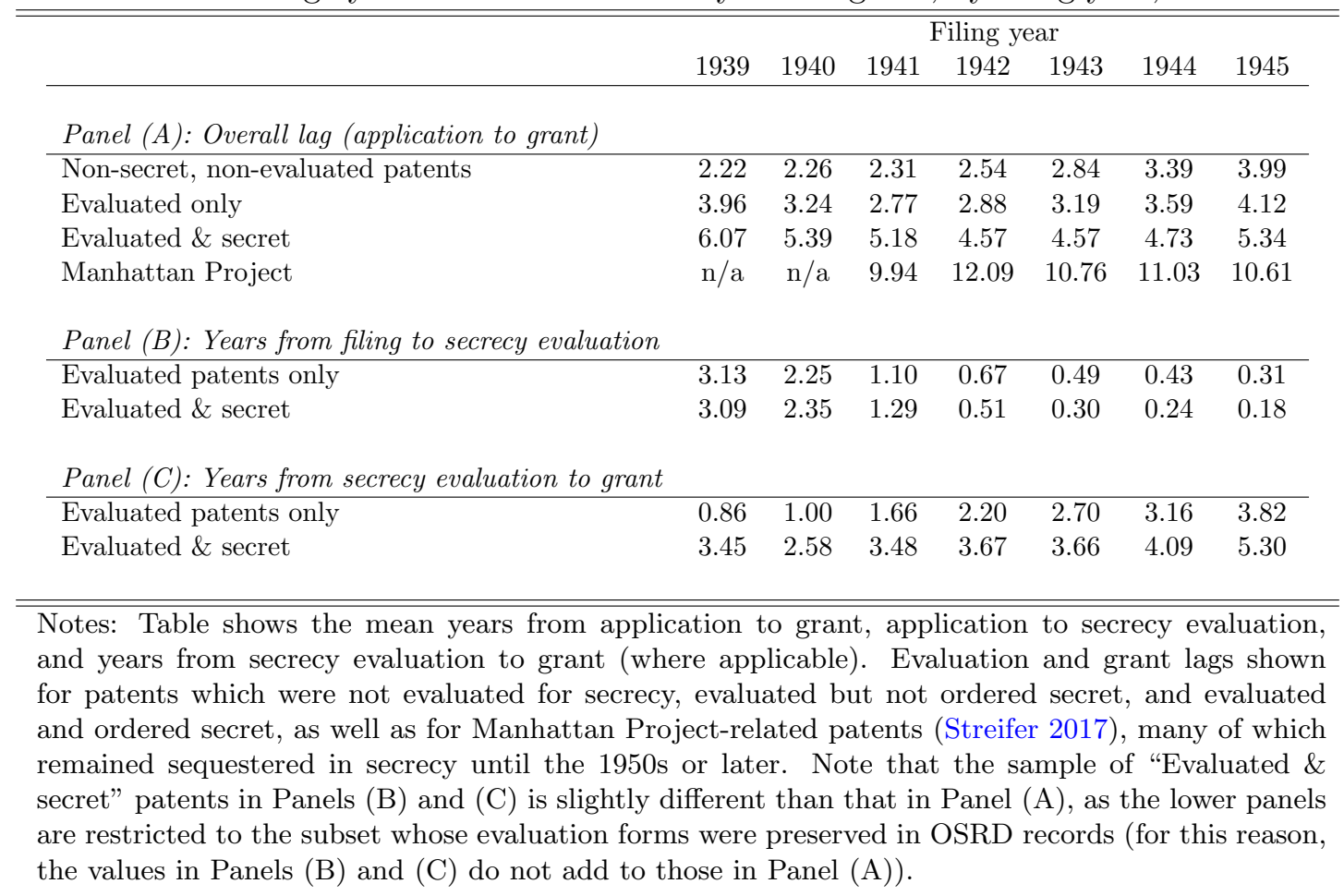


Table C. 2 provides a more detailed look at who the OSRD contractors are, providing context for the analysis in Section 4 which splits patents into subsamples of OSRD and non-OSRD firms-i.e., firms which were performing R\&D under contract for the war effort, versus those which were notto draw out differences in the effects. The table examines the set of all assignees who filed a patent in the 1940s, and the patents filed in this period with a known assignee. Out of nearly 135,000 unique assignees, roughly 21,000 were firms. Of these, the majority (66\%) filed no patents in the 1930s, and nearly $90 \%$ filed fewer than 10 patents. Many of the OSRD assignees, on the other hand, were among the most active filers in this era. Nearly $85 \%$ were firms, and the distribution skews towards large, R\&D-intensive outfits like Bell Labs, General Electric, Westinghouse, Du Pont, and so on. Although OSRD assignees comprise only $0.2 \%$ of assignees in the 1940s, they account for $19.1 \%$ of patents, and nearly $35 \%$ of patents filed by firms.

Table C.2: Characteristics of OSRD and non-OSRD patent filing in the 1940s

\begin{tabular}{|c|c|c|c|c|c|c|}
\hline & \multicolumn{2}{|c|}{ All assignees } & Non-OSRD & assignees & \multicolumn{2}{|c|}{ OSRD assignees } \\
\hline & Number & $\begin{array}{l}\text { Percent } \\
\text { of firms }\end{array}$ & Number & $\begin{array}{l}\text { Percent } \\
\text { of firms }\end{array}$ & Number & $\begin{array}{l}\text { Percent } \\
\text { of firms }\end{array}$ \\
\hline Patents & 375,680 & & 303,205 & & 72,475 & \\
\hline Assignees & 134,779 & & 134,473 & & 306 & \\
\hline Firms & 21,123 & $100.0 \%$ & 20,869 & $100.0 \%$ & 254 & $100.0 \%$ \\
\hline with 0 patents in 1930 s & 13,860 & $65.6 \%$ & 13,817 & $66.2 \%$ & 43 & $16.9 \%$ \\
\hline with $1-5$ patents & 3,982 & $18.9 \%$ & 3,948 & $18.9 \%$ & 34 & $13.4 \%$ \\
\hline with $6-10$ patents & 1,043 & $4.9 \%$ & 1,028 & $4.9 \%$ & 15 & $5.9 \%$ \\
\hline with $11-20$ patents & 905 & $4.3 \%$ & 891 & $4.3 \%$ & 14 & $5.5 \%$ \\
\hline with $21-50$ patents & 784 & $3.7 \%$ & 740 & $3.5 \%$ & 44 & $17.3 \%$ \\
\hline with $51-100$ patents & 292 & $1.4 \%$ & 256 & $1.2 \%$ & 36 & $14.2 \%$ \\
\hline with $101-200$ patents & 141 & $0.7 \%$ & 118 & $0.6 \%$ & 23 & $9.1 \%$ \\
\hline with $201-500$ patents & 85 & $0.4 \%$ & 57 & $0.3 \%$ & 28 & $11.0 \%$ \\
\hline with $501+$ patents & 31 & $0.1 \%$ & 14 & $0.1 \%$ & 17 & $6.7 \%$ \\
\hline \multicolumn{7}{|l|}{ OSRD percent of... } \\
\hline Assignees & $0.2 \%$ & & & & & \\
\hline Patents & $19.3 \%$ & & & & & \\
\hline Patents by firms & $35.0 \%$ & & & & & \\
\hline
\end{tabular}

Notes: Table shows characteristics of assignees who filing in the 1940s, focusing on the number of all / non-OSRD / OSRD assignees, the number which were firms, and the fraction of those with zero, few, or many patents in the prior decade. The table illustrates that the OSRD contractors are disproportionately large, $\mathrm{R} \& \mathrm{D}$-intensive firms. 
Figure C.2 shows the distribution of patents by assignee type over the World War II period, first for all patents (left panel) and then specifically for patents with secrecy orders (right panel). The assignee categories "firms", "individuals", and "government agencies" are mutually exclusive and add to approximately one. The "OSRD contractor" category is separately measured and primarily comprised of firms. Although OSRD contractors were responsible for around 20-25\% of patenting over this period, their share of secret patents was higher, in the range of $60 \%$ to $80 \%$ throughout the war. This nevertheless implies that many patents not directly related to the war effort were ordered secret, including (i) other patents of OSRD contractors, which tended to be large firms like those mentioned above, and (ii) patents of non-OSRD contractors.

Figure C.2: Patent shares by assignee type, 1939-1945

all patents vs. secret patents
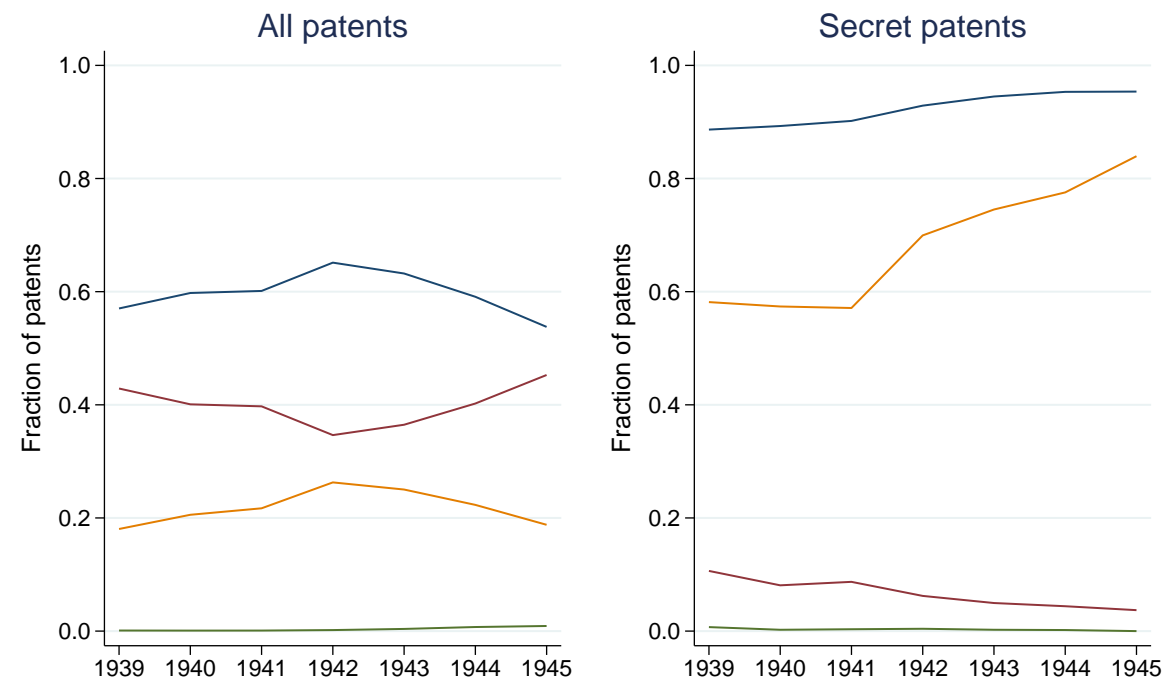

Fraction from firms
Fraction from govs.

Fraction from individuals Fraction from OSRD contractors

Notes: Figure shows annual patent shares across application years, by assignee type. Firms, individuals, and government organizations are mutually exclusive categories, and patents with assignees in multiple categories are omitted. 


\section{Supplementary Results}

\section{D.1 No evidence of time-varying selection into secrecy}

Figure D.1: Indirect evidence of no time-varying selection into secrecy orders

Panel (A)

F. citations vs. patent length

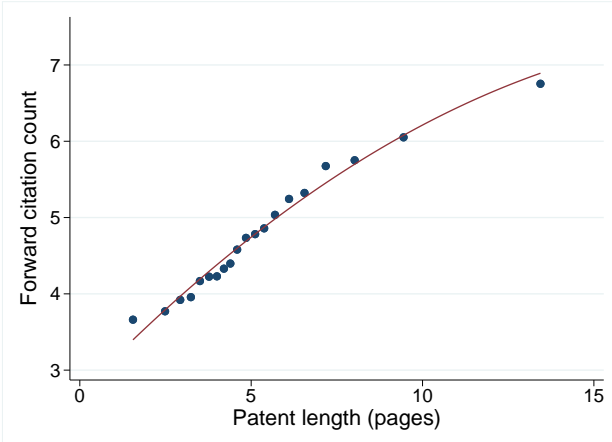

Panel (B)

Patent length over time

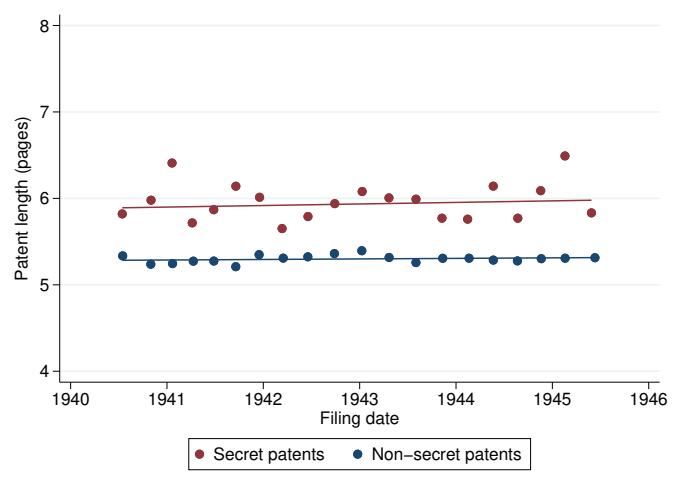

Notes: Panel (A) illustrates the relationship between patent length and forward citations, controlling for patent class $\mathrm{x}$ filing year FEs (which have been residualized out). Panel (B) illustrates differences in the mean length of secret and non-secret patents over time, controlling for patent class FEs. Taken together, the figure shows that (i) patent length predicts forward citations (Panel A), and (ii) the mean length of secret and non-secret patents are not differentially changing over the period (Panel B), suggesting that although patents with secrecy orders are selected (as discussed in the paper), this selection is stable over time.

Figure D.2: Fraction of patents evaluated or ordered secret, by filing year, 1940-1945

Panel (A)

Fraction evaluated or ordered secret

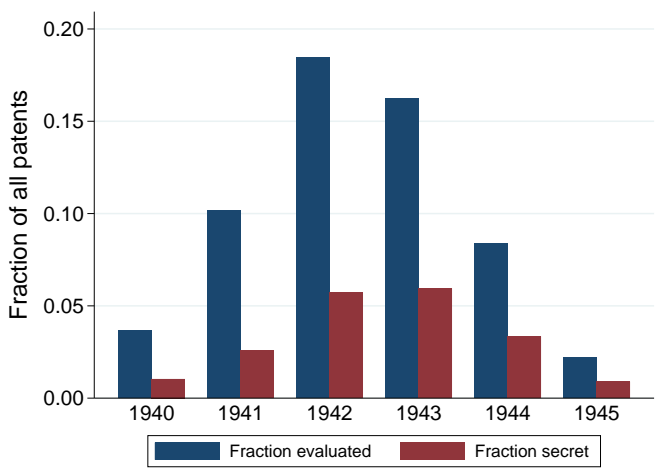

Panel (B)

Rate at which ordered secret

Notes: Figure shows the fraction of all patent which were evaluated for secrecy and ordered secret, by application year (Panel A), and the fraction of evaluated patents which were ordered secret (Panel B). That the fraction of evaluations ending in secrecy orders was rising modestly during the period (Panel B) suggests that conditional on evaluation, reviewers were not ordering a more selective set of patents into secrecy (if anything, the opposite). 


\section{D.2 Supplementary results for assignees' post-war patenting}

Table D.2.1: Effects of secrecy orders on $\operatorname{Pr}($ Assignee patents in given class), binned treatment

\begin{tabular}{|c|c|c|c|c|c|c|c|}
\hline & $\begin{array}{l}\text { (1) } \\
\text { All }\end{array}$ & $\begin{array}{c}(2) \\
\text { Non-OSRD }\end{array}$ & $\begin{array}{c}(3) \\
\text { OSRD }\end{array}$ & $\begin{array}{c}(4) \\
\text { Small }\end{array}$ & $\begin{array}{c}(5) \\
\text { Large }\end{array}$ & $\begin{array}{c}(6) \\
\text { Entrant }\end{array}$ & $\begin{array}{c}(7) \\
\text { Entrant }\end{array}$ \\
\hline Wartime Sec. Rate in $(0.25,0.75] *(1935-39)$ & $\begin{array}{c}0.137^{* *} \\
(0.061)\end{array}$ & $\begin{array}{c}0.188^{* *} \\
(0.081)\end{array}$ & $\begin{array}{c}0.023 \\
(0.089)\end{array}$ & $\begin{array}{c}0.031 \\
(0.125)\end{array}$ & $\begin{array}{c}0.081 \\
(0.065)\end{array}$ & & \\
\hline Wartime Sec. Rate in $(0.25,0.75]^{*}(1946-50)$ & $\begin{array}{l}-0.088 \\
(0.065)\end{array}$ & $\begin{array}{l}-0.154 \\
(0.095)\end{array}$ & $\begin{array}{l}-0.001 \\
(0.085)\end{array}$ & $\begin{array}{c}-0.333^{* *} \\
(0.142)\end{array}$ & $\begin{array}{l}-0.061 \\
(0.075)\end{array}$ & $\begin{array}{c}-0.290^{* * *} \\
(0.068)\end{array}$ & $\begin{array}{c}-0.423^{* * *} \\
(0.099)\end{array}$ \\
\hline Wartime Sec. Rate in $(0.25,0.75]^{*}(1951-55)$ & $\begin{array}{l}-0.099 \\
(0.064)\end{array}$ & $\begin{array}{c}-0.163^{*} \\
(0.092)\end{array}$ & $\begin{array}{c}0.015 \\
(0.086)\end{array}$ & $\begin{array}{c}-0.313^{* *} \\
(0.140)\end{array}$ & $\begin{array}{l}-0.060 \\
(0.076)\end{array}$ & $\begin{array}{c}-0.284^{* * *} \\
(0.070)\end{array}$ & $\begin{array}{c}-0.406^{* * *} \\
(0.099)\end{array}$ \\
\hline Wartime Sec. Rate in $(0.25,0.75]^{*}(1956-60)$ & $\begin{array}{c}-0.099^{*} \\
(0.060)\end{array}$ & $\begin{array}{l}-0.103 \\
(0.085)\end{array}$ & $\begin{array}{l}-0.048 \\
(0.081)\end{array}$ & $\begin{array}{c}-0.254^{* *} \\
(0.126)\end{array}$ & $\begin{array}{l}-0.057 \\
(0.074)\end{array}$ & $\begin{array}{c}-0.265^{* * *} \\
(0.071)\end{array}$ & $\begin{array}{c}-0.236^{* *} \\
(0.095)\end{array}$ \\
\hline Wartime Sec. Rate in $(0.75,1] *(1935-39)$ & $\begin{array}{c}0.095 \\
(0.109)\end{array}$ & $\begin{array}{c}0.025 \\
(0.124)\end{array}$ & $\begin{array}{c}0.192 \\
(0.232)\end{array}$ & $\begin{array}{l}-0.215 \\
(0.155)\end{array}$ & $\begin{array}{c}0.057 \\
(0.175)\end{array}$ & & \\
\hline Wartime Sec. Rate in $(0.75,1]^{*}(1946-50)$ & $\begin{array}{c}-0.271^{* * *} \\
(0.085)\end{array}$ & $\begin{array}{c}-0.358^{* * *} \\
(0.099)\end{array}$ & $\begin{array}{c}0.119 \\
(0.193)\end{array}$ & $\begin{array}{c}-0.536^{* * *} \\
(0.135)\end{array}$ & $\begin{array}{c}-0.288^{* *} \\
(0.137)\end{array}$ & $\begin{array}{c}-0.543^{* * *} \\
(0.060)\end{array}$ & $\begin{array}{c}-0.630^{* * *} \\
(0.084)\end{array}$ \\
\hline Wartime Sec. Rate in $(0.75,1] *(1951-55)$ & $\begin{array}{c}-0.296^{* * *} \\
(0.080)\end{array}$ & $\begin{array}{c}-0.328^{* * *} \\
(0.094)\end{array}$ & $\begin{array}{c}0.009 \\
(0.230)\end{array}$ & $\begin{array}{c}-0.554^{* * *} \\
(0.126)\end{array}$ & $\begin{array}{l}-0.190 \\
(0.149)\end{array}$ & $\begin{array}{c}-0.542^{* * *} \\
(0.063)\end{array}$ & $\begin{array}{c}-0.597^{* * *} \\
(0.091)\end{array}$ \\
\hline Wartime Sec. Rate in $(0.75,1] *(1956-60)$ & $\begin{array}{c}-0.240^{* * *} \\
(0.083) \\
\end{array}$ & $\begin{array}{c}-0.216^{* *} \\
(0.097) \\
\end{array}$ & $\begin{array}{l}-0.048 \\
(0.243) \\
\end{array}$ & $\begin{array}{c}-0.351^{* * *} \\
(0.134)\end{array}$ & $\begin{array}{l}-0.217 \\
(0.146)\end{array}$ & $\begin{array}{c}-0.441^{* * *} \\
(0.065) \\
\end{array}$ & $\begin{array}{c}-0.360^{* * *} \\
(0.092) \\
\end{array}$ \\
\hline $\mathrm{N}$ & 3635 & 1960 & 1675 & 905 & 2730 & 1809 & 1071 \\
\hline$R^{2}$ & 0.51 & 0.52 & 0.39 & 0.47 & 0.45 & 0.19 & 0.21 \\
\hline Assignee x NBER Cat FEs & $\mathrm{Y}$ & $\mathrm{Y}$ & $\mathrm{Y}$ & $\mathrm{Y}$ & Y & & \\
\hline NBER Cat FEs & & & & & & $\mathrm{Y}$ & $\mathrm{Y}$ \\
\hline
\end{tabular}

Notes: Table estimates the effect of the secrecy order program on affected assignees' post-war patenting, relative to pre-war patenting, in a given technology category where it received secrecy orders. Observations are assignees x NBER categories x years, in all cases organized into a balanced panel from 1930 to 1960 , and aggregated to the periods 1930-1934, 1935-1939, 1940-1945, 1946-1950, 1951-1955, 1956-1960. The dependent variable measures whether the assignee filed any patent in the given NBER category and period. "Wartime secrecy rate" measures the fraction of the given assignee's filings from 1940 to 1945 in the given NBER category which received a secrecy order, which is binned and interacted with indicators for later periods. Samples are restricted to assignee-categories with $\geq 1$ pre-war patent and $\geq 1$ secrecy order, and omits the 1940-1945 period, such that the table shows a pre- vs. post-war comparison. All regressions include dummies for each of the interacted post-periods (not shown). ${ }^{*},{ }^{* *}, * * *$ represent significance at the $0.1,0.05$, and 0.01 levels, respectively. SEs clustered by assignee in parentheses. 
Table D.2.2: Effects of secrecy orders on $\operatorname{Pr}($ Assignee patents in any class), binned treatment

\begin{tabular}{|c|c|c|c|c|c|c|c|c|}
\hline & $\begin{array}{l}(1) \\
\text { All }\end{array}$ & $\begin{array}{c}(2) \\
\text { Non-OSRD }\end{array}$ & $\begin{array}{c}(3) \\
\text { OSRD }\end{array}$ & $\begin{array}{c}(4) \\
\text { Small } \\
\end{array}$ & $\begin{array}{c}(5) \\
\text { Large }\end{array}$ & $\begin{array}{c}(6) \\
\text { Focused }\end{array}$ & $\begin{array}{c}(7) \\
\text { Diversified }\end{array}$ & $\begin{array}{c}(8) \\
\text { Entrant }\end{array}$ \\
\hline Wartime Sec. Rate in $(0.1,0.25]^{*}(1935-1939)$ & $\begin{array}{l}0.093^{*} \\
(0.053)\end{array}$ & $\begin{array}{c}0.078 \\
(0.064)\end{array}$ & $\begin{array}{c}0.055 \\
(0.072)\end{array}$ & $\begin{array}{l}-0.080 \\
(0.099)\end{array}$ & $\begin{array}{c}0.000 \\
(0.026)\end{array}$ & $\begin{array}{c}-0.500^{* * *} \\
(0.168)\end{array}$ & $\begin{array}{l}0.077^{*} \\
(0.044)\end{array}$ & \\
\hline Wartime Sec. Rate in $(0.1,0.25] *(1946-1950)$ & $\begin{array}{l}-0.083 \\
(0.060)\end{array}$ & $\begin{array}{l}-0.114 \\
(0.072)\end{array}$ & $\begin{array}{c}0.011 \\
(0.089)\end{array}$ & $\begin{array}{c}-0.285^{* * *} \\
(0.102)\end{array}$ & $\begin{array}{l}-0.087 \\
(0.061)\end{array}$ & $\begin{array}{c}-0.429^{* *} \\
(0.210)\end{array}$ & $\begin{array}{c}-0.120^{* *} \\
(0.057)\end{array}$ & $\begin{array}{c}-0.404^{* * * *} \\
(0.084)\end{array}$ \\
\hline Wartime Sec. Rate in $(0.1,0.25]^{*}(1951-1955)$ & $\begin{array}{l}-0.056 \\
(0.068)\end{array}$ & $\begin{array}{l}-0.086 \\
(0.081)\end{array}$ & $\begin{array}{c}0.092 \\
(0.098)\end{array}$ & $\begin{array}{c}-0.204^{*} \\
(0.121)\end{array}$ & $\begin{array}{l}-0.061 \\
(0.077)\end{array}$ & $\begin{array}{c}-0.417^{*} \\
(0.223)\end{array}$ & $\begin{array}{l}-0.099 \\
(0.066)\end{array}$ & $\begin{array}{c}-0.253^{* *} \\
(0.117)\end{array}$ \\
\hline Wartime Sec. Rate & $\begin{array}{l}-0.083 \\
(0.071)\end{array}$ & $\begin{array}{l}-0.099 \\
(0.084)\end{array}$ & $\begin{array}{c}0.053 \\
(0.124)\end{array}$ & $\begin{array}{l}-0.240^{*} \\
(0.125)\end{array}$ & $\begin{array}{l}-0.048 \\
(0.087)\end{array}$ & $\begin{array}{c}-0.631^{* * *} \\
(0.214)\end{array}$ & $\begin{array}{l}-0.099 \\
(0.073)\end{array}$ & $\begin{array}{c}0.080 \\
(0.119)\end{array}$ \\
\hline Wartime Sec. Rate in $(0.25,1] *(1935-1939)$ & $\begin{array}{l}0.144^{*} \\
(0.079)\end{array}$ & $\begin{array}{c}0.128 \\
(0.089)\end{array}$ & $\begin{array}{c}0.039 \\
(0.142)\end{array}$ & $\begin{array}{l}-0.115 \\
(0.111)\end{array}$ & $\begin{array}{c}0.098 \\
(0.089)\end{array}$ & $\begin{array}{c}-0.617^{* * *} \\
(0.144)\end{array}$ & $\begin{array}{c}0.130 \\
(0.085)\end{array}$ & \\
\hline Wartime Sec. Rate in $(0.25,1] *(1946-1950)$ & $\begin{array}{c}-0.163^{* *} \\
(0.072)\end{array}$ & $\begin{array}{c}-0.206^{* *} \\
(0.081)\end{array}$ & $\begin{array}{c}0.039 \\
(0.142)\end{array}$ & $\begin{array}{c}-0.425^{* * *} \\
(0.101)\end{array}$ & $\begin{array}{l}-0.046 \\
(0.149)\end{array}$ & $\begin{array}{c}-0.793^{* * *} \\
(0.186)\end{array}$ & $\begin{array}{l}-0.142^{*} \\
(0.083)\end{array}$ & $\begin{array}{c}-0.731^{* * *} \\
(0.048)\end{array}$ \\
\hline Wartime Sec. Rate in $(0.25,1] *(1951-1955)$ & $\begin{array}{c}-0.185^{* *} \\
(0.072)\end{array}$ & $\begin{array}{c}-0.207^{* *} \\
(0.081)\end{array}$ & $\begin{array}{l}-0.023 \\
(0.187)\end{array}$ & $\begin{array}{c}-0.386^{* * *} \\
(0.114)\end{array}$ & $\begin{array}{l}-0.057 \\
(0.144)\end{array}$ & $\begin{array}{c}-0.858^{* * *} \\
(0.182)\end{array}$ & $\begin{array}{c}-0.165^{*} \\
(0.088)\end{array}$ & $\begin{array}{c}-0.582^{* * *} \\
(0.093)\end{array}$ \\
\hline Wartime Sec. Rate in $(0.25,1] *(1956-1960)$ & $\begin{array}{l}-0.118^{*} \\
(0.070)\end{array}$ & $\begin{array}{c}-0.133^{*} \\
(0.080)\end{array}$ & $\begin{array}{c}0.097 \\
(0.172)\end{array}$ & $\begin{array}{c}-0.307^{* * *} \\
(0.114)\end{array}$ & $\begin{array}{c}0.035 \\
(0.146)\end{array}$ & $\begin{array}{c}-0.879^{* * *} \\
(0.183)\end{array}$ & $\begin{array}{l}-0.099 \\
(0.082)\end{array}$ & $\begin{array}{c}-0.225^{* *} \\
(0.096)\end{array}$ \\
\hline $\mathrm{N}$ & 2380 & 1885 & 495 & 1290 & 1090 & 435 & 1945 & 969 \\
\hline$R^{2}$ & 0.52 & 0.52 & 0.34 & 0.48 & 0.46 & 0.45 & 0.51 & 0.20 \\
\hline Ass & $\mathrm{Y}$ & $\mathrm{Y}$ & $\mathrm{Y}$ & $\mathrm{Y}$ & $\mathrm{Y}$ & Y & $\mathrm{Y}$ & \\
\hline
\end{tabular}

Notes: Table estimates the effect of the secrecy order program on affected assignees' post-war patenting, relative to pre-war patenting, in any technology category. Observations are assignees $\mathrm{x}$ years, in all cases organized into a balanced panel from 1930 to 1960, and aggregated to the periods 1930-1934, 1935-1939, 1940-1945, 1946-1950, 1951-1955, 1956-1960. The dependent variable measures whether the assignee filed any patent in the period. "Wartime secrecy rate" measures the fraction of the given assignee's filings from 1940 to 1945 which received a secrecy order, which is binned and interacted with indicators for later periods. Samples are restricted to assignees with $\geq 1$ pre-war patent and $\geq 1$ secrecy order, and omits the 1940-1945 period, such that the table shows a pre- vs. post-war comparison. All regressions include dummies for each of the interacted post-periods (not shown). ${ }^{*}, * *, * * *$ represent significance at the $0.1,0.05$, and 0.01 levels, respectively. SEs clustered by assignee in parentheses. 


\section{D.3 Supplementary results for follow-on invention}

\section{D.3.1 Robustness checks and additional results}

Table D.3.1: Effects of secrecy on probability of any forward citations (logit)

\begin{tabular}{|c|c|c|c|c|c|}
\hline & \multirow[b]{2}{*}{$\begin{array}{l}\text { All } \\
(1)\end{array}$} & \multirow[b]{2}{*}{$\begin{array}{c}\text { Non-OSRD } \\
(2)\end{array}$} & \multirow[b]{2}{*}{$\begin{array}{l}\text { OSRD } \\
(3)\end{array}$} & \multicolumn{2}{|c|}{ Triple difference } \\
\hline & & & & $\begin{array}{l}\text { All } \\
(4)\end{array}$ & $\begin{array}{c}\text { OSRD } \\
\text { (rel. to all) } \\
(5)\end{array}$ \\
\hline Secrecy ordered & $\begin{array}{c}0.131 \\
(0.274)\end{array}$ & $\begin{array}{l}-0.556^{*} \\
(0.300)\end{array}$ & $\begin{array}{l}0.793^{*} \\
(0.419)\end{array}$ & $\begin{array}{l}-0.555^{*} \\
(0.301)\end{array}$ & $\begin{array}{c}1.353^{* * *} \\
(0.457)\end{array}$ \\
\hline * filed in 1941 & $\begin{array}{l}-0.205 \\
(0.302)\end{array}$ & $\begin{array}{c}0.111 \\
(0.382)\end{array}$ & $\begin{array}{l}-0.466 \\
(0.433)\end{array}$ & $\begin{array}{c}0.116 \\
(0.385)\end{array}$ & $\begin{array}{l}-0.568 \\
(0.559)\end{array}$ \\
\hline * filed in 1942 & $\begin{array}{c}0.191 \\
(0.269)\end{array}$ & $\begin{array}{c}0.465 \\
(0.351)\end{array}$ & $\begin{array}{l}-0.240 \\
(0.395)\end{array}$ & $\begin{array}{c}0.460 \\
(0.352)\end{array}$ & $\begin{array}{l}-0.682 \\
(0.493)\end{array}$ \\
\hline * filed in 1943 & $\begin{array}{c}0.123 \\
(0.272)\end{array}$ & $\begin{array}{c}0.644^{*} \\
(0.385)\end{array}$ & $\begin{array}{c}-0.534 \\
(0.366)\end{array}$ & $\begin{array}{c}0.641^{*} \\
(0.386)\end{array}$ & $\begin{array}{c}-1.153^{* *} \\
(0.508)\end{array}$ \\
\hline * filed in 1944 & $\begin{array}{c}0.316 \\
(0.307)\end{array}$ & $\begin{array}{c}0.655 \\
(0.403)\end{array}$ & $\begin{array}{l}-0.228 \\
(0.467)\end{array}$ & $\begin{array}{l}0.681^{*} \\
(0.408)\end{array}$ & $\begin{array}{l}-0.941 \\
(0.587)\end{array}$ \\
\hline * filed in 1945 & $\begin{array}{c}0.417 \\
(0.373)\end{array}$ & $\begin{array}{c}2.356^{* *} \\
(1.099)\end{array}$ & $\begin{array}{l}-0.308 \\
(0.517)\end{array}$ & $\begin{array}{c}2.350^{* *} \\
(1.098)\end{array}$ & $\begin{array}{c}-2.794^{* *} \\
(1.251)\end{array}$ \\
\hline Secrecy evaluated & $\begin{array}{c}0.126 \\
(0.136)\end{array}$ & $\begin{array}{l}0.313^{*} \\
(0.177)\end{array}$ & $\begin{array}{c}-0.032 \\
(0.202)\end{array}$ & $\begin{array}{c}0.351^{* *} \\
(0.177)\end{array}$ & $\begin{array}{c}-0.526^{*} \\
(0.272)\end{array}$ \\
\hline * filed in 1941 & $\begin{array}{c}0.172 \\
(0.147)\end{array}$ & $\begin{array}{l}-0.010 \\
(0.193)\end{array}$ & $\begin{array}{c}0.301 \\
(0.228)\end{array}$ & $\begin{array}{l}-0.032 \\
(0.191)\end{array}$ & $\begin{array}{c}0.404 \\
(0.307)\end{array}$ \\
\hline * filed in 1942 & $\begin{array}{l}-0.019 \\
(0.145)\end{array}$ & $\begin{array}{l}-0.246 \\
(0.212)\end{array}$ & $\begin{array}{c}0.084 \\
(0.192)\end{array}$ & $\begin{array}{l}-0.285 \\
(0.213)\end{array}$ & $\begin{array}{l}0.517^{*} \\
(0.280)\end{array}$ \\
\hline * filed in 1943 & $\begin{array}{c}0.151 \\
(0.143)\end{array}$ & $\begin{array}{l}-0.132 \\
(0.177)\end{array}$ & $\begin{array}{c}0.344 \\
(0.213)\end{array}$ & $\begin{array}{l}-0.163 \\
(0.176)\end{array}$ & $\begin{array}{c}0.599^{* *} \\
(0.269)\end{array}$ \\
\hline * filed in 1944 & $\begin{array}{c}0.187 \\
(0.174)\end{array}$ & $\begin{array}{l}-0.058 \\
(0.219)\end{array}$ & $\begin{array}{c}0.169 \\
(0.237)\end{array}$ & $\begin{array}{l}-0.130 \\
(0.219)\end{array}$ & $\begin{array}{l}0.596^{*} \\
(0.307)\end{array}$ \\
\hline * filed in 1945 & $\begin{array}{c}0.286 \\
(0.226)\end{array}$ & $\begin{array}{c}0.039 \\
(0.270)\end{array}$ & $\begin{array}{c}0.227 \\
(0.296)\end{array}$ & $\begin{array}{l}-0.028 \\
(0.271)\end{array}$ & $\begin{array}{c}0.581 \\
(0.355)\end{array}$ \\
\hline $\mathrm{N}$ & 162346 & 124958 & 37388 & & 2346 \\
\hline Grant year FEs & $\mathrm{Y}$ & $\mathrm{Y}$ & $\mathrm{Y}$ & & $\mathrm{Y}$ \\
\hline Class-year FEs & $\mathrm{Y}$ & $\mathrm{Y}$ & $\mathrm{Y}$ & & $\mathrm{Y}$ \\
\hline Mean of DV & 0.86 & 0.86 & 0.89 & & 0.86 \\
\hline s.d. of DV & 0.34 & 0.35 & 0.32 & & 0.34 \\
\hline
\end{tabular}

Notes: Table estimates the probability that a patent filed between July 1940 and June 1945 generates any forward citations, as a function of whether the patent was evaluated for secrecy and/or ordered secret, with estimates by filing year, and with 1940 being the omitted reference year. Column (1) includes all such patents. Columns (2) and (3) restricts the sample to patents by non-OSRD and OSRD contractors, respectively. Columns (4) and (5) repeat this comparison in a pooled, triple-differenced sample. All columns control for (i) patent class $\mathrm{x}$ filing year and (ii) grant year fixed effects. Specifications estimated via logit. $*, * *, * * *$ represent significance at the $0.1,0.05$, and 0.01 levels, respectively. SEs clustered by patent class in parentheses. 
Table D.3.2: Effects of secrecy on probability of any forward citations

excl. secrecy orders rescinded prior to the General Rescinding Order (August 30, 1945)

\begin{tabular}{|c|c|c|c|c|c|}
\hline & \multirow[b]{2}{*}{$\begin{array}{l}\text { All } \\
(1)\end{array}$} & \multirow[b]{2}{*}{$\begin{array}{c}\text { Non-OSRD } \\
(2)\end{array}$} & \multirow[b]{2}{*}{$\begin{array}{c}\text { OSRD } \\
(3)\end{array}$} & \multicolumn{2}{|c|}{ Triple difference } \\
\hline & & & & $\begin{array}{l}\text { All } \\
(4)\end{array}$ & $\begin{array}{c}\text { OSRD } \\
\text { (rel. to all) } \\
(5)\end{array}$ \\
\hline \multirow{2}{*}{ Secrecy ordered } & -0.009 & $-0.077^{*}$ & 0.046 & $-0.080^{*}$ & $0.129^{* * *}$ \\
\hline & $(0.024)$ & $(0.042)$ & $(0.031)$ & $(0.041)$ & $(0.048)$ \\
\hline \multirow[t]{2}{*}{ * filed in 1941} & -0.015 & 0.033 & -0.047 & 0.035 & -0.095 \\
\hline & $(0.026)$ & $(0.050)$ & $(0.037)$ & $(0.049)$ & $(0.060)$ \\
\hline \multirow[t]{2}{*}{ * filed in 1942} & 0.018 & 0.056 & -0.017 & 0.060 & -0.086 \\
\hline & $(0.026)$ & $(0.045)$ & $(0.034)$ & $(0.044)$ & $(0.053)$ \\
\hline \multirow[t]{2}{*}{ * filed in 1943} & 0.027 & $0.095^{* *}$ & -0.036 & $0.093^{* *}$ & $-0.124^{* *}$ \\
\hline & $(0.027)$ & $(0.048)$ & $(0.032)$ & $(0.047)$ & $(0.053)$ \\
\hline \multirow{2}{*}{ * filed in 1944} & 0.029 & 0.079 & -0.022 & $0.086^{*}$ & $-0.114^{* *}$ \\
\hline & $(0.029)$ & $(0.050)$ & $(0.035)$ & $(0.049)$ & $(0.053)$ \\
\hline \multirow[t]{2}{*}{ * filed in 1945} & 0.038 & $0.141^{* * *}$ & -0.014 & $0.155^{* * *}$ & $-0.192^{* * *}$ \\
\hline & $(0.029)$ & $(0.052)$ & $(0.041)$ & $(0.050)$ & $(0.058)$ \\
\hline \multirow[t]{2}{*}{ Secrecy evaluated } & 0.019 & $0.036^{* *}$ & -0.010 & $0.039^{* *}$ & $-0.048^{* *}$ \\
\hline & $(0.013)$ & $(0.017)$ & $(0.022)$ & $(0.016)$ & $(0.024)$ \\
\hline \multirow[t]{2}{*}{ * filed in 1941} & 0.010 & -0.002 & 0.027 & -0.004 & 0.029 \\
\hline & $(0.015)$ & $(0.019)$ & $(0.024)$ & $(0.018)$ & $(0.027)$ \\
\hline \multirow{2}{*}{ * filed in 1942} & -0.004 & -0.021 & 0.016 & -0.022 & 0.037 \\
\hline & $(0.014)$ & $(0.020)$ & $(0.023)$ & $(0.018)$ & $(0.024)$ \\
\hline \multirow[t]{2}{*}{ * filed in 1943} & 0.009 & -0.008 & 0.030 & -0.013 & $0.044^{*}$ \\
\hline & $(0.015)$ & $(0.019)$ & $(0.023)$ & $(0.018)$ & $(0.026)$ \\
\hline \multirow[t]{2}{*}{ * filed in 1944} & 0.007 & -0.014 & 0.027 & -0.016 & 0.046 \\
\hline & $(0.017)$ & $(0.022)$ & $(0.024)$ & $(0.021)$ & $(0.028)$ \\
\hline \multirow[t]{2}{*}{ * filed in 1945} & 0.010 & -0.010 & 0.026 & -0.021 & $0.059^{*}$ \\
\hline & $(0.019)$ & $(0.026)$ & $(0.025)$ & $(0.025)$ & $(0.031)$ \\
\hline $\mathrm{N}$ & 161937 & 124793 & 37144 & \multicolumn{2}{|c|}{161937} \\
\hline$R^{2}$ & 0.05 & 0.05 & 0.10 & \multicolumn{2}{|c|}{0.05} \\
\hline Grant year FEs & $\mathrm{Y}$ & $\mathrm{Y}$ & $\mathrm{Y}$ & \multicolumn{2}{|c|}{$\mathrm{Y}$} \\
\hline Class-year FEs & $\mathrm{Y}$ & Y & $\mathrm{Y}$ & \multicolumn{2}{|r|}{$\mathrm{Y}$} \\
\hline Mean of DV & 0.86 & 0.86 & 0.88 & \multicolumn{2}{|c|}{0.86} \\
\hline s.d. of DV & 0.34 & 0.35 & 0.32 & \multicolumn{2}{|c|}{0.34} \\
\hline
\end{tabular}

Notes: Table estimates a variant on Table 6 of the paper, excluding secret patents which were granted before the General Rescinding Order (August 30, 1945), and thus whose secrecy orders were rescinded early. See table notes in the body of the paper for additional explanation. *,**,*** represent significance at the $0.1,0.05$, and 0.01 levels, respectively. SEs clustered by patent class in parentheses. 
Table D.3.3: Effects of secrecy on probability of any forward citations excl. patents in weapons-related classes (firearms/ammunition/ordnance/explosives)

\begin{tabular}{|c|c|c|c|c|c|}
\hline & \multirow{4}{*}{$\begin{array}{l}\text { All } \\
(1)\end{array}$} & \multirow{4}{*}{$\begin{array}{c}\text { Non-OSRD } \\
(2)\end{array}$} & \multirow{4}{*}{$\begin{array}{c}\text { OSRD } \\
(3)\end{array}$} & \multicolumn{2}{|c|}{ Triple difference } \\
\hline & & & & & OSRD \\
\hline & & & & All & (rel. to all) \\
\hline & & & & (4) & $(5)$ \\
\hline \multirow[t]{2}{*}{ Secrecy ordered } & -0.002 & $-0.075^{* *}$ & 0.047 & $-0.074^{* *}$ & $0.125^{* * *}$ \\
\hline & $(0.021)$ & $(0.034)$ & $(0.031)$ & $(0.032)$ & $(0.041)$ \\
\hline \multirow{2}{*}{ * filed in 1941} & -0.023 & 0.036 & -0.051 & 0.033 & $-0.095^{*}$ \\
\hline & $(0.024)$ & $(0.042)$ & $(0.036)$ & $(0.041)$ & $(0.053)$ \\
\hline \multirow[t]{2}{*}{ * filed in 1942} & 0.010 & 0.053 & -0.017 & 0.054 & $-0.083^{*}$ \\
\hline & $(0.022)$ & $(0.039)$ & $(0.032)$ & $(0.037)$ & $(0.048)$ \\
\hline \multirow[t]{2}{*}{ * filed in 1943} & 0.020 & $0.103^{* *}$ & -0.043 & $0.097^{* *}$ & $-0.135^{* * *}$ \\
\hline & $(0.024)$ & $(0.043)$ & $(0.031)$ & $(0.041)$ & $(0.048)$ \\
\hline \multirow[t]{2}{*}{ * filed in 1944} & 0.020 & 0.075 & -0.025 & $0.077^{*}$ & $-0.109^{* *}$ \\
\hline & $(0.026)$ & $(0.046)$ & $(0.035)$ & $(0.043)$ & $(0.051)$ \\
\hline \multirow[t]{2}{*}{ * filed in 1945} & 0.026 & $0.126^{* * *}$ & -0.018 & $0.139^{* * *}$ & $-0.182^{* * *}$ \\
\hline & $(0.028)$ & $(0.046)$ & $(0.041)$ & $(0.042)$ & $(0.052)$ \\
\hline \multirow[t]{2}{*}{ Secrecy evaluated } & 0.013 & 0.028 & -0.013 & $0.032^{* *}$ & $-0.047^{*}$ \\
\hline & $(0.014)$ & $(0.017)$ & $(0.023)$ & $(0.016)$ & $(0.025)$ \\
\hline \multirow{2}{*}{ * filed in 1941} & 0.019 & 0.011 & 0.030 & 0.006 & 0.026 \\
\hline & $(0.014)$ & $(0.019)$ & $(0.025)$ & $(0.017)$ & $(0.028)$ \\
\hline \multirow[t]{2}{*}{ * filed in 1942} & 0.002 & -0.013 & 0.021 & -0.015 & 0.034 \\
\hline & $(0.014)$ & $(0.020)$ & $(0.024)$ & $(0.018)$ & $(0.025)$ \\
\hline \multirow[t]{2}{*}{ * filed in 1943} & 0.016 & -0.002 & 0.036 & -0.008 & $0.046^{*}$ \\
\hline & $(0.015)$ & $(0.020)$ & $(0.024)$ & $(0.018)$ & $(0.026)$ \\
\hline \multirow[t]{2}{*}{ * filed in 1944} & 0.015 & -0.005 & 0.032 & -0.009 & 0.046 \\
\hline & $(0.017)$ & $(0.023)$ & $(0.025)$ & $(0.022)$ & $(0.029)$ \\
\hline \multirow{2}{*}{ * filed in 1945} & 0.019 & -0.000 & 0.033 & -0.014 & $0.060^{*}$ \\
\hline & $(0.019)$ & $(0.027)$ & $(0.026)$ & $(0.025)$ & $(0.033)$ \\
\hline $\mathrm{N}$ & 160312 & 123232 & 37080 & \multicolumn{2}{|c|}{160312} \\
\hline$R^{2}$ & 0.05 & 0.05 & 0.10 & \multicolumn{2}{|c|}{0.05} \\
\hline Grant year FEs & $\mathrm{Y}$ & $\mathrm{Y}$ & $\mathrm{Y}$ & \multicolumn{2}{|c|}{ Y } \\
\hline Class-year FEs & $\mathrm{Y}$ & $\mathrm{Y}$ & $\mathrm{Y}$ & \multicolumn{2}{|c|}{$\mathrm{Y}$} \\
\hline Mean of DV & 0.86 & 0.86 & 0.89 & \multicolumn{2}{|c|}{0.86} \\
\hline s.d. of DV & 0.34 & 0.35 & 0.32 & \multicolumn{2}{|c|}{0.34} \\
\hline
\end{tabular}

Notes: Table estimates a variant on Table 6 of the paper, excluding patents in weaponsrelated classes with mainly military application (USPC 42, 86, 89, 102, and 149, covering firearms, ammunition, ordnance, and explosives). See table notes in the body of the paper for additional explanation. $*, * *, * * *$ represent significance at the $0.1,0.05$, and 0.01 levels, respectively. SEs clustered by patent class in parentheses. 
Table D.3.4: Effects of secrecy on probability of assorted types of forward citations

\begin{tabular}{|c|c|c|c|c|c|}
\hline & $\begin{array}{l}\text { (1) } \\
\text { All }\end{array}$ & $\begin{array}{c}(2) \\
\text { Non-self }\end{array}$ & $\begin{array}{l}(3) \\
\text { Self }\end{array}$ & $\begin{array}{c}\text { (4) } \\
\text { Firms }\end{array}$ & $\begin{array}{c}(5) \\
\text { Indivs. }\end{array}$ \\
\hline Secrecy ordered & $\begin{array}{l}-0.065^{*} \\
(0.033)\end{array}$ & $\begin{array}{c}-0.056 \\
(0.035)\end{array}$ & $\begin{array}{c}0.005 \\
(0.046)\end{array}$ & $\begin{array}{c}-0.092^{* *} \\
(0.040)\end{array}$ & $\begin{array}{c}0.029 \\
(0.067)\end{array}$ \\
\hline * filed in 1941 & $\begin{array}{c}0.026 \\
(0.041)\end{array}$ & $\begin{array}{c}0.022 \\
(0.043)\end{array}$ & $\begin{array}{c}-0.011 \\
(0.050)\end{array}$ & $\begin{array}{c}0.058 \\
(0.044)\end{array}$ & $\begin{array}{l}-0.053 \\
(0.065)\end{array}$ \\
\hline * filed in 1942 & $\begin{array}{c}0.048 \\
(0.038)\end{array}$ & $\begin{array}{c}0.046 \\
(0.040)\end{array}$ & $\begin{array}{l}-0.008 \\
(0.049)\end{array}$ & $\begin{array}{l}0.078^{*} \\
(0.045)\end{array}$ & $\begin{array}{l}-0.045 \\
(0.070)\end{array}$ \\
\hline * filed in 1943 & $\begin{array}{c}0.086^{* *} \\
(0.042)\end{array}$ & $\begin{array}{c}0.087^{* *} \\
(0.043)\end{array}$ & $\begin{array}{c}0.037 \\
(0.051)\end{array}$ & $\begin{array}{c}0.103^{* *} \\
(0.049)\end{array}$ & $\begin{array}{l}-0.012 \\
(0.071)\end{array}$ \\
\hline * filed in 1944 & $\begin{array}{c}0.069 \\
(0.044)\end{array}$ & $\begin{array}{c}0.060 \\
(0.046)\end{array}$ & $\begin{array}{c}0.018 \\
(0.058)\end{array}$ & $\begin{array}{c}0.135^{* *} \\
(0.054)\end{array}$ & $\begin{array}{c}0.013 \\
(0.077)\end{array}$ \\
\hline * filed in 1945 & $\begin{array}{c}0.129^{* * *} \\
(0.044)\end{array}$ & $\begin{array}{c}0.122^{* * *} \\
(0.046)\end{array}$ & $\begin{array}{c}0.050 \\
(0.078)\end{array}$ & $\begin{array}{c}0.167^{* *} \\
(0.073)\end{array}$ & $\begin{array}{c}0.064 \\
(0.091)\end{array}$ \\
\hline Secrecy evaluated & $\begin{array}{c}0.036^{* *} \\
(0.017)\end{array}$ & $\begin{array}{c}0.041^{* *} \\
(0.018)\end{array}$ & $\begin{array}{c}0.036^{*} \\
(0.019)\end{array}$ & $\begin{array}{c}0.059^{* * * *} \\
(0.022)\end{array}$ & $\begin{array}{c}0.022 \\
(0.026)\end{array}$ \\
\hline * filed in 1941 & $\begin{array}{l}-0.001 \\
(0.019)\end{array}$ & $\begin{array}{c}-0.007 \\
(0.020)\end{array}$ & $\begin{array}{c}0.006 \\
(0.023)\end{array}$ & $\begin{array}{l}-0.004 \\
(0.025)\end{array}$ & $\begin{array}{c}0.014 \\
(0.031)\end{array}$ \\
\hline * filed in 1942 & $\begin{array}{l}-0.020 \\
(0.020)\end{array}$ & $\begin{array}{l}-0.025 \\
(0.020)\end{array}$ & $\begin{array}{l}-0.011 \\
(0.021)\end{array}$ & $\begin{array}{l}-0.013 \\
(0.024)\end{array}$ & $\begin{array}{l}-0.027 \\
(0.031)\end{array}$ \\
\hline * filed in 1943 & $\begin{array}{l}-0.008 \\
(0.019)\end{array}$ & $\begin{array}{l}-0.019 \\
(0.021)\end{array}$ & $\begin{array}{l}-0.018 \\
(0.024)\end{array}$ & $\begin{array}{c}0.001 \\
(0.029)\end{array}$ & $\begin{array}{l}-0.028 \\
(0.029)\end{array}$ \\
\hline * filed in 1944 & $\begin{array}{l}-0.014 \\
(0.022)\end{array}$ & $\begin{array}{l}-0.016 \\
(0.022)\end{array}$ & $\begin{array}{l}-0.028 \\
(0.024)\end{array}$ & $\begin{array}{l}-0.008 \\
(0.029)\end{array}$ & $\begin{array}{l}-0.041 \\
(0.031)\end{array}$ \\
\hline * filed in 1945 & $\begin{array}{l}-0.010 \\
(0.026)\end{array}$ & $\begin{array}{l}-0.015 \\
(0.027)\end{array}$ & $\begin{array}{c}0.004 \\
(0.035)\end{array}$ & $\begin{array}{l}-0.010 \\
(0.042)\end{array}$ & $\begin{array}{l}-0.050 \\
(0.048)\end{array}$ \\
\hline $\mathrm{N}$ & 125130 & 125130 & 125130 & 125130 & 125130 \\
\hline$R^{2}$ & 0.05 & 0.05 & 0.05 & 0.11 & 0.10 \\
\hline Grant year FEs & Y & $\mathrm{Y}$ & $\mathrm{Y}$ & Y & $\mathrm{Y}$ \\
\hline Class-year FEs & $\mathrm{Y}$ & $\mathrm{Y}$ & $\mathrm{Y}$ & $\mathrm{Y}$ & $\mathrm{Y}$ \\
\hline Mean of DV & 0.86 & 0.84 & 0.11 & 0.69 & 0.60 \\
\hline s.d. of DV & 0.35 & 0.36 & 0.32 & 0.46 & 0.49 \\
\hline
\end{tabular}

Notes: Table expands on Tables 6 and 7 of the paper, estimating effects on the likelihood of various types of forward citations. Column (1) repeats the baseline result for all citations. Columns (2) and (3) examine non-self and self citations, respectively. Columns (4) and (5) examine citations from firms and individuals. See table notes in the body of the paper for additional explanation. $*, * *, * * *$ represent significance at the $0.1,0.05$, and 0.01 levels, respectively. SEs clustered by patent class in parentheses. 
Table D.3.5: Effects of secrecy on (i) probability of exceeding various thresholds in the number of forward citations, and (ii) forward citation counts

\begin{tabular}{|c|c|c|c|c|c|c|c|}
\hline & \multicolumn{6}{|c|}{ OLS } & \multirow{2}{*}{$\begin{array}{c}\text { Poisson } \\
(7)\end{array}$} \\
\hline & (1) & $(2)$ & $(3)$ & (4) & $(5)$ & (6) & \\
\hline & $\geq 1$ & $\geq 2$ & $\geq 4$ & $\geq 6$ & $\geq 8$ & $\geq 10$ & Count \\
\hline \multirow[t]{2}{*}{ Secrecy ordered } & $-0.065^{*}$ & -0.060 & 0.016 & 0.064 & 0.024 & 0.031 & 1.004 \\
\hline & $(0.033)$ & $(0.043)$ & $(0.061)$ & $(0.060)$ & $(0.053)$ & $(0.044)$ & $(0.153)$ \\
\hline \multirow[t]{2}{*}{ * filed in 1941} & 0.026 & 0.032 & -0.044 & -0.088 & -0.055 & -0.039 & 0.952 \\
\hline & $(0.041)$ & $(0.045)$ & $(0.059)$ & $(0.060)$ & $(0.054)$ & $(0.057)$ & $(0.177)$ \\
\hline \multirow[t]{2}{*}{ * filed in 1942} & 0.048 & 0.037 & -0.020 & -0.048 & 0.027 & 0.019 & 1.226 \\
\hline & $(0.038)$ & $(0.050)$ & $(0.066)$ & $(0.067)$ & $(0.066)$ & $(0.049)$ & $(0.202)$ \\
\hline \multirow[t]{2}{*}{ * filed in 1943} & $0.086^{* *}$ & 0.082 & 0.045 & 0.042 & 0.062 & 0.057 & 1.257 \\
\hline & $(0.042)$ & $(0.053)$ & $(0.066)$ & $(0.065)$ & $(0.058)$ & $(0.049)$ & $(0.262)$ \\
\hline \multirow[t]{2}{*}{ * filed in 1944} & 0.069 & $0.120^{* *}$ & 0.047 & 0.004 & 0.031 & 0.022 & 1.233 \\
\hline & $(0.044)$ & $(0.059)$ & $(0.075)$ & $(0.075)$ & $(0.063)$ & $(0.052)$ & $(0.158)$ \\
\hline \multirow[t]{2}{*}{ * filed in 1945} & $0.129^{* * *}$ & $0.172^{* *}$ & 0.118 & 0.034 & 0.166 & 0.090 & $1.765^{* * *}$ \\
\hline & $(0.044)$ & $(0.070)$ & $(0.090)$ & $(0.122)$ & $(0.118)$ & $(0.120)$ & $(0.264)$ \\
\hline \multirow[t]{2}{*}{ Secrecy evaluated } & $0.036^{* *}$ & $0.051^{* *}$ & $0.059^{* *}$ & $0.046^{*}$ & $0.046^{*}$ & 0.021 & $1.236^{* * *}$ \\
\hline & $(0.017)$ & $(0.022)$ & $(0.029)$ & $(0.026)$ & $(0.024)$ & $(0.020)$ & $(0.073)$ \\
\hline \multirow{2}{*}{ * filed in 1941} & -0.001 & 0.004 & 0.013 & 0.032 & 0.031 & $0.046^{*}$ & 1.078 \\
\hline & $(0.019)$ & $(0.025)$ & $(0.033)$ & $(0.029)$ & $(0.027)$ & $(0.024)$ & $(0.074)$ \\
\hline \multirow[t]{2}{*}{ * filed in 1942} & -0.020 & -0.016 & -0.013 & 0.008 & -0.006 & 0.007 & 0.924 \\
\hline & $(0.020)$ & $(0.023)$ & $(0.033)$ & $(0.030)$ & $(0.028)$ & $(0.022)$ & $(0.050)$ \\
\hline \multirow[t]{2}{*}{ * filed in 1943} & -0.008 & -0.015 & -0.005 & 0.002 & -0.001 & 0.012 & 0.979 \\
\hline & $(0.019)$ & $(0.030)$ & $(0.034)$ & $(0.031)$ & $(0.028)$ & $(0.026)$ & $(0.061)$ \\
\hline \multirow{2}{*}{ * filed in 1944} & -0.014 & -0.000 & -0.003 & 0.004 & -0.024 & -0.016 & 0.998 \\
\hline & $(0.022)$ & $(0.029)$ & $(0.036)$ & $(0.034)$ & $(0.030)$ & $(0.024)$ & $(0.071)$ \\
\hline \multirow[t]{2}{*}{ * filed in 1945} & -0.010 & -0.018 & -0.004 & -0.004 & -0.020 & 0.003 & 1.001 \\
\hline & $(0.026)$ & $(0.043)$ & $(0.048)$ & $(0.047)$ & $(0.044)$ & $(0.040)$ & $(0.110)$ \\
\hline $\mathrm{N}$ & 125130 & 125130 & 125130 & 125130 & 125130 & 125130 & 124958 \\
\hline$R^{2}$ & 0.05 & 0.06 & 0.07 & 0.07 & 0.06 & 0.06 & \\
\hline Filing year FEs & & & & & & & $\mathrm{Y}$ \\
\hline Grant year FEs & $\mathrm{Y}$ & Y & $\mathrm{Y}$ & $\mathrm{Y}$ & $\mathrm{Y}$ & $\mathrm{Y}$ & $\mathrm{Y}$ \\
\hline Class-year FEs & $\mathrm{Y}$ & $\mathrm{Y}$ & $\mathrm{Y}$ & $\mathrm{Y}$ & $\mathrm{Y}$ & $\mathrm{Y}$ & \\
\hline Mean of DV & 0.86 & 0.70 & 0.44 & 0.28 & 0.18 & 0.12 & 4.49 \\
\hline s.d. of DV & 0.35 & 0.46 & 0.50 & 0.45 & 0.38 & 0.32 & 5.29 \\
\hline
\end{tabular}

Notes: Columns (1) to (6) expand on Tables 6 and 7 of the paper, estimating effects on the likelihood of exceeding various thresholds in forward citations, as indicated in the column headers. See table notes in the body of the paper for additional explanation. Column (7) estimates effects on forward citation counts with a conditional fixed-effects Poisson model to account for the count nature of the dependent variable, limiting the fixed effects to filing year and grant year only (due to the limitations of the estimation method). Column (7) reports incidence-rate ratios for ease of interpretation. ${ }^{*}, * *, * * *$ represent significance at the $0.1,0.05$, and 0.01 levels, respectively. SEs clustered by patent class in parentheses. 
Table D.3.6: Effects of secrecy on probability of citation in a given year since filing

\begin{tabular}{|c|c|c|c|c|c|c|c|c|}
\hline & $\begin{array}{c}(1) \\
2 \text { years }\end{array}$ & $\begin{array}{c}(2) \\
3 \text { years }\end{array}$ & $\begin{array}{c}(3) \\
4 \text { years }\end{array}$ & $\begin{array}{c}(4) \\
5 \text { years }\end{array}$ & $\begin{array}{c}(5) \\
10 \text { years }\end{array}$ & $\begin{array}{c}(6) \\
15 \text { years }\end{array}$ & $\begin{array}{c}(7) \\
20 \text { years }\end{array}$ & $\begin{array}{c}(8) \\
25 \text { years }\end{array}$ \\
\hline Secrecy ordered & $\begin{array}{c}0.006 \\
(0.037)\end{array}$ & $\begin{array}{l}-0.073 \\
(0.055)\end{array}$ & $\begin{array}{l}-0.025 \\
(0.052)\end{array}$ & $\begin{array}{c}0.038 \\
(0.056)\end{array}$ & $\begin{array}{c}0.009 \\
(0.043)\end{array}$ & $\begin{array}{l}-0.032 \\
(0.033)\end{array}$ & $\begin{array}{c}0.042 \\
(0.043)\end{array}$ & $\begin{array}{c}0.016 \\
(0.028)\end{array}$ \\
\hline * filed in 1941 & $\begin{array}{c}0.002 \\
(0.041)\end{array}$ & $\begin{array}{c}0.041 \\
(0.068)\end{array}$ & $\begin{array}{c}0.027 \\
(0.053)\end{array}$ & $\begin{array}{c}0.021 \\
(0.064)\end{array}$ & $\begin{array}{l}-0.000 \\
(0.046)\end{array}$ & $\begin{array}{c}0.043 \\
(0.043)\end{array}$ & $\begin{array}{l}-0.049 \\
(0.043)\end{array}$ & $\begin{array}{l}-0.016 \\
(0.033)\end{array}$ \\
\hline * filed in 1942 & $\begin{array}{l}-0.034 \\
(0.039)\end{array}$ & $\begin{array}{c}0.078 \\
(0.058)\end{array}$ & $\begin{array}{c}0.083 \\
(0.054)\end{array}$ & $\begin{array}{l}-0.003 \\
(0.060)\end{array}$ & $\begin{array}{c}0.003 \\
(0.046)\end{array}$ & $\begin{array}{c}0.024 \\
(0.042)\end{array}$ & $\begin{array}{l}-0.033 \\
(0.049)\end{array}$ & $\begin{array}{l}-0.014 \\
(0.032)\end{array}$ \\
\hline * filed in 1943 & $\begin{array}{c}0.015 \\
(0.046)\end{array}$ & $\begin{array}{c}0.171^{* * *} \\
(0.063)\end{array}$ & $\begin{array}{l}0.103^{*} \\
(0.061)\end{array}$ & $\begin{array}{c}0.025 \\
(0.058)\end{array}$ & $\begin{array}{c}0.040 \\
(0.051)\end{array}$ & $\begin{array}{c}0.046 \\
(0.039)\end{array}$ & $\begin{array}{c}-0.022 \\
(0.045)\end{array}$ & $\begin{array}{l}-0.010 \\
(0.029)\end{array}$ \\
\hline * filed in 1944 & $\begin{array}{c}0.051 \\
(0.058)\end{array}$ & $\begin{array}{c}0.107^{*} \\
(0.060)\end{array}$ & $\begin{array}{c}0.043 \\
(0.066)\end{array}$ & $\begin{array}{c}0.027 \\
(0.066)\end{array}$ & $\begin{array}{c}0.017 \\
(0.055)\end{array}$ & $\begin{array}{c}0.061 \\
(0.042)\end{array}$ & $\begin{array}{c}-0.020 \\
(0.047)\end{array}$ & $\begin{array}{c}-0.014 \\
(0.037)\end{array}$ \\
\hline * filed in 1945 & $\begin{array}{c}0.048 \\
(0.066)\end{array}$ & $\begin{array}{c}0.227^{* * *} \\
(0.076)\end{array}$ & $\begin{array}{c}0.186^{* *} \\
(0.085)\end{array}$ & $\begin{array}{c}0.095 \\
(0.120)\end{array}$ & $\begin{array}{c}0.067 \\
(0.095)\end{array}$ & $\begin{array}{c}0.070 \\
(0.061)\end{array}$ & $\begin{array}{c}-0.011 \\
(0.067)\end{array}$ & $\begin{array}{c}0.035 \\
(0.047)\end{array}$ \\
\hline evaluated & $\begin{array}{c}0.024^{* *} \\
(0.011)\end{array}$ & $\begin{array}{c}0.080^{* * *} \\
(0.021)\end{array}$ & $\begin{array}{c}0.072^{* * *} \\
(0.024)\end{array}$ & $\begin{array}{c}0.032 \\
(0.025)\end{array}$ & $\begin{array}{c}0.010 \\
(0.021)\end{array}$ & $\begin{array}{c}0.003 \\
(0.016)\end{array}$ & $\begin{array}{l}-0.009 \\
(0.017)\end{array}$ & $\begin{array}{l}-0.019 \\
(0.014)\end{array}$ \\
\hline * filed in 1941 & $\begin{array}{c}0.011 \\
(0.014)\end{array}$ & $\begin{array}{l}-0.004 \\
(0.024)\end{array}$ & $\begin{array}{c}0.002 \\
(0.029)\end{array}$ & $\begin{array}{c}0.019 \\
(0.030)\end{array}$ & $\begin{array}{c}0.028 \\
(0.023)\end{array}$ & $\begin{array}{c}0.019 \\
(0.020)\end{array}$ & $\begin{array}{c}0.024 \\
(0.019)\end{array}$ & $\begin{array}{c}0.025 \\
(0.017)\end{array}$ \\
\hline * filed in 1942 & $\begin{array}{c}0.020 \\
(0.016)\end{array}$ & $\begin{array}{l}-0.028 \\
(0.021)\end{array}$ & $\begin{array}{c}-0.022 \\
(0.028)\end{array}$ & $\begin{array}{l}-0.003 \\
(0.028)\end{array}$ & $\begin{array}{c}0.033 \\
(0.023)\end{array}$ & $\begin{array}{c}0.019 \\
(0.017)\end{array}$ & $\begin{array}{c}0.017 \\
(0.019)\end{array}$ & $\begin{array}{c}0.018 \\
(0.016)\end{array}$ \\
\hline * filed in 1943 & $\begin{array}{c}0.021 \\
(0.019)\end{array}$ & $\begin{array}{l}-0.048^{*} \\
(0.027)\end{array}$ & $\begin{array}{l}-0.037 \\
(0.028)\end{array}$ & $\begin{array}{l}-0.012 \\
(0.029)\end{array}$ & $\begin{array}{c}0.019 \\
(0.022)\end{array}$ & $\begin{array}{l}-0.004 \\
(0.019)\end{array}$ & $\begin{array}{c}0.021 \\
(0.020)\end{array}$ & $\begin{array}{c}0.034^{* *} \\
(0.016)\end{array}$ \\
\hline * filed in 1944 & $\begin{array}{c}0.016 \\
(0.022)\end{array}$ & $\begin{array}{c}-0.064^{* *} \\
(0.026)\end{array}$ & $\begin{array}{l}-0.043 \\
(0.031)\end{array}$ & $\begin{array}{l}-0.022 \\
(0.030)\end{array}$ & $\begin{array}{c}0.005 \\
(0.027)\end{array}$ & $\begin{array}{c}0.015 \\
(0.023)\end{array}$ & $\begin{array}{l}-0.001 \\
(0.021)\end{array}$ & $\begin{array}{c}0.016 \\
(0.016)\end{array}$ \\
\hline * filed in 1945 & $\begin{array}{c}0.045 \\
(0.030) \\
\end{array}$ & $\begin{array}{c}-0.058^{*} \\
(0.032)\end{array}$ & $\begin{array}{c}-0.060 \\
(0.038)\end{array}$ & $\begin{array}{l}-0.028 \\
(0.040) \\
\end{array}$ & $\begin{array}{c}-0.034 \\
(0.034) \\
\end{array}$ & $\begin{array}{c}0.040 \\
(0.030) \\
\end{array}$ & $\begin{array}{c}0.004 \\
(0.024) \\
\end{array}$ & $\begin{array}{c}0.021 \\
(0.023) \\
\end{array}$ \\
\hline $\mathrm{N}$ & 125130 & 125130 & 125130 & 125130 & 125130 & 125130 & 125130 & 125130 \\
\hline$R^{2}$ & 0.08 & 0.07 & 0.05 & 0.04 & 0.03 & 0.03 & 0.03 & 0.03 \\
\hline Class & Y & $\mathrm{Y}$ & Y & Y & $\mathrm{Y}$ & $\mathrm{Y}$ & $\mathrm{Y}$ & $\mathrm{Y}$ \\
\hline Mean of DV & 0.09 & 0.14 & 0.18 & 0.19 & 0.16 & 0.12 & 0.09 & 0.06 \\
\hline s.d. of DV & 0.28 & 0.34 & 0.38 & 0.40 & 0.36 & 0.32 & 0.28 & 0.24 \\
\hline
\end{tabular}

Notes: Columns (1) to (7) estimate effects on the likelihood of receiving any forward citations from future patents filed in a given number of years (in this table: 2, 3, 4, 5, 10, 15, 20, and 25) since the focal patent's filing. All columns control for post-February 1947 examination lags (i.e., time elapsed between February 1947, when the citation record begins, and grant), to account for the fact that patents are not citeable until issued, and these delays can mechanically reduce citations within fixed windows since filing. $*, * *, * * *$ represent significance at the $0.1,0.05$, and 0.01 levels, respectively. SEs clustered by patent class in parentheses. 


\section{D.4 Results for word use in patent full text and Google Books corpus}

Figure D.4.1: Annual use of new word stems from evaluated vs. non-evaluated patent titles, measuring use in patents' full text

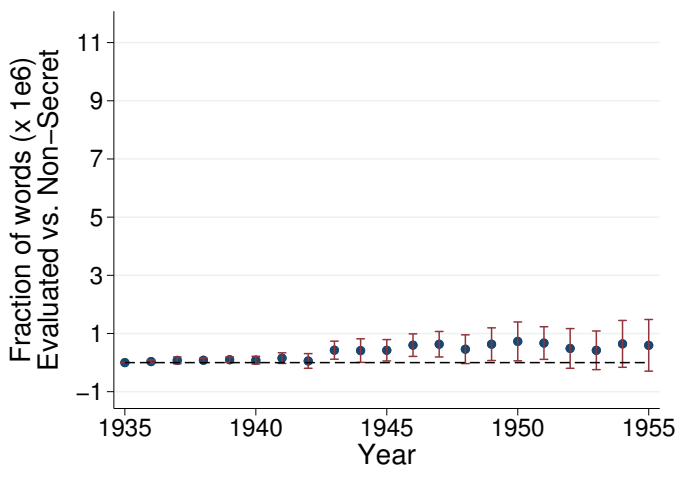

Notes: Figure shows estimated differences over time in the patent full text frequency of word stems which first appeared in the title of an evaluated versus non-evaluated patent filed in the 1940-1945 period. In the underlying regression, observations are new stems in patent titles from this period, crossed by year, and the outcome variable is the fraction of nonsecret patents with the stem in their full text in the given year. This outcome is regressed on indicators for the year, interacted with indicators for whether the stem was first used in the title of a patent which was (i) evaluated for secrecy and (ii) ordered secret. The figure plots effects for the former. Specification includes stem fixed effects, such that comparisons are within stems, over time. Omitted category is 1935 for stems from both evaluated and non-evaluated patents. Sample censors stems at the 90th percentile of pre-patent usage in patents' full text, to eliminate already-common language. Error bars represent $95 \%$ confidence intervals, computed from SEs clustered at the stem level.

Figure D.4.2: Annual use of new word stems from evaluated vs. non-evaluated patent titles, measuring use in the Google Books corpus

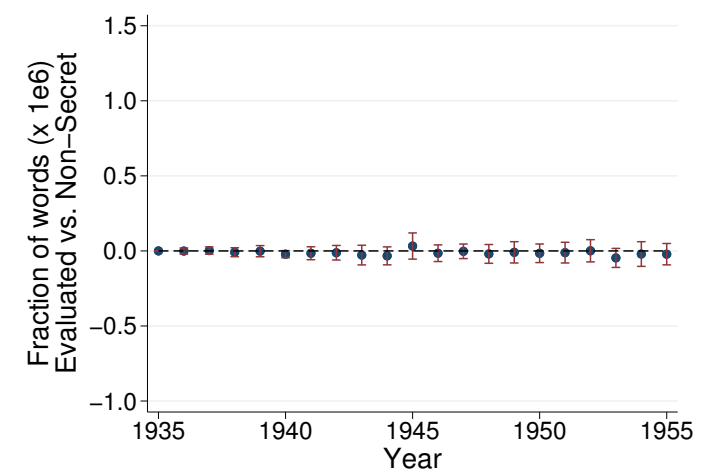

Notes: Figure shows estimated differences over time in the Google Books frequency of word stems which first appeared in the title of an evaluated versus non-evaluated patent filed in the 1940-1945 period. In the underlying regression, observations are new stems in patent titles from this period, crossed by year, and the outcome variable is each stem's fraction of words in the Google Books corpus in the given year. This outcome is regressed on indicators for the year, interacted with indicators for whether the stem was first used in the title of a patent which was (i) evaluated for secrecy and (ii) ordered secret. The figure plots effects for the former. Specification includes stem fixed effects, such that comparisons are within stems, over time. Omitted category is 1935 for stems from both evaluated and non-evaluated patents. Sample censors stems at the 90th percentile of pre-patent usage in the Google Books corpus, to eliminate already-common language. Error bars represent 95\% confidence intervals, computed from SEs clustered at the stem level. 
Table D.4.1: Annual use of new word stems from secret vs. non-secret patent titles, measuring use in the Google Books corpus, difference-in-differences, pre- vs. post-1945

\begin{tabular}{lcccccc}
\hline \hline & \multicolumn{2}{c}{ Fraction of words $(\mathrm{x} 1 \mathrm{e} 6)$} & \multicolumn{3}{c}{ Fraction of works (x1e3) } \\
& $(1)$ & $(2)$ & $(3)$ & $(4)$ & $(5)$ & $(6)$ \\
& $75 \mathrm{th}$ & $90 \mathrm{th}$ & $95 \mathrm{th}$ & 75 th & $90 \mathrm{th}$ & $95 \mathrm{th}$ \\
\hline Secrecy ordered x post-1945 & $0.462^{* *}$ & $0.415^{* *}$ & $0.475^{* *}$ & $5.707^{* *}$ & $6.743^{* * *}$ & $6.502^{* * *}$ \\
& $(0.228)$ & $(0.193)$ & $(0.196)$ & $(2.723)$ & $(2.531)$ & $(2.485)$ \\
Secrecy evaluated x post-1945 & -0.006 & -0.008 & -0.011 & 0.052 & -0.104 & -0.036 \\
& $(0.013)$ & $(0.019)$ & $(0.021)$ & $(0.238)$ & $(0.316)$ & $(0.563)$ \\
Post-1945 & $0.038^{* * *}$ & $0.060^{* * *}$ & $0.072^{* * *}$ & $0.885^{* * *}$ & $1.449^{* * *}$ & $1.862^{* * *}$ \\
& $(0.009)$ & $(0.009)$ & $(0.012)$ & $(0.141)$ & $(0.178)$ & $(0.237)$ \\
\hline N & 16989 & 20433 & 21567 & 16989 & 20433 & 21567 \\
$R^{2}$ & 0.53 & 0.69 & 0.88 & 0.63 & 0.87 & 0.98 \\
Stem FEs & $\mathrm{Y}$ & $\mathrm{Y}$ & $\mathrm{Y}$ & $\mathrm{Y}$ & $\mathrm{Y}$ & $\mathrm{Y}$ \\
Mean of DV & 0.07 & 0.21 & 0.42 & 1.79 & 5.63 & 13.46 \\
s.d. of DV & 0.44 & 0.61 & 1.18 & 5.76 & 13.27 & 38.78 \\
\hline \hline
\end{tabular}

Notes: Table estimates a difference-in-difference of the pre- vs. post-1945 Google Books frequency of word stems which first appeared in the title of a patent filed in the 1940-1945 period and was evaluated for secrecy and/or ordered secret. Columns (1) to (3) estimate effects on the fraction of words with a given stem, and Columns (4) to (6) estimate effects on the fraction of works with the given stem. Each column censors stems at the given percentile (75th, 90th, 95th) of pre-patent usage in the corpus, to eliminate already-common language. All columns include stem FEs. The table is effectively a difference-in-difference presentation of the results in Figure 5. *,**,*** represent significance at the 0.1, 0.05, and 0.01 levels, respectively. SEs clustered by stem in parentheses.

Table D.4.2: Annual use of new word stems from secret vs. non-secret patent titles, measuring use in the Google Books corpus, difference-in-differences, w/ multiple periods

\begin{tabular}{lcccccc}
\hline \hline & \multicolumn{2}{c}{ Fraction of words $(\mathrm{x} 1 \mathrm{e} 6)$} & \multicolumn{3}{c}{ Fraction of works (x1e3) } \\
& $(1)$ & $(2)$ & $(3)$ & $(4)$ & $(5)$ & $(6)$ \\
& $75 \mathrm{th}$ & $90 \mathrm{th}$ & $95 \mathrm{th}$ & 75 th & 90 th & $95 \mathrm{th}$ \\
\hline Secrecy ordered x 1940-1945 & 0.102 & 0.073 & 0.111 & 1.155 & 0.961 & 0.521 \\
& $(0.092)$ & $(0.079)$ & $(0.092)$ & $(0.800)$ & $(0.753)$ & $(1.426)$ \\
Secrecy ordered x post-1945 & $0.518^{*}$ & $0.455^{* *}$ & $0.536^{* *}$ & $6.337^{* *}$ & $7.267^{* *}$ & $6.786^{* *}$ \\
& $(0.271)$ & $(0.229)$ & $(0.230)$ & $(3.098)$ & $(2.865)$ & $(2.977)$ \\
Secrecy evaluated x 1940-1945 & 0.016 & -0.011 & 0.016 & 0.132 & -0.361 & 1.147 \\
& $(0.020)$ & $(0.023)$ & $(0.029)$ & $(0.257)$ & $(0.331)$ & $(0.789)$ \\
Secrecy evaluated x post-1945 & 0.003 & -0.014 & -0.002 & 0.124 & -0.301 & 0.589 \\
& $(0.022)$ & $(0.027)$ & $(0.032)$ & $(0.349)$ & $(0.444)$ & $(0.863)$ \\
1940-1945 & $0.030^{* * *}$ & $0.070^{* * *}$ & $0.079^{* * *}$ & $0.752^{* * *}$ & $1.468^{* * *}$ & $1.322^{* * *}$ \\
& $(0.006)$ & $(0.012)$ & $(0.012)$ & $(0.127)$ & $(0.235)$ & $(0.254)$ \\
Post-1945 & $0.054^{* * *}$ & $0.099^{* * *}$ & $0.115^{* * *}$ & $1.295^{* * *}$ & $2.250^{* * *}$ & $2.583^{* * *}$ \\
& $(0.010)$ & $(0.013)$ & $(0.015)$ & $(0.185)$ & $(0.274)$ & $(0.316)$ \\
\hline N & 16989 & 20433 & 21567 & 16989 & 20433 & 21567 \\
$R^{2}$ & 0.53 & 0.69 & 0.88 & 0.63 & 0.87 & 0.98 \\
Stem FEs & $\mathrm{Y}$ & $\mathrm{Y}$ & $\mathrm{Y}$ & $\mathrm{Y}$ & $\mathrm{Y}$ & $\mathrm{Y}$ \\
Mean of DV & 0.07 & 0.21 & 0.42 & 1.79 & 5.63 & 13.46 \\
s.d. of DV & 0.44 & 0.61 & 1.18 & 5.76 & 13.27 & 38.78 \\
\hline \hline
\end{tabular}

Notes: Table expands on Table D.4.1 by separating the pre-1940, 1940-1945, and post-1945 periods in estimating difference-in-differences effects for Google Books corpus stem frequency. See table notes in the body of the paper. *, **, *** represent significance at the $0.1,0.05$, and 0.01 levels, respectively. SEs clustered by stem in parentheses. 
Figure D.4.3: Usage of select stems from secret patents in Google Books corpus, 1935-1955

Panel (A): Radar

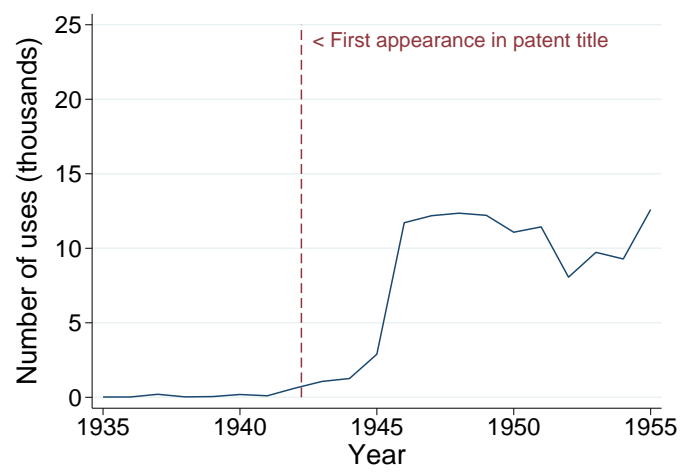

Panel (C): Antibiot

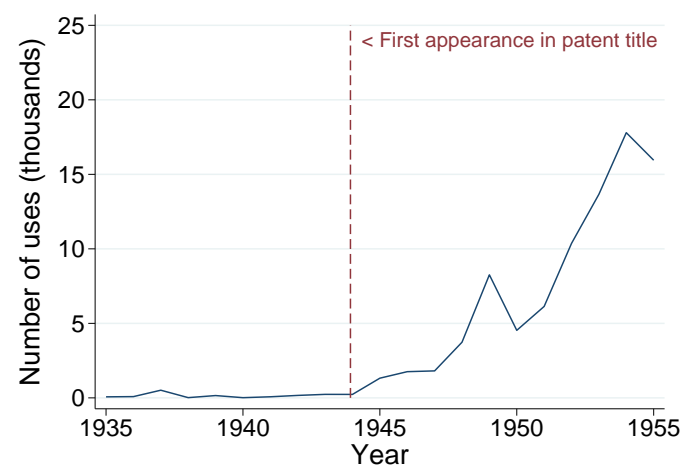

Panel (B): Penicillin

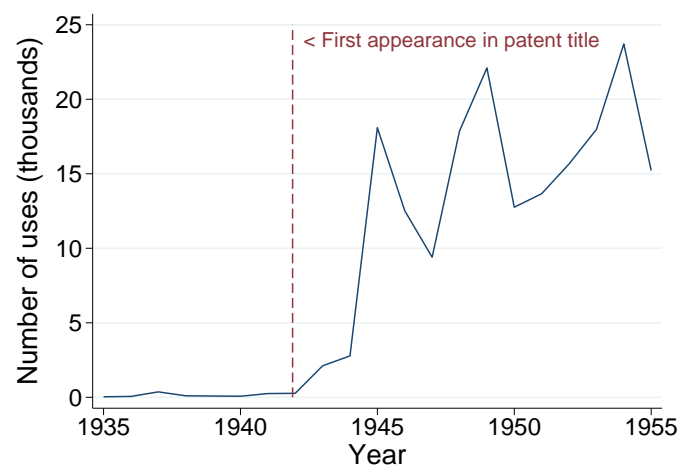

Panel (D): Fission

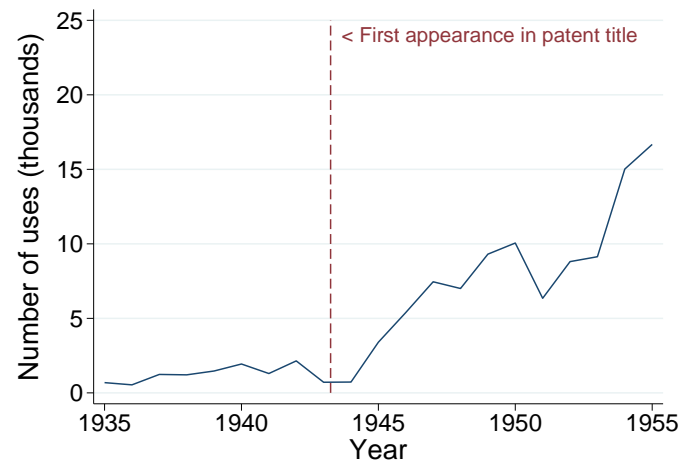

Notes: Figure plots annual uses of the given word stems in the Google Books corpus from 1935 to 1955. All are examples of words which first appeared in the title of a patent which was ordered secret. The dashed vertical line marks the filing date of the first patent with the given stem in its title. 


\section{E Effects on Commercialization}

Secrecy orders prohibited the inventor from disclosing "the invention or any hitherto unpublished details" of the invention (Appendix B). Contemporary sources (including statute) are unclear on whether this restriction would have impeded the commercial use or sale of the invention, particularly when the invention is a component or a method of manufacture that would not be easily detected or reverse-engineered. However, in the case of inventions which are themselves final goods, such as drugs and specialty chemicals, this restriction could have conceivably interfered with commercialization and kept new inventions out of the product market.

The most accessible setting for testing this question is in the specialty chemicals industry. Much as they do now, large chemical manufacturers in the 1940s circulated product catalogs which listed their commercially available products and where we can search for chemical terms from the titles of patents which were subjected to secrecy orders. Although many such catalogs have likely not been preserved, several editions of the Du Pont Products Index (DPPI) are available from the Du Pont collection at the Hagley Museum. For the purposes of this paper, I extracted the text of five editions-1938, 1944, 1946, 1949, and 1955-56 - to be used below. ${ }^{8}$

To build a sample of words to search for in these catalogs, I began with the set of words whose stems first entered the patent record in the title of a patent filed between 1940 and 1945 and classified in a chemical patent class (per Hall et al. 2001). I then manually reviewed these stems to identify those which were chemical compounds or processes - yielding a sample of 544 unique stems - and programmatically searched for these stems in each edition of the DPPI. The test I then run is to see whether the stems from secret versus non-secret patent titles were differentially likely to appear in each edition of the Du Pont catalog. ${ }^{9}$ Specifically, I regress an indicator for a stem's presence in the given edition of the DPPI on indicators for whether the stem originated in a patent which was issued a secrecy order or evaluated for secrecy, as follows:

$$
\mathbb{1}(\text { Word is in DPPI })_{i}=\beta_{1} \cdot \mathbb{1}(\text { Secret })_{i}+\beta_{2} \cdot \mathbb{1}(\text { Evaluated })_{i}+\alpha+\varepsilon_{i}
$$

where $i$ indexes stems, and $\alpha$ is a constant (for stems from non-secret, non-evaluated patents). Table E.1 shows the results: stems which first appeared in a secret patent are less likely to be included in the catalog in 1944 and 1946, with no significant differences in the other years, nor

\footnotetext{
${ }^{8}$ The Du Pont Products Index was the only major chemical manufacturer catalog from the 1940s that could be located (others company catalogs searched for included Dow Chemical and American Cyanamid). Du Pont was also the firm with (i) the most patents and (ii) the most secret patents in chemical classes in the 1940s. These editions were chosen to enable a search for keywords in the pre-war, mid-war, and short- and long-run post-war periods, but the Hagley collection includes many more volumes, spanning the 1910s to the 1980s.

${ }^{9}$ Note that whereas the specification in Section 4 leveraged intensive variation in the duration of secrecy, the regressions here and in the next section test whether secrecy orders were in fact binding for non-patent, contemporary outcomes during the war, for which the duration of secrecy is not material. Secrecy orders could potentially also be positively selected with respect to these outcomes, but this selection only risks biasing estimated effects upwards (i.e., in the more conservative direction, for negative effects), and should also manifest in patents evaluated for secrecy but not ordered secret, which provides a natural placebo below.
} 
for stems which first appeared in a patent which was evaluated for secrecy but not ordered secret. When compared against the baseline rate of $\approx 10 \%$ of non-evaluated stems appearing in the catalog, the effect size indicates that almost none of the words with stems from secret patents show up in 1944 and 1946. Results are similar for a sample of the full words themselves, rather than stems, when testing for the presence of each of these words in the DPPI volumes.

Table E.1: Presence of new chemical word stems in the Du Pont Products Index

\begin{tabular}{lccccc}
\hline \hline & $(1)$ & $(2)$ & $(3)$ & $(4)$ & $(5)$ \\
& 1938 & 1944 & 1946 & 1949 & 1955 \\
\hline Secrecy ordered & -0.022 & $-0.095^{* * *}$ & $-0.092^{* *}$ & -0.029 & -0.000 \\
& $(0.039)$ & $(0.029)$ & $(0.038)$ & $(0.047)$ & $(0.061)$ \\
Secrecy evaluated & -0.012 & 0.000 & 0.003 & -0.026 & -0.025 \\
& $(0.028)$ & $(0.032)$ & $(0.035)$ & $(0.033)$ & $(0.038)$ \\
\hline $\mathrm{N}$ & 572 & 572 & 572 & 572 & 572 \\
$R^{2}$ & 0.00 & 0.01 & 0.01 & 0.00 & 0.00 \\
Mean of DV & 0.07 & 0.09 & 0.10 & 0.11 & 0.15 \\
s.d. of DV & 0.26 & 0.28 & 0.31 & 0.32 & 0.36 \\
Non-secret stems & 527 & 527 & 527 & 527 & 527 \\
Non-secret in DPPI & 40 & 50 & 59 & 61 & 81 \\
Secret stems & 45 & 45 & 45 & 45 & 45 \\
Secret in DPPI & 2 & 0 & 1 & 3 & 6 \\
\hline \hline
\end{tabular}

Notes: Table estimates the probability that a word stem which first appeared in the title of a patent filed in a chemical class in the 1940-1945 period appears in the Du Pont Products Index in 1938, 1944, 1946, 1949, and 1955 , as a function of whether the first patent with the stem was evaluated for secrecy and/or ordered secret. The stems in this sample were further screened by the author to identify stems related to chemical content and processes. * ${ }^{* *},{ }^{* * *}$ represent significance at the $0.1,0.05$, and 0.01 levels, respectively. Heteroskedascity-robust SEs in parentheses.

These results could reflect different phenomena: they could be due to withholding inventions from the product market or a reduction in licensing and sale of external inventions. Distinguishing these channels is difficult, not only due to measurement challenges but also due to the sample size. In unreported results I split Table E.1 into stems originating in the titles of Du Pont patents versus other patents, and find that the results are driven by the words from non-Du Pont patents, but the Du Pont-only sample is too small (with $N=74$ stems, only 13 of which first appeared in the title of secret patents) to draw strong conclusions. ${ }^{10}$

\footnotetext{
${ }^{10}$ Another natural question is whether the unavoidably noisy nature of the optical character recognition used to extract text from the DPPI catalogs might be interfering with these results. Although the best available commercial software (ABBYY FineReader 14) was used for the OCR, its output is imperfect. The analysis described above was repeated with fuzzy matching to the DPPI catalogs, allowing matches with a Levenshtein edit distance of up to one character - though it is not obvious that this is an improvement, given that one character differences can represent distinct molecular structures (e.g., octane versus octene). The results with fuzzy matching are similar to those in Table E.1 for the sample of words, but the effects fade for the sample of stems.
} 


\section{F The Aggregate View}

Given the scale of the secrecy order program in key fields of invention, it could have plausibly had systemic consequences for innovation in affected technology areas. For example, by curtailing the spread of information about new invention, secrecy orders may have increased barriers to entry in the affected fields or slowed technological progress, and by delaying the granting of property rights over new inventions and evidently hindering commercialization, the program may have distorted incentives for $\mathrm{R} \& \mathrm{D}$ or patenting in sensitive subject matter.

In the results below, I examine aggregate patenting over time at the patent class level, comparing classes which were more versus less affected by secrecy orders in the 1940s, where class-level treatment is defined as the fraction of patents filed between July 1940 and June 1945 which were issued a secrecy order (which I term the class-level "secrecy rate"). Because this measure is skewed (with a few classes heavily affected by secrecy orders, and many only modestly or not at all affected), and sensitive to small numbers, I bin classes into treatment quartiles. The baseline specification for these tests takes the following form, where $i$ indexes patent classes and $t$ indexes years, run on a sample of all patent classes between 1930 and 1960, and controlling for quartiles of the analogously-defined class-level evaluation rate, similar to previous specifications:

$$
\begin{aligned}
\operatorname{Ln}(\text { Patents })_{i t}= & \sum_{q=1}^{4} \sum_{t=1931}^{1960}\left[\beta_{q t}^{1} \cdot \mathbb{1}(\text { Class } i \text { in secrecy rate quartile } q)\right. \\
& \left.+\beta_{q t}^{2} \cdot \mathbb{1}(\text { Class } i \text { in evaluation rate quartile } q)\right]+\alpha_{i}+\delta_{t}+\varepsilon_{i t}
\end{aligned}
$$

This regression compares patent classes in different quartiles of the class-level secrecy rate, with the omitted category being the set of classes in which no patents in the 1940 to 1945 period received a secrecy order (38.4\% of 429 classes), and the omitted year being 1930, such that $\beta_{q t}^{1}$ should be interpreted as the mean difference in the given year between classes in secrecy rate quartile $q$ versus classes without any secrecy orders, relative to the difference in 1930, controlling for secrecy evaluation rates. Standard errors are clustered at the patent class level.

Figure F.1 plots the effects for the top quartile of classes (the $\beta_{4 t}^{1}$ parameters). Even after controlling for selection into evaluation, the most-affected classes were growing quickly before, during, and after the war-although there is a noticeable level decline in 1946-1948, just after the war (and secrecy program) concluded, after which growth resumes on its previous trend. Although this drop-off could potentially be related to secrecy, a causal interpretation is difficult given the myriad adjustments taking place in the immediate aftermath of the war, and it may simply reflect the demobilization of the American research effort in World War II. 
Figure F.1: Changes over time in log patenting in patent classes in the top quartile of secrecy order issuance rate from 1940-1945, relative to classes without secrecy orders

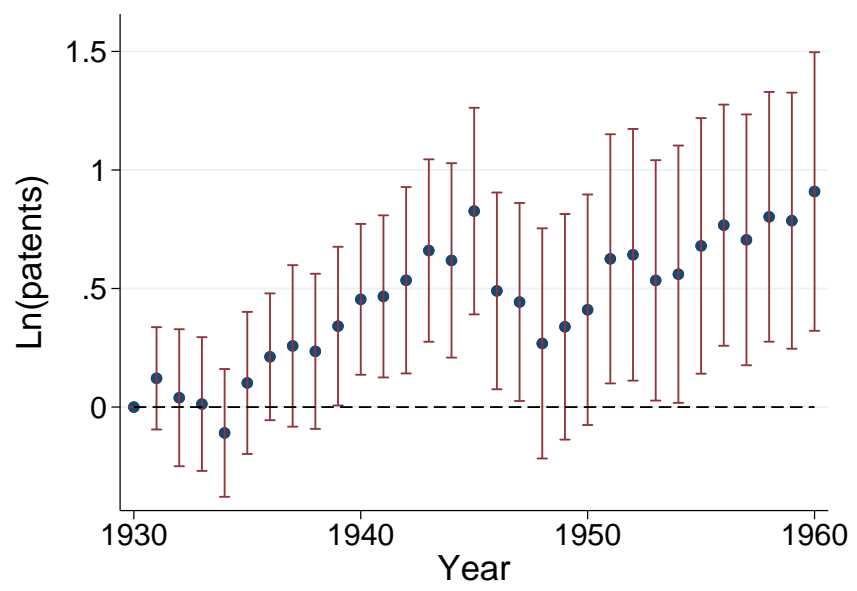

Notes: Figure shows the estimated mean difference in log patents for classes in the highest quartile of class-level wartime secrecy rates (defined as the fraction of patents filed in a given class between 1940 and 1945 which were issued a secrecy order), relative to classes without any secrecy orders, by year. Error bars represent $95 \%$ confidence intervals, computed from SEs clustered at the patent class level. 


\section{Appendix references}

Alcácer, Juan, Michelle Gittelman, and Bhaven N. Sampat. 2009. "Applicant and Examiner Citations in US Patents: An overview and analysis," Research Policy, Vol. 38, No. 2, pp. 415-427.

Cockburn, Iain M., Samuel Kortum, and Scott Stern. 2002. Are All Patent Examiners Equal? The Impact of Characteristics on Patent Statistics and Litigation Outcomes. NBER Working Paper No. 8980.

Cotropia, Christopher A., Mark A. Lemley, and Bhaven N. Sampat. 2013. "Do Applicant Patent Citations Matter?" Research Policy, Vol. 42, No. 4, pp. 844-854.

Galasso, Alberto and Mark Schankerman. 2015. "Patents and Cumulative Innovation: Causal Evidence from the Courts," Quarterly Journal of Economics, Vol. 130, pp. 317-369.

Hall, Bronwyn H., Adam B. Jaffe, and Manuel Trajtenberg. 2001. NBER Patent Citations Data File: Lessons, Insights and Methodological. NBER Working Paper No. 8498.

Iaria, Alessandro, Carlo Schwarz, and Fabian Waldinger. 2018. "Frontier Knowledge and Scientific Production: Evidence from the Collapse of International Science," Quarterly Journal of Economics, Vol. 133, No. 2, pp. 927-991.

Jaffe, Adam B., Manuel Trajtenberg, and Rebecca Henderson. 1993. "Geographic Localization of Knowledge Spillovers as Evidenced by Patent Citations," Quarterly journal of Economics, Vol. 108, No. 3, pp. 577598.

Marco, Alan C., Michael Carley, Steven Jackson, and Amanda Myers. 2015. The USPTO Historical Patent Data Files: Two Centuries of Innovation. SSRN working paper, available at https://ssrn.com/abstract= 2616724.

Moser, Petra, Joerg Ohmstedt, and Paul W. Rhode. 2017. "Patent Citations-An Analysis of Quality Differences and Citing Practices in Hybrid Corn," Management Science, Vol. 64, No. 4, pp. 1926-1940.

Roach, Michael and Wesley M. Cohen. 2013. "Lens or Prism? Patent citations as a measure of knowledge flows from public research," Management Science, Vol. 59, No. 2, pp. 504-525.

Sampat, Bhaven N. 2010. "When Do Applicants Search for Prior Art?" Journal of Law and Economics, Vol. 53, No. 2, pp. 399-416.

Streifer, Bill. 2017. U.S. Department of Energy List of U.S. Patents Related to the Manhattan Project. Obtained via FOIA request by Bill Streifer and available at the Wilson Center History and Public Policy Program Digital Archive, https://digitalarchive.wilsoncenter.org/document/165247.

Younge, Kenneth A. and Jeffrey M. Kuhn. 2016. Patent-to-Patent Similarity: A Vector Space Model. SSRN working paper, available at https://ssrn.com/abstract=2709238. 